\title{
Hot Money And External Adjustment
}

\author{
Martin D. D. Evans \\ Department of Economics \\ Georgetown University* \\ First Draft
}

July 4, 2013

This paper studies the behavior of international capital flows driven by the portfolio reallocation decisions of international investors; so-called hot money. I develop an open economy model with endowment and preference shocks that can account for the empirical behavior of real exchange rates, interest rates and consumption in the U.S. and Europe. The model includes financial frictions that impede international risk-sharing and hot money flows driven by optimal portfolio reallocations. My analysis reveals that hot money flows are an economically insignificant part of the international adjustment process following standard (temporary) endowment shocks. In contrast, preference shocks that change investors' risk aversion produce sizable hot money flows. These shocks also produce sizable variations in the expected return differentials on foreign assets and liabilities that allow for external adjustment via the valuation channel. Consistent with the model's predictions, I show that forecasts of future return differentials contributed most to the volatility of the U.S. net foreign asset position in the post Bretton-Woods era. Together, these findings indicate that hot money flows are an integral and empirically important part of the external adjustment process.

Keywords: Hot Money, International Capital Flows, External Adjustment, Open-Economy Macro Models, Habits, Incomplete Markets, Collateral Constraints.

JEL Codes: F3; F4; G1.

\footnotetext{
* This paper was prepared for the International Seminar on Macroeconomics held at the Bank of Italy in June 2013. I thank the discussants, Jeffrey Frankel and Robert Kollmann, and the other seminar participants for many useful comments and discussions. Any remaining errors are my own. Email: evansmdd@gmail.com.
} 


\section{Introduction}

Are hot money flows, the capital flows driven by the portfolio choices of foreign investors, a source of international instability or are they part of a beneficially international adjustment process? To many, the answer seems rather obvious. Sudden inflows of hot money are thought to often produce bubbles in the local asset prices, excess credit expansion, inflation, excessive exchange rate appreciation and current account deficits. And, when they are reversed, hot money outflows are believed to deflate local asset prices, leading to a rapid contraction in domestic credit that sends the economy into a recession and possibly a foreign debt crisis (see, e.g., Reinhart and Reinhart, 2008).

While these arguments appear relevant in understanding particular episodes, such as the 1997 Asian Financial crisis, their general applicability is less obvious. Are all hot money flows a source of instability, or just flows over a certain size? And, if so, how should this threshold be measured? Unfortunately, existing models give little guidance on these questions. Hot money flows aren't identified in models where all international asset trade takes place via a single risk free bond, and have no real effects in multi-asset models where markets are complete. ${ }^{1}$ In this paper I develop a new macro model to study the role of hot money flows in the international adjustment process. In particular, I investigate whether there are circumstances where the hot money flows produced by optimal portfolio reallocations actually facilitate the external adjustment process following domestic and foreign shocks.

The model is built around a standard core. There are two countries, each populated by a continuum of infinitely-lived households with preferences defined over the consumption of two perishable traded goods. Households have access to a wide array of financial assets: domestic equity and risk free bonds as well as foreign equity and bonds. Their optimal portfolio decisions are the driver of hot money bond and equity flows in the model. On the production side I assume that the world supply of each traded good follows an exogenous endowment process and that there are no impediments to international goods trade. Foreign direct investment is absent in this environment so international capital flows are comprised entirely of hot money. I add three key elements to this simple structure: collateral constraints that limit international borrowing in bonds, a restriction that limits the flexibility households have in re-allocating their wealth among foreign bonds and equity, and habits in households' preferences. The first two elements make markets incomplete so households' portfolio decisions affect equilibrium consumption, savings and international trade flows. The third element allows me to study the role hot money plays in the adjustment process following preference shocks that change households' risk aversion. The financial and macro effects of these risk shocks are quite different from endowment shocks and play a central role in my analysis.

I obtain three main results:

1. When the parameters governing the dynamics of endowments and habits are estimated so that the model replicates the moments of real exchange rates, real interest rates and consumption; risk shocks

\footnotetext{
${ }^{1}$ While there is no single definition in the literature, hot money capital flows are generally viewed as excluding foreign direct investment, so they are not the focus of the literature examining investment flows between rich and poor countries, see e.g., Lucas (1990). Hot money flows are also sometimes defined as being "short-term", but Claessens, Dooley, and Warner (1995) find that capital flows labelled "short-term" exhibit the same degree of time-series persistence as other flows, so its not clear what this definition means in practice.
} 
are found to be the dominant driver of international adjustment between the U.S. and Europe; affecting real exchange rates, real interest differentials, consumption growth differentials and real trade flows. ${ }^{2}$

2. The model identifies two distinct external adjustment processes. Temporary endowment shocks produce jumps in a country's net foreign asset position that reflect changes in the expected path of future exports and imports. This is the standard process that underlies the intertemporal approach to the current account; referred to as "the trade channel" by Gourinchas and Rey (2007). In contrast, risk shocks produce jumps in a country's net foreign asset position that primarily reflect new expectations concerning the future return differentials between foreign assets and liabilities. Gourinchas and Rey refer to this mechanism as "the valuation channel" of external adjustment. Since risk shocks are estimated to be the dominant driver of international adjustment between the U.S. and E.U., the model predicts that most variation in their net foreign asset positions should come via the valuation channel. Consistent with this prediction, I show that forecasts of future return differentials contributed most to the volatility of the U.S. net foreign asset position in the post Bretton-Woods era (1973-2007).

3. The model also makes stark predictions about the behavior of hot money. Temporary endowment shocks produce negligible hot money flows because they have minimal affects on the optimal allocation of households' portfolios. In contrast, risk shocks produce large hot money flows via portfolio re-allocations because they alter the hedging properties of risky assets and drive households towards their collateral constraints. These hot money flows represent part of the valuation channel of external adjustment. Moreover, they appear beneficial in the sense that they allow households to fund consumption paths that closely approximate the paths under complete markets.

The remainder of the paper is divided into six sections. The model I develop draws on several lines of research from the asset-pricing and open-economy macro literatures. Section 1 discusses this research and explains where I extend existing work. Section 2 presents the model. Section 3 explains how I solve and calibrate the model to match the U.S. and E.U. data. In Section 4 I identify the elements that contribute to the external adjustment process. Section 5 contains my quantitative analysis of the model, including my empirical examination of the U.S. valuation channel. Section 6 concludes. Information concerning the data used in my empirical analysis, the solution method and other mathematical details can be found in a Web Appendix.

\section{Related Literature}

My analysis is related to three main areas of research: The first studies the asset-pricing implications of non-standard preferences, the second examines portfolio choice in open economy general equilibrium models, and the third focuses on the process of international external adjustment.

This paper adds to a large literature that uses habit formation to explain asset prices in closed and open economies (see, e.g., Sundaresan, 1989, Abel 1990, Constantinides 1990, Detemple and Zapatero 1991, Ferson

\footnotetext{
${ }^{2}$ In a companion piece, Evans (2012a), I use estimates of a simplified version of the model to show that the presence of risk shocks can account for some long-standing exchange rate puzzles; such as excess volatility, deviations from uncovered interest parity (UIP) and the disconnect between rates and macro fundamentals (see, e.g., Evans, 2011).
} 
and Constantinides 1991, Heaton 1995, Jermann 1998, Boldrin, Christiano, and Fisher 2001, Chan and Kogan 2002, Menzly, Santos, and Veronesi 2004, Santos and Veronesi 2010 and Buraschi and Jiltsov 2007). The model I develop adapts the Campbell and Cochrane (1999) habit specification to an open-economy setting. In their model habits are a function of past consumption shocks which are completely determined by an exogenous endowment process. As in Bekaert, Engstrom, and Xing (2009), I allow habits to depend on domestic consumption and exogenous preference shocks. These shocks have the natural interpretation of risk shocks because they change the local curvature of the households' utility. They are correlated with equilibrium consumption via variations in the terms of trade so that habits remain tightly linked to current and past consumption, as in Campbell and Cochrane (hereafter C\&C).

In the $\mathrm{C} \& \mathrm{C}$ model consumption shocks can have differing effects on the marginal utility of investors (depending the proximity of current consumption to the level of habit) producing variations in the price of risk. Several papers in the international asset-pricing literature exploit this feature. Verdelhan (2010) uses the $\mathrm{C} \& \mathrm{C}$ habit specification to account for the forward premium anomaly in a two-country model with complete markets. ${ }^{3}$ In his model shocks to domestic consumption produce pro-cyclical movements in the real interest rates and counter-cyclical variations in the foreign exchange risk premia. Moore and Roche (2010) and Heyerdahl-Larsen (2012) also use models with habits and complete markets to account for the forward premium anomaly, but here habits are relate to the consumption of individual goods (so called deep-habits). I extend this line of research in two directions: First, I calibrate the model to replicate the forward premium anomaly in U.S. and E.U. data in an equilibrium with incomplete risk-sharing and financial frictions. Second, I specify households' preferences over multiple traded goods to allow for consumption home bias, international trade and realistic co-movements between real exchange rates and the terms of trade (see, e.g., Engel, 1999). ${ }^{4}$ These extensions narrow the gap between international asset-pricing and open economy macro literatures (see, e.g., Engel, 2013 and Lewis, 2011).

The model I develop falls into the class of dynamic general equilibrium models with portfolio choice. Papers by Coeurdacier and Gourinchas (2008), Engel and Matsumoto (2009), Coeurdacier, Kollmann, and Martin (2010), Hnatkovska (2010), Devereux and Sutherland (2010b), Coeurdacier and Rey (2012) and others use these models to examine the reasons for home bias in equity portfolio holdings. This literature considers home bias arising from exchange-rate risk and non-tradable income risk, primarily in a complete markets setting. Home equity bias arises in my model for a different reason: The presence of financial frictions stop the equilibrium risk premia from providing sufficient compensation to households for the poor exchange-rate

\footnotetext{
${ }^{3}$ Under UIP the expected change in the spot exchange rate should equal the interest differential between foreign and domestic risk-free bonds. Under conventional rational expectations assumptions, UIP implies that the slope coefficient from a regression of future spot rate changes on the current interest differential should equal one. Instead, a very large literature finds estimates less than one and often negative; see, Lewis (1995) and Engel (1996, 2013) for surveys. The literature refers to these findings as the UIP puzzle or forward premium anomaly.

${ }^{4}$ In contrast, Verdelhan (2010) assumes that households only consume domestically produced goods. This extreme form of home bias allows him to circumvent the problems induced by variations in the terms of trade but at the cost of eliminating international trade. Bansal and Shaliastovich (2010) and Colacito and Croce (2011) also assume an extreme form of home bias to avoid a similar problem in their adaption of the long-run risk framework proposed by Bansal and Yaron (2004). In Moore and Roche (2010) households consume a basket comprising a single traded and nontraded good so variations in the terms of trade are absent. This is also true in the Appendix of Verdelhan (2010) which considers a model variant where households consume a single trade good subject to trading costs. Stathopoulos (2012) also studies a two-country external habit model where households' preferences are defined over multiple traded goods. His focus is on the co-movements in consumption growth and real exchange rates rather than the forward premium anomaly. And, again, he studies a complete markets equilibrium without financial frictions.
} 
hedging properties of foreign equity. The financial frictions take two forms: they impair households' ability to re-allocate portfolios among foreign bonds and equity, and they limit international borrowing via a collateral constraint. These frictions have two important dynamic implications. First they impede international risksharing following shocks. ${ }^{5}$ Second they amplify the effects of shocks on the portfolio reallocations that drive hot money flows. Similar amplification effects arising from the presence of financial frictions are studied in the literature on sudden stops (see, e.g., Mendoza, 2010 and Jeanne and Korinek, 2010).

My analysis also relates to research on the joint determination of capital flows and equity returns. Representative papers in this area include Bohn and Tesar (1996), Froot and Teo (2004) and Froot, O'Connell, and Seasholes (2001). Hau and Rey $(2006,2004)$ extend the analysis of the equity return-capital flow interaction to include the real exchange rate. Evans and Hnatkovska (2005), Devereux and Sutherland (2010b), Tille and van Wincoop (2010) and Coeurdacier, Kollmann, and Martin (2010) all model capital flows as the result of optimal portfolio reallocations in a similar manner to this paper. One noteworthy aspect of my analysis relative to these papers is that it draws a sharp contrast between the effects of risk shocks on equity returns and capital flows and the effects of more standard output (productivity) shocks.

Finally, the paper adds to a growing recent literature on international external adjustment. In canonical models changes in a country's net foreign asset position coincide with the current account because all international asset trade takes place via a single riskless bond. Here movements in the current account accommodate consumption smoothing in response to temporary shocks (see, e.g., Obstfeld and Rogoff, 1995). While straightforward, this intertemporal approach to the current account cannot accommodate the large cross boarder holdings of many different financial assets found in the data. In recognition of this deficiency, Gourinchas and Rey (2007) consider the adjustment process a world with complex international asset holdings where changes in a country's net foreign asset position are linked to revisions in expected future trade flows (the trade channel) and to changing expectations of future returns on foreign assets and liabilities (the valuation channel). Their empirical analysis revealed that revisions in expected future returns played a significant role in the cyclical dynamics of the U.S. net foreign asset position. As Gourinchas and Rey (2013) note, these results present something of a challenge. While shocks can produce unexpected valuation effects on a country's net foreign asset in standard models, they do not generate differences between the expected future returns on assets and liabilities that drive changes in net foreign asset positions. ${ }^{6}$ By contrast, my model produces variations in expected returns and net foreign asset positions that match U.S. data because risk shocks produce sizable variations in risk premia. Since risk shocks also induce large portfolio reallocations, the model ties hot money flows to the valuation channel of external adjustment. The external adjustment process in the model is also consistent with the evidence presented by Corsetti and Konstantinou (2012). They find that transitory shocks drive changes in the net foreign asset position while variations in aggregate consumption and gross positions are dominated by permanent shocks. In my model, risk shocks

\footnotetext{
${ }^{5}$ This is also true in Evans and Hnatkovska (2005, 2007), Hnatkovska (2010), Devereux and Sutherland (2010b), Tille and van Wincoop (2010) who all study open economy models with portfolio choice and incomplete markets. The effects of trading costs and informational frictions on home equity bias is discussed by Coeurdacier and Rey (2012) .

${ }^{6}$ For example, in Devereux and Sutherland (2010b) and Tille and van Wincoop (2010) markets are incomplete but shocks produce negligible changes in expected return differentials between foreign assets and liabilities so expected valuation effects play no role in net foreign asset dynamics. Expected valuation effects are also absent in Pavlova and Rigobon (2008) and Coeurdacier, Kollmann, and Martin (2010).
} 
are the dominant source of transitory shocks while permanent shocks originate from shocks to growth in endowments.

\section{The Model}

The model comprises two symmetric countries, which I refer to as the U.S. and Europe. Each country is populated by infinitely-lived households with preferences defined over the consumption of two perishable traded goods. For simplicity, there are no nontraded goods or impediments to trade in goods between the two countries. I also assume that the world supply of each traded good follows an exogenous endowment process, one located in each country. ${ }^{7}$ The model includes three key features beyond this simple structure: habits in household preferences, a collateral constrain that limits international borrowing, and a restriction that limits portfolio reallocations among foreign assets.

\subsection{Household Preferences}

Each country is populated by a continuum of identical households distributed on the interval $[0,1]$. Households' preferences are defined over a basket of traded consumption goods. In particular, the expected utility of a representative U.S. household $i \in[0,1]$ in period $t$ is given by

$$
\mathbb{U}_{i, t}=\mathbb{E}_{t} \sum_{j=0}^{\infty} \beta^{j} \mathcal{U}\left(C_{i, t+j}, H_{t+j}\right), \quad \text { with } \quad \mathcal{U}\left(C_{i, t}, H_{t}\right)=\frac{1}{1-\gamma}\left\{\left(C_{i, t}-H_{t}\right)^{1-\gamma}-1\right\}
$$

where $1>\beta>0, \gamma>0$ and $\mathbb{E}_{t}$ denotes expectations conditioned on period- $t$ information, which is common to all households. Each household's sub-utility $\mathcal{U}\left(C_{i, t}, H_{t}\right)$ depends on current consumption, $C_{i, t}$, and the subsistence level of consumption, or habit level, $H_{t}$. This habit level is treated as exogenous by individual U.S. households but varies with aggregate U.S. consumption, $C_{t}{ }^{8}$ Specifically, let $S_{t}=\left(C_{t}-H_{t}\right) / C_{t}$ denote the aggregate surplus consumption ratio. Following C\&C, I assume that the log surplus ratio $s_{t}=\ln \left(S_{t}\right)$ follows a heteroskedastic $\operatorname{AR}(1)$ process

$$
s_{t+1}=(1-\phi) \bar{s}+\phi s_{t}+\omega\left(s_{t}\right) v_{t+1},
$$

where $1>\phi>0$ and $\bar{s}$ is the steady state value of $s_{t}$. (Hereafter I use lowercase letters to denote the natural $\log$ of their uppercase counterpart.) The i.i.d. mean-zero, unit variance $v_{t}$ shocks affect the surplus ratio via a non-negative sensitivity function $\omega\left(s_{t}\right)$, which I discuss below. Notice that the U.S. habit level is given by $H_{t}=\left[1-\exp \left(s_{t}\right)\right] C_{t}$ so negative $v_{t}$ shocks raise habit relative to current aggregate consumption, but

\footnotetext{
${ }^{7}$ This assumption rules out the possibility that domestic production could be impaired by the effects of capital outflows on domestic credit markets, as in the literature on sudden stops. Clearly, this is a concern in economies where the domestic banking system is heavily dependent on foreign funding and domestic firms have limited access to world capital markets. My focus in this paper is on large economies where these issues are much less of a concern. I leave the task of extending the model to include production and domestic banking for future work.

${ }^{8}$ In this specification the level of habit is determined externally by the consumption decisions of all U.S. households. Alternatively, the level of habit could be determined internally by the consumption decisions of individual households. C\&C find that most asset-pricing implications of their model are robust to the presence of internal rather than external habits. Since models with internal habits are inherently more complex, I utilize the external habit specification here.
} 
they cannot push habit above current consumption. The surplus ratio also determines the local curvature of households' utility functions. For a representative household $-C_{i, t} \mathcal{U}_{c}\left(C_{i, t}, H_{t}\right) / \mathcal{U}_{c c}\left(C_{i, t}, H_{t}\right)=\gamma / S_{t}$, so their risk aversion tends toward infinity as the surplus ratio goes to zero.

The U.S. consumption basket comprises U.S. and E.U. traded goods:

$$
C_{i, t}=\mathcal{C}\left(C_{i, t}^{\mathrm{US}}, C_{i, t}^{\mathrm{EU}}\right)=\left(\eta^{\frac{1}{\theta}} C_{i, t}^{\mathrm{US} \frac{\theta-1}{\theta}}+(1-\eta)^{\frac{1}{\theta}} C_{i, t}^{\mathrm{EU} \frac{\theta-1}{\theta}}\right)^{\frac{\theta}{\theta-1}}
$$

where $C_{i, t}^{\mathrm{US}}$ and $C_{i, t}^{\mathrm{EU}}$ identify the consumption of U.S. and E.U. goods by U.S. household $i$. The parameter $\eta \in(0,1)$ governs the desired share of each good in the basket and $\theta$ is the elasticity of substitution between goods. I follow standard practice in the literature and focus on the case where $\eta>1 / 2$, so that households' preferences exhibit consumption home-bias.

E.U. household $i \in[0,1]$ has analogous preferences:

$$
\widehat{\mathbb{U}}_{i, t}=\mathbb{E}_{t} \sum_{j=0}^{\infty} \beta^{j} \mathcal{U}\left(\hat{C}_{i, t+j}, \hat{H}_{t+j}\right),
$$

where the E.U. consumption basket is

$$
\hat{C}_{i, t}=\mathcal{C}\left(\hat{C}_{i, t}^{\mathrm{EU}}, \hat{C}_{i, t}^{\mathrm{US}},\right)=\left(\eta^{\frac{1}{\theta}} \hat{C}_{i, t}^{\mathrm{EU}} \frac{\theta-1}{\theta}+(1-\eta)^{\frac{1}{\theta}} \hat{C}_{i, t}^{\mathrm{US}} \frac{\theta-1}{\theta}\right)^{\frac{\theta}{\theta-1}}
$$

The external E.U. habit level $\hat{H}_{t}=\left[1-\exp \left(\hat{s}_{t}\right)\right] \hat{C}_{t}$ depends on aggregate E.U. consumption, $\hat{C}_{t}$, and the $\log$ surplus ratio, $\hat{s}_{t}=\ln \hat{S}_{t}$, which follows

$$
\hat{s}_{t+1}=(1-\phi) \bar{s}+\phi \hat{s}_{t}+\omega\left(\hat{s}_{t}\right) \hat{v}_{t+1}
$$

where $\hat{v}_{t+1}$ are i.i.d. mean-zero, unit variance shocks. As above, the surplus ratio $\hat{S}_{t}$ determines the local curvature of E.U. household utility: $-\hat{C}_{i, t} \mathcal{U}_{c}\left(\hat{C}_{i, t}, \hat{H}_{t}\right) / \mathcal{U}_{c c}\left(\hat{C}_{i, t}, \hat{H}_{t}\right)=\gamma / \hat{S}_{t}$.

In the $\mathrm{C} \& \mathrm{C}$ model shocks to the log surplus ratio are perfectly correlated with unexpected changes in aggregate consumption. In their closed economy equilibrium consumption is determined by an endowment process so unexpected consumption depends on the exogenous endowment shock. This specification also implies that the level of external habit is a nonlinear function of current and past aggregate consumption. Here, in contrast, each country's aggregate consumption comprises a basket of traded goods so shocks affecting the endowments of either good and/or relative prices contribute to unexpected consumption in both countries. Thus, in this setting the $\mathrm{C} \& \mathrm{C}$ specification would produce a cross-country correlation between shocks to the log surplus ratios that greatly complicates the analysis of how changes in risk-aversion are transmitted internationally. To facilitate this analysis, I assume instead that shocks to the log surplus processes in (2) and (6) are independent and exogenous. They thus have the natural interpretation as risk shocks because they change the local curvature of households' utility. This specification enables us to study how changes in risk aversion originating in one country are transmitted internationally by tracing their effects on equilibrium asset prices and capital flows. 
My specification for the $s_{t}$ and $\hat{s}_{t}$ processes has two other noteworthy implications. First, it does not rule out a correlation between consumption growth and the log surplus ratio in each country. On the contrary, risk shocks affect consumption growth because they alter the real exchange rate and the terms of trade, which in turn induce households to adjust the composition of their consumption baskets. Thus, consumption growth is correlated with the log surplus ratios, but the correlation is imperfect and is determined as part of the model's equilibrium. This feature of the model is consistent with the results in Bekaert, Engstrom, and Xing (2009). They find evidence in U.S. data of an imperfect correlation between the log surplus ratio and consumption growth in a model that adds exogenous shocks to the $\mathrm{C} \& \mathrm{C}$ specification.

The second implication concerns the dynamics of habits. By definition the level of U.S. habit is given by $H_{t}=\left[1-\exp \left(s_{t}\right)\right] C_{t}$, so domestic risk shocks can in principle affect the level of habit independently of their effect on aggregate consumption (i.e., via their impact on $s_{t}$ ). This is not an important effect in the calibrated equilibrium of the model. I show below that almost all the variations in the level of habit are related to current and past innovations in domestic consumption.

The processes for the log surplus ratios in (2) and (6) also contain a sensitivity function that governs the reaction of the ratios to risk shocks. I assume that the function is decreasing in the log surplus:

$$
\omega(\mathrm{s})=\left\{\begin{array}{cl}
\sqrt{\omega\left(s_{\max }-\mathrm{s}\right)} & \mathrm{s} \leq s_{\max } \\
0 & \mathrm{~s}>s_{\max }
\end{array}\right.
$$

where $\omega$ is a positive parameter. In the continuous time limit, $s_{t}$ and $\hat{s}_{t}$ never exceed the upper bound of $s_{\max }$, so there is a corresponding lower limit on households' risk-aversion. The sensitivity function in the $\mathrm{C} \& \mathrm{C}$ specification is also decreasing in the log surplus ratio but is parameterized to keep risk free interest rates constant. The specification here allows for variations in the risk free rates depending on the values for $w$ and $s_{\max }$. I estimate these parameters from data on real exchange rates, real interest rates and consumption below.

\section{Prices and Exchange Rates}

The model contains two international relative prices: the terms of trade and the real exchange rate. These prices are linked through the consumption price indices in each country. Let $P_{t}^{\mathrm{US}}$ and $P_{t}^{\mathrm{EU}}$ denote the prices of the U.S. and E.U. goods in dollars, while $\hat{P}_{t}^{\mathrm{US}}$ and $\hat{P}_{t}^{\mathrm{EU}}$ denote their prices in euros, respectively. The U.S. and E.U. price indices corresponding to the consumption baskets in (3) and (5) are

$$
P_{t}=\left(\eta\left(P_{t}^{\mathrm{US}}\right)^{1-\theta}+(1-\eta)\left(P_{t}^{\mathrm{EU}}\right)^{1-\theta}\right)^{\frac{1}{1-\theta}} \quad \text { and } \quad \hat{P}_{t}=\left(\eta\left(\hat{P}_{t}^{\mathrm{EU}}\right)^{1-\theta}+(1-\eta)\left(\hat{P}_{t}^{\mathrm{US}}\right)^{1-\theta}\right)^{\frac{1}{1-\theta}} .
$$

The real exchange rate is defined as the relative price of the E.U. consumption basket in terms of the U.S. basket, $\mathcal{E}_{t}=\mathcal{S}_{t} \hat{P}_{t} / P_{t}$, where $\mathcal{S}_{t}$ denotes the dollar price of euros. There are no impediments to international trade between the U.S. and the E.U. so the law of one price applies to both the U.S. and E.U. goods: i.e., $P_{t}^{\mathrm{US}}=\mathcal{S}_{t} \hat{P}_{t}^{\mathrm{uS}}$ and $P_{t}^{\mathrm{EU}}=\mathcal{S}_{t} \hat{P}_{t}^{\mathrm{EU}}$. Combining these expressions with the definitions of the real exchange rate 
and the price indices gives

$$
\mathcal{E}_{t}=\left(\frac{\eta \mathcal{T}_{t}^{1-\theta}+(1-\eta)}{\eta+(1-\eta) \mathcal{T}_{t}^{1-\theta}}\right)^{\frac{1}{1-\theta}},
$$

where $\mathcal{T}_{t}$ denotes the U.S. terms of trade, defined as the relative price of imports in terms of exports, $P_{t}^{\mathrm{EU}} / P_{t}^{\mathrm{US}}$. When there is home bias in consumption $(\eta>1 / 2)$, a deterioration in the U.S. terms of trade (i.e. a rise in $\mathcal{T}_{t}$ ) is associated with a real depreciation of the dollar (i.e. a rise in $\mathcal{E}_{t}$ ).

Equation (7) makes clear that the model attributes all variations in real exchange rates to changes in the relative prices of traded goods via the terms of trade. This feature of the model is broadly consistent with existing empirical evidence on the source of real exchange rate variations. For example, Engel (1999) finds that little of the variation in real depreciations rates over horizons of five years or less originate from differences between the relative prices of traded and nontraded goods across countries. The omission of non-traded goods from the model doesn't significantly impair its ability to replicate the short- and mediumterm dynamics of real exchange rates. Equation (7) also implies that the real depreciation rate is strongly correlated with changes in the terms of trade when there is home bias in consumption. This implication is also consistent with the data. Real depreciation rates are very strongly correlated with changes in terms of trade over short horizons (see, e.g., Evans, 2011).

\section{Assets and Goods Markets}

There are four financial markets: a market for U.S. equities, E.U. equities, U.S. bonds and E.U. bonds. U.S. equity represents a claim on the stream of U.S. good endowments. In particular, at the start of period $t$, the holder of one share of U.S. equity receives a dividend of $D_{t}=\left(P_{t}^{\text {us }} / P_{t}\right) Y_{t}$, measured in terms of the U.S. consumption basket, where $Y_{t}$ is the endowment of the U.S. good. The ex-dividend price of U.S. equity in period $t$ is $Q_{t}$, again measured in terms of U.S. consumption. A share of E.U. equity pays a period- $t$ dividend of $\hat{D}_{t}=\left(\hat{P}_{t}^{\mathrm{EU}} / \hat{P}_{t}\right) \hat{Y}_{t}$ and has an ex-dividend price of $\hat{Q}_{t}$, where $\hat{Y}_{t}$ is the period- $t$ endowment of the E.U. good. Notice that $\hat{Q}_{t}$ and $\hat{D}_{t}$ are measured relative to the E.U. consumption basket. The gross real returns on U.S. and E.U equity are given by

$$
R_{t+1}^{\mathrm{EQ}}=\left(Q_{t+1}+D_{t+1}\right) / Q_{t} \quad \text { and } \quad \hat{R}_{t+1}^{\mathrm{EQ}}=\left(\hat{Q}_{t+1}+\hat{D}_{t+1}\right) / \hat{Q}_{t} .
$$

Households can also hold one-period real U.S. and E.U. bonds. The gross return on holding U.S. bonds between periods $t$ and $t+1$ is $R_{t}$, measured in terms of U.S. consumption; the analogous return on E.U. bonds is $\hat{R}_{t}$, measured in terms of E.U. consumption.

Households have access to both domestic and foreign bond and equity markets subject to two financial frictions (discussed below). Let $B_{i, t}^{\mathrm{US}}, B_{i, t}^{\mathrm{EU}}, A_{i, t}^{\mathrm{US}}$ and $A_{i, t}^{\mathrm{EU}}$ respectively denote U.S. household $i^{\prime} s$ holdings of U.S. and E.U. bonds, and shares of U.S. and E.U. equity in period $t$. The budget constraint facing the 
household is

$$
\begin{aligned}
\mathcal{E}_{t} \hat{Q}_{t} A_{i, t}^{\mathrm{EU}}+\mathcal{E}_{t} B_{i, t}^{\mathrm{EU}}+Q_{t} A_{i, t}^{\mathrm{US}}+B_{i, t}^{\mathrm{US}}+C_{i, t}= & \\
& R_{t-1} B_{i, t-1}^{\mathrm{US}}+A_{i, t-1}^{\mathrm{US}}\left(Q_{t}+D_{t}\right)+\mathcal{E}_{t} \hat{R}_{t-1} B_{i, t-1}^{\mathrm{EU}}+\mathcal{E}_{t} A_{i, t-1}^{\mathrm{EU}}\left(\hat{Q}_{t}+\hat{D}_{t}\right) .
\end{aligned}
$$

Notice that the first two terms on the left-hand-side represent the value of U.S. foreign asset holdings in period $t$. The budget constraint facing E.U. household $i$ is

$$
\begin{aligned}
Q_{t} \hat{A}_{i, t}^{\mathrm{US}} / \mathcal{E}_{t}+\hat{B}_{i, t}^{\mathrm{US}} / \mathcal{E}_{t}+\hat{B}_{i, t}^{\mathrm{EU}}+\hat{Q}_{t} \hat{A}_{i, t}^{\mathrm{EU}}+\hat{C}_{i, t}= \\
\hat{A}_{i, t-1}^{\mathrm{EU}}\left(\hat{Q}_{t}+\hat{D}_{t}\right)+\hat{R}_{t-1} \hat{B}_{i, t-1}^{\mathrm{EU}}+R_{t-1} \hat{B}_{i, t-1}^{\mathrm{US}} / \mathcal{E}_{t}+\hat{A}_{i, t-1}^{\mathrm{US}}\left(Q_{t}+D_{t}\right) / \mathcal{E}_{t},
\end{aligned}
$$

where $\hat{B}_{i, t}^{\mathrm{US}}, \hat{B}_{i, t}^{\mathrm{EU}}, \hat{A}_{i, t}^{\mathrm{US}}$ and $\hat{A}_{i, t}^{\mathrm{EU}}$ respectively denote the number of U.S. bonds, E.U. bonds and the number of shares of U.S. and E.U. equity held by E.U. household $i$ in period $t$.

The market clearing conditions are straightforward. Both U.S. and E.U bonds are in zero net supply so the bond market clearing conditions are

$$
0=\int_{0}^{1} B_{i, t}^{\mathrm{US}} d i+\int_{0}^{1} \hat{B}_{i, t}^{\mathrm{US}} d i \quad \text { and } \quad 0=\int_{0}^{1} B_{i, t}^{\mathrm{EU}} d i+\int_{0}^{1} \hat{B}_{i, t}^{\mathrm{EU}} d i
$$

The supplies of the U.S. and E.U. equities are normalized to one, so market clearing requires that

$$
1=\int_{0}^{1} A_{i, t}^{\mathrm{US}} d i+\int_{0}^{1} \hat{A}_{i, t}^{\mathrm{US}} d i \quad \text { and } \quad 1=\int_{0}^{1} A_{i, t}^{\mathrm{EU}} d i+\int_{0}^{1} \hat{A}_{i, t}^{\mathrm{EU}} d i
$$

Market clearing in the goods markets requires that aggregate demand from U.S. and E.U. households matches the world endowment of each traded good:

$$
Y_{t}=\int_{0}^{1} C_{i, t}^{\mathrm{US}} d i+\int_{0}^{1} \hat{C}_{i, t}^{\mathrm{US}} d i \quad \text { and } \quad \hat{Y}_{t}=\int_{0}^{1} C_{i, t}^{\mathrm{EU}} d i+\int_{0}^{1} \hat{C}_{i, t}^{\mathrm{EU}} d i
$$

Endowments of the two traded goods are driven by exogenous non-stationary processes. Specifically, I assume that the $\log$ endowments $y_{t}=\ln Y_{t}$ and $\hat{y}_{t}=\ln \hat{Y}_{t}$ follow:

$$
\begin{aligned}
& y_{t}=\bar{z}_{t}+z_{t} \quad \text { and } \quad \hat{y}_{t}=\bar{z}_{t}+\hat{z}_{t}, \quad \text { with } \\
& \bar{z}_{t}=\bar{z}_{t-1}+g+u_{t}, \quad z_{t}=\rho z_{t-1}+e_{t} \quad \text { and } \quad \hat{z}_{t}=\rho \hat{z}_{t-1}+\hat{e}_{t} .
\end{aligned}
$$

Here $\bar{z}_{t}$ identifies the stochastic trend (unit root process), while $z_{t}$ and $\hat{z}_{t}$ denote the cyclical components that follow $\operatorname{AR}(1)$ processes with $1>\rho>0$. The three endowment shocks, $u_{t}, e_{t}$ and $\hat{e}_{t}$ are mutually uncorrelated mean-zero random variables, with variances $\sigma_{u}^{2}, \sigma_{e}^{2}$ and $\sigma_{e}^{2}$, respectively. In the absence of any shocks, both endowments grow at rate $g$. 


\section{Financial Frictions and Household Decisions}

Households face two financial frictions when making their optimal consumption and portfolio decisions. The first limits their ability to reallocate their foreign asset holdings between bonds and equities. The second friction takes the form of a collateral constraint that prevents rolling over international debt through the use of Ponzi schemes.

To limit portfolio reallocations among foreign assets, I assume that each household can only hold foreign equity and bonds as part of a foreign asset portfolio with fixed weights. Specifically let $F A_{i, t}=\mathcal{E}_{t} \hat{Q}_{t} A_{i, t}^{\mathrm{EU}}+$ $\mathcal{E}_{t} B_{i, t}^{\mathrm{EU}}$ denote the value of the foreign asset portfolio held by U.S. household $i$ in period $t$. The portfolio weights for equity and bonds are fixed at $\wp$ and $1-\wp$, so that the value of E.U. equity and bond holdings held by U.S. household $i$ are

$$
\mathcal{E}_{t} \hat{Q}_{t} A_{i, t}^{\mathrm{EU}}=\wp F A_{i, t} \quad \text { and } \quad \mathcal{E}_{t} B_{i, t}^{\mathrm{EU}}=(1-\wp) F A_{i, t} .
$$

Similarly, E.U. households hold U.S. bonds and equities as part of a their foreign asset portfolio, $\widehat{F A}_{i, t}=$ $Q_{t} \hat{A}_{i, t}^{\mathrm{US}} / \mathcal{E}_{t}+\hat{B}_{i, t}^{\mathrm{us}} / \mathcal{E}_{t}$, such that

$$
Q_{t} \hat{A}_{i, t}^{\mathrm{US}} / \mathcal{E}_{t}=\wp \widehat{F A}_{i, t} \quad \text { and } \quad \hat{B}_{i, t}^{\mathrm{us}} / \mathcal{E}_{t}=(1-\wp) \widehat{F A}_{i, t} .
$$

With these restrictions, the return on U.S. and E.U foreign assets are given by

$$
R_{t+1}^{\mathrm{FA}}=\left(\mathcal{E}_{t+1} / \mathcal{E}_{t}\right)\left(\wp \hat{R}_{t+1}^{\mathrm{EQ}}+(1-\wp) \hat{R}_{t}\right) \quad \text { and } \quad \hat{R}_{t+1}^{\mathrm{FA}}=\left(\mathcal{E}_{t} / \mathcal{E}_{t+1}\right)\left(\wp R_{t+1}^{\mathrm{EQ}}+(1-\wp) R_{t}\right)
$$

These restrictions limit households' ability to change the composition of their foreign asset portfolios but not the value of foreign assets in their total wealth. While portfolio reallocations could be limited by other means (e.g., via the introduction of transactions costs as in Tille and van Wincoop, 2010), this is a tractable way to give households' more flexibility in re-allocating their wealth among domestic than foreign assets.

The restrictions in (14) and (15) have two other useful features. First, we can use solutions of the model with different values for $\wp$ to study how greater financial integration in world equity markets affects the behavior of capital flows. For example, when $\wp$ is set equal to zero all foreign assets are held in the form of bonds, so international bond transactions exclusively drive capital flows. When $\wp$ is set above zero, capital flows in the model comprise bond and equity flows. My analysis below is based on a calibration of the model where the value of $\wp$ matches the average equity-to-debt ratio in U.S. foreign asset positions (see Section 3.3). These data show that the shares of equity and debt in foreign assets and liabilities are quite stable on a quarter-by-quarter basis and only make a small contribution to the variability of asset and liability returns. The restriction does not materially hamper the ability of the model to replicate the behavior of U.S. foreign asset and liability returns.

The restrictions in (14) and (15) can also be interpreted as arising from the presence of fixed re-allocation costs. Suppose that households can choose from a continuum of foreign asset portfolios, each characterized by a different value for $\wp$, and that moving wealth from one portfolio to another incurs a fixed cost. In the 
steady state all households would choose the portfolio with the value for $\wp$, say $\wp^{*}$, that maximizes expected utility. Away from the steady state, they would compare the utility from moving to a new portfolio net of the fixed cost with the utility of keeping the $\wp^{*}$ portfolio. Under these circumstances (14) and (15) would arise with $\wp=\wp^{*}$ if the fixed costs are sufficiently large to make changing portfolios unattractive. In the calibrated model the value for $\wp^{*}$ is 0.491 (see Section 3.3), which is close to the average equity-to-debt ratio in U.S. foreign asset positions.

The second friction takes the form of a collateral constraint. For the case of U.S. household $i$, the constraint takes the form of a lower bound on U.S. bond holdings:

$$
B_{i, t}^{\mathrm{US}} \geq-(1+\varkappa) F A_{i, t}
$$

where $\varkappa>0$. The constraint implies that U.S. households can borrow by issuing domestic bonds up to the point where the real vale of their debt is $(1+\varkappa)$ times the value of their foreign asset holdings. The constraint facing E.U. household $i$ takes an analogous form:

$$
\hat{B}_{i, t}^{\mathrm{EU}} \geq-(1+\varkappa) \widehat{F A}_{i, t} .
$$

The constraints in (16) and (17) have several noteworthy implications. First, they do not limit the total amount of borrowing by any household. Second, foreign bonds and equity have equal value as collateral; the constraints in (16) and (17) apply to the value of total foreign asset holdings not the value of foreign bond and equity holdings individually. Third, variations in both exchange rates and equity prices affect the collateral value of foreign asset holdings. For example, since $F A_{i, t}=\mathcal{E}_{t} \hat{Q}_{t} A_{i, t}^{\mathrm{EU}}+\mathcal{E}_{t} B_{i, t}^{\mathrm{EU}}$, a shock inducing a fall in foreign equity prices $\hat{Q}_{t}$ and/or a real appreciation of the dollar (i.e. a fall in $\mathcal{E}_{t}$ ) will push U.S. households towards the point where the constraint binds. This, in turn, can lead to financial amplification. If households react in a way that induces a further fall in foreign equity prices and/or an appreciation of the dollar, the effects of the shock will be amplified by the presence of the constraint (see Jeanne and Korinek, 2010 and Brunnermeier, Eisenbach, and Sannikov, 2012). Lastly, (16) and (17) exclude the use of domestic equity as collateral. Since U.S. households only hold E.U. equity as part of their foreign asset portfolio, E.U. equity has no value as collateral when E.U. households want to borrow internationally.

I now describe the consumption and portfolio allocations decisions facing households. Let $W_{i, t}$ denote the real wealth of U.S. household $i$ at the start of period $t$ and let $\alpha_{i, t}^{\mathrm{EQ}}$ and $\alpha_{i, t}^{\mathrm{FA}}$ identify the fraction of wealth held in domestic equity and foreign assets at the end of period $t$ :

$$
\alpha_{i, t}^{\mathrm{EQ}}=Q_{t} A_{i, t}^{\mathrm{US}} /\left(W_{i, t}-C_{i, t}\right) \quad \text { and } \quad \alpha_{i, t}^{\mathrm{FA}}=F A_{i, t} /\left(W_{i, t}-C_{i, t}\right) .
$$


The problem facing U.S. household $i$ may now be written as

$$
\begin{array}{ll} 
& \operatorname{Max}_{\left\{C_{i, t}^{\mathrm{US}}, C_{i, t}^{\mathrm{EU}}, \alpha_{i, t}^{\mathrm{EQ}}, \alpha_{i, t}^{\mathrm{FA}}\right\}} \mathbb{E}_{t} \sum_{j=0}^{\infty} \beta^{j} \mathcal{U}\left(\mathcal{C}\left(C_{i, t+j}^{\mathrm{US}}, C_{i, t+j}^{\mathrm{EU}}\right), H_{t+j}\right) \\
\text { s.t. } & W_{i, t+1}=R_{i, t+1}^{\mathrm{W}}\left(W_{i, t}-C_{i, t}\right) \quad \text { and } \\
& N_{i, t}=\left(1-\alpha_{i, t}^{\mathrm{EQ}}+\varkappa \alpha_{i, t}^{\mathrm{FA}}\right)\left(W_{i, t}-C_{i, t}\right) \geq 0 .
\end{array}
$$

Equation (18c) rewrites the collateral restriction in (16) using the portfolio shares. Equation (18b) rewrites the budget constraint in terms of wealth and the real return on the households' portfolio:

$$
R_{i, t+1}^{\mathrm{W}}=R_{t}+\alpha_{i, t}^{\mathrm{EQ}}\left(R_{t+1}^{\mathrm{EQ}}-R_{t}\right)+\alpha_{i, t}^{\mathrm{FA}}\left(R_{t+1}^{\mathrm{FA}}-R_{t}\right)
$$

The problem facing E.U. household $i$ is analogous:

$$
\begin{array}{ll} 
& \operatorname{Max}_{\left\{\hat{C}_{i, t}^{\mathrm{US}}, \hat{C}_{i, t}^{\mathrm{EU}}, \hat{\alpha}_{i, t}^{\mathrm{EQ}}, \hat{\alpha}_{i, t}^{\mathrm{FA}}\right\}} \mathbb{E}_{t} \sum_{j=0}^{\infty} \beta^{j} \mathcal{U}\left(\mathcal{C}\left(\hat{C}_{i, t+j}^{\mathrm{EU}}, \hat{C}_{i, t+j}^{\mathrm{US}}\right), \hat{H}_{t+j}\right) \\
\text { s.t. } & \hat{W}_{i, t+1}=\hat{R}_{i, t+1}^{\mathrm{W}}\left(\hat{W}_{i, t}-\hat{C}_{i, t}\right) \quad \text { and } \\
& \hat{N}_{i, t}=\left(1-\hat{\alpha}_{i, t}^{\mathrm{EQ}}+\varkappa \hat{\alpha}_{i, t}^{\mathrm{FA}}\right)\left(\hat{W}_{i, t}-\hat{C}_{t}\right) \geq 0 .
\end{array}
$$

Here $\hat{\alpha}_{i, t}^{\mathrm{EQ}}=\hat{Q}_{t} \hat{A}_{i, t}^{\mathrm{EU}} /\left(\hat{W}_{i, t}-\hat{C}_{i, t}\right)$ and $\hat{\alpha}_{i, t}^{\mathrm{FA}}=\widehat{F A}_{i, t}\left(\hat{W}_{i, t}-\hat{C}_{i, t}\right)$ are the fractions of wealth invested in E.U. equity and foreign assets; $\hat{W}_{i, t}$ is real wealth (measured in terms of E.U. consumption) at the start of period $t$, and $\hat{R}_{i, t+1}^{\mathrm{w}}$ is the real return on the household's portfolio:

$$
\hat{R}_{i, t+1}^{\mathrm{W}}=\hat{R}_{t}+\hat{\alpha}_{i, t}^{\mathrm{EQ}}\left(\hat{R}_{t+1}^{\mathrm{EQ}}-\hat{R}_{t}\right)+\hat{\alpha}_{i, t}^{\mathrm{FA}}\left(\hat{R}_{t+1}^{\mathrm{FA}}-\hat{R}_{t}\right)
$$

Since households within each country have the same preferences and face the same constraints, we can focus on the behavior of a representative U.S. and E.U. household without loss of generality. Hereafter, I drop the $i$ subscripts on consumption and the portfolio shares to simplify notation.

\section{Equilibrium}

\subsection{Solution Method}

An equilibrium in this model comprises a sequence for the real exchange rate $\left\{\mathcal{E}_{t}\right\}$, real interest rates $\left\{R_{t}\right.$ and $\left.\hat{R}_{t}\right\}$, and equity returns $\left\{R_{t}^{\mathrm{EQ}}\right.$ and $\left.\hat{R}_{t}^{\mathrm{EQ}}\right\}$, consistent with market clearing in the goods and asset markets given the optimal consumption and portfolio decisions of households and the exogenous endowments. Finding the equilibrium processes for $\left\{\mathcal{E}_{t}, R_{t}, \hat{R_{t}}, R_{t}^{\mathrm{EQ}}\right.$ and $\left.\hat{R}_{t}^{\mathrm{EQ}}\right\}$ is complicated by the presence of incomplete markets, portfolio choice, and occasionally binding collateral constraints. In principle, models with these features can be solved with existing global methods, but here the method is computationally infeasible because the 
state space is too large. ${ }^{9}$ Local methods, based on approximations around the steady state, often provide a computationally attractive alternative when this curse of dimensionality appears. For example, Evans and Hnatkovska (2012) Tille and van Wincoop (2010) and Devereux and Sutherland (2010b) show how models with portfolio choice, incomplete markets and large state spaces can be solved with local methods, but they do not accommodate occasionally binding constraints. In recognition of these problems, I use a new solution method developed Evans (2012a). It combines barrier methods and approximations around the model's stochastic steady state to produce an accurate solution in a very computationally efficient manner. Consequently, I am able to use the solution method as part of an GMM estimation procedure in which the model is solved thousands of times to match moments of U.S. and E.U. data. Below, I provide a brief overview of the method. A detailed description and accuracy assessment can be found in the Web Appendix.

Barrier methods are widely used in the optimal control literature to solve optimization problems involving inequality constraints (see, e.g., Forsgren Anders and Wright, 2002). The basic idea is to modify the objective function so that the optimizing agent is penalized as his actions bring him closer to the barrier described by the inequality constraint. This approach converts the original optimization problem with inequality constraints into one with only equality constraints that can be readily combined with the other equilibrium conditions to derive an approximate solution to the model. Preston and Roca (2007) and Kim and Kim (2010) use barrier methods in this way to solve incomplete markets' models with heterogenous agents.

Following Kim and Kim (2010), I modify the sub-utility functions for the representative U.S. and E.U. households to

$$
\mathcal{U}\left(C_{t}, H_{t}, N_{t}\right)=\frac{1}{1-\gamma}\left\{\left(C_{t}-H_{t}\right)^{1-\gamma}-1\right\}+\frac{\mu \bar{N}_{t}}{\left(\bar{C}_{t} \bar{S}\right)^{\gamma}}\left\{\ln \left(\frac{N_{t}}{\bar{N}_{t}}\right)-\left(\frac{N_{t}-\bar{N}_{t}}{\bar{N}_{t}}\right)\right\}
$$

and

$$
\mathcal{U}\left(\hat{C}_{t}, \hat{H}_{t}, \hat{N}_{t}\right)=\frac{1}{1-\gamma}\left\{\left(\hat{C}_{t}-\hat{H}_{t}\right)^{1-\gamma}-1\right\}+\frac{\mu \bar{N}_{t}}{(\bar{C} \bar{t})^{\gamma}}\left\{\ln \left(\frac{\hat{N}_{t}}{\bar{N}_{t}}\right)-\left(\frac{\hat{N}_{t}-\bar{N}_{t}}{\bar{N}_{t}}\right)\right\}
$$

where $\mu>0$ and bars denote the values of variables in the steady state. These modifications penalize households as their portfolio choices bring them closer to their respective collateral constraints. For example, as U.S. households' foreign asset holdings close in on the point where the constraint binds, $N_{t}=\left(1-\alpha_{t}^{\mathrm{EQ}}+\right.$ $\left.\varkappa \alpha_{t}^{\mathrm{FA}}\right)\left(W_{t}-C_{t}\right)$ nears zero, and the last term on the right-hand-side of (22a) approaches its limiting value of $-\infty$. Similarly, the last term in (22b) approaches $-\infty$ when E.U. households near the point where their collateral constraint binds. As a consequence, households will occasionally choose portfolios that come close to the point where the collateral constraint binds, but never to the point where is actually does. The importance of this distinction depends on the size of the barrier parameter, $\mu$, that governs the rate at which the utility cost rises as the household approaches the constraint. If we consider a sequence of solutions to the modified households' problems as $\mu$ takes smaller and smaller values, the sequence will converge to the solutions of their original problem in the limit as $\mu \rightarrow 0$ (see, e.g., Forsgren Anders and Wright, 2002). The

\footnotetext{
${ }^{9}$ Stepanchuk and Tsyrennikov (2013) use a global solution method to analyze a model with similar features, but they are forced to restrict their state space and focus on a wealth-recursive Markov equilibrium in which the distribution of wealth is a sufficient statistic for all the equilibrium variables. Their approach cannot be applied to my model, nor is it computationally efficient enough to be used as part of the estimation procedure described below.
} 
solutions of the model I examine below are robust to alternative choses for $\mu$ that are close to zero. Notice, also, that the last terms on the right-hand-side on (22) disappear when $N_{t}=\hat{N}_{t}=\bar{N}_{t}$. This implies that household decisions are unaffected by collateral constraints in the steady state.

I use standard log-linear approximations to the households' first-order conditions from the modified optimization problems and the market clearing conditions to find the equilibrium process for the real exchange rate, real interest rates, and other endogenous variables. These approximations are computed around the model's stochastic steady state. ${ }^{10}$ This is the point at which the exogenous surplus ratios, $s_{t}$ and $\hat{s}_{t}$, equal their long run value of $\bar{s}$, and the cyclical components in the endowment processes, $z_{t}$ and $\hat{z}_{t}$, equal zero so the endowments of U.S. and E.U. goods are equal and follow the stochastic trend (i.e., $y_{t}=\hat{y}_{t}=\bar{z}_{t}$ ). ${ }^{11}$ In the stochastic steady state households expect both endowments to grow at rate $g$, (i.e., $\mathbb{E}_{t} \Delta y_{t+i}=\mathbb{E}_{t} \Delta \hat{y}_{t+i}=g$, for all $i>0$ ), but they do not expect any future changes in the surplus ratios (i.e., $\mathbb{E}_{t} s_{t+i}=\mathbb{E}_{t} \hat{s}_{t+i}=\bar{s}$ for all $i>0$ ). Households also recognize that future endowments and surplus ratios are subject to shocks. It is this recognition that distinguishes the stochastic steady state from its conventional deterministic counterpart. It implies that households' steady state portfolios are uniquely identified from the joint conditional distribution of future returns and marginal utility. ${ }^{12}$

\subsection{Parameterization}

The model contains 15 parameters: the preference parameters, $\beta, \gamma, \eta$ and $\theta$; the parameters governing the surplus ratios, $\phi, \bar{s}, s_{\max }$ and $\omega$; the parameters of the endowment processes, $\rho, g, \sigma_{e}^{2}$ and $\sigma_{u}^{2}$; the collateral constraint, $\varkappa$, the barrier parameter, $\mu$, and foreign asset weight, $\wp$. I set the values for some parameters to be consistent with the values that appear elsewhere in the literature. The values for other parameters are estimated by the Generalized Method of Moments (GMM) using U.S. and E.U. data.

The values assigned to the model's parameters are shown in Table 1. The model is parameterized so that one period corresponds to one quarter. $\beta$ is set equal to 0.99 , while $\gamma$ and $\eta$ are assigned standard values of 2 and 0.85 , respectively. Thus, households are risk-averse and have a strong bias towards the consumption of domestic goods. In actual economies the local prices of domestic- and foreign-produced consumer goods are relatively unresponsive to quarterly variations in spot exchange rates because the effects are absorbed by the production and distribution sectors. These sectors are absent in the model. Consequently, variations in the real exchange rate are directly reflected in the relative prices that drive households's consumption decisions. To compensate for this feature, I treat $\theta$ as a composite parameter, $\theta^{*}(1-\varsigma)$, where $\varsigma$ denotes the fraction of exchange rate variations absorbed by the un-modeled production and distribution sectors, and $\theta^{*}$ is the "true" elasticity of substitution. Setting $\theta^{*}$ equal to 0.72, as in Hnatkovska (2010) and Corsetti, Dedola, and

\footnotetext{
${ }^{10}$ In some models, incomplete risk-sharing induces non-stationary dynamics in household wealth so there is no unique deterministic steady state around which to approximate equilibrium dynamics. Schmitt-Grohe and Uribe (2003) discuss how the introduction of endogenous discounting in households' preferences, asset-holding costs and (ad hoc) debt-elastic interest rates can induce stationarity. In this model stationarity is induced endogenously via the collateral constraints that make interest rates sensitive to a country's net foreign asset position.

${ }^{11}$ Coeurdacier, Rey, and Winant (2011) use a similar steady state concept, but their definition includes all the state variables not just the exogenous state variables as I do here.

${ }^{12}$ All assets have the same riskless return in the deterministic steady state so portfolios are not uniquely identified. One approach to this identification problem is to consider the portfolio choices in the limit as the variance of exogenous shocks goes to zero; see, e.g., Judd and Guu (2001).
} 
Table 1: Parameterization

\begin{tabular}{|c|c|c|}
\hline Symbol & Parameter & Values \\
\hline \multicolumn{3}{|c|}{ A: Assigned Values } \\
\hline$\beta$ & discount function & 0.990 \\
\hline$\gamma$ & utility curvature & 2.000 \\
\hline$\eta$ & home good share & 0.850 \\
\hline$\theta$ & elasticity of substitution & 0.110 \\
\hline$g$ & steady state growth rate & 0.028 \\
\hline $\bar{S}$ & average log consumption-surplus & 0.050 \\
\hline$\wp$ & equity share in foreign asset portfolios & 0.420 \\
\hline$\varkappa$ & collateral constraint & 0.500 \\
\hline$\mu$ & barrier parameter & 0.030 \\
\hline \multicolumn{3}{|c|}{ B: GMM Estimates } \\
\hline$\phi$ & autocorrelation in log surplus & 0.826 \\
\hline$S_{\max }$ & upper bound on log surplus & 0.060 \\
\hline$\omega$ & variance sensitivity & 0.198 \\
\hline$\rho$ & autocorrelation in endowments & 0.877 \\
\hline$\sigma_{e}$ & standard deviation of endowment shocks* & 0.777 \\
\hline
\end{tabular}

Notes: * expressed in percent per quarter.

Leduc (2008), and $\varsigma$ equal to 0.85 , gives a value for $\theta$ of $0.11 .{ }^{13}$

The parameters $\wp, \varkappa$ and $\mu$ determine how financial frictions affect the model's equilibrium. In the benchmark parameterization I set the share of equity in foreign asset portfolios $\wp$ equal to 0.42 . This is one half the average share of equity and FDI in U.S. foreign assets and liability portfolios between 1973 and 2007. The values for $\varkappa$ and $\mu$ are chosen to imply reasonable restrictions on the degree of international borrowing. I set the value of $\varkappa$ equal to 0.5 so that households can issue debt up to 150 percent of the value of their foreign asset holdings. This limit implies an upper bound on the ratio of net foreign debt (i.e. debt minus foreign assets) to trend GDP of approximately 190 percent. I set $\mu$ equal to 0.03 and check that the solution is robust to using alternative small values for the barrier parameter.

The remaining parameters govern the endowment and log surplus processes. I assign values to two of these parameters. The first is the value for the long run growth rate, $g$, which I set equal to 0.028 . The values of $\beta, \gamma$ and $g$ together imply that the steady state real interest rate in both countries equals 1.5 percent per year. Following Campbell and Cochrane (1999) I also assign a value to the steady state surplus consumption ratio, $\bar{S}$, of 0.057 , so the steady state level of habit is 94 percent of consumption. The remaining parameters are estimated by GMM so that the model's equilibrium matches five key moments of quarterly

\footnotetext{
${ }^{13}$ Obviously, this is a very reduced-form approach of capturing the low rate of exchange-rate pass-through we observe empirically (see, e.g., Campa and Goldberg, 2008).
} 
U.S. and E.U data (described below): (i) the variance of the real depreciation rate for the USD/EUR, (ii) the variance in the per capita consumption growth differential between the U.S. and E.U., (iii) the variance of the real interest differential between the U.S. and E.U., (iv) the first-order autocorrelation in the real interest differential, and (v) the slope coefficient from a regression of the real depreciation rate on the real interest differential. I find the GMM estimates for $\phi, s_{\max }, \omega, \rho$, and $\sigma_{e}^{2}$ that match the unconditional moments computed from the equilibrium of the model with statistics computed from quarterly data spanning 1990:I to 2007:IV. The results are reported in the panel B of Table $1 .{ }^{14}$

Three aspects of GMM estimates deserve comment. First, matching the moments in this model requires less persistence in the log surplus ratios that is assumed in other models. For example, C\&C andVerdelhan (2010) use values for $\phi$ very close to one, well above the GMM value of 0.826 . Second, the GMM value for the upper bound on the surplus ratio $S_{\max }$ is close to $\bar{S}$ so the unconditional distribution for $s_{t}$ is skewed further to the left of $\bar{s}$ than in other habit models. The third feature concerns the relative importance of endowment shocks and risk shocks in the stochastic steady state. The GMM values imply that in the steady state the standard deviation of the log surplus ratios $\left(s_{t}\right.$ and $\left.\hat{s}_{t}\right)$ is 11 times that of the cyclical endowments $\left(z_{t}\right.$ and $\hat{z}_{t}$ ). This means that time series variations in the log surplus ratios are the dominant driver of equilibrium exchange rates, real rate and consumption growth differentials. As we shall see, they also turn out to be the main source of hot money capital flows.

\subsection{Equilibrium Dynamics}

\section{Exchange Rates, Interest Rates and Consumption}

Table 2 compares the unconditional moments of the real exchange rate, real interest rates, and consumption growth produced from the equilibrium of the model with sample moments computed in U.S. and E.U. data. These data come from Datastream and span the period 1990:I to 2007:IV. The real exchange rate at the start of month $t, \mathcal{E}_{t} \equiv \exp \left(\varepsilon_{t}\right)$, is computed as $S_{t} \hat{P}_{t} / P_{t}$, where $S_{t}$ is the spot rate (USD/EUR) at the end of trading (i.e. 12:00 noon E.S.T.) on the last trading day (Monday - Friday) in quarter $t-1 . P_{t}$ and $\hat{P}_{t}$ are the last reported levels for the U.S. and E.U. consumer price indices before the start of quarter $t$. The real interest differential is computed from inflation and the three month nominal rates on Eurodeposits. Specifically, I estimate the U.S. real rate at the start of quarter $t$ as the fitted value from an $\operatorname{AR}(2)$ regression for the ex post real return on Eurodeposits, $i_{t}-\left(p_{t+1}-p_{t}\right)$, where $i_{t}$ is the midpoint of the bid and offer rates on the last trading day of quarter $t-1$. The E.U. real rate is similarly computed as the fitted value from an $\operatorname{AR}(2)$ for the ex post real return, $\hat{\imath}_{t}-\left(\hat{p}_{t+1}-\hat{p}_{t}\right)$. The consumption growth rates are computed from real consumption expenditures on nondurables.

Panel A of Table 2 shows that the variance of the real depreciation rate is approximately four times larger than the variance of the consumption growth differential, which in turn is 30 percent larger than the variance of the interest differential. The model accounts for these differences via the influence of the risk

\footnotetext{
${ }^{14}$ The endowment process also depends on the variance of common growth shocks, $\sigma_{u}^{2}$. I choose the value for $\sigma_{u}^{2}$ so that the long run correlation between consumption growth in each country matches the unconditional sample correlation in US and Euro-area data. Because growth shocks affect both countries equally, the value of this parameter does not affect the analysis of the model below.
} 
Table 2: Exchange Rates, Interest Rates and Consumption

\begin{tabular}{|c|c|c|c|}
\hline & & Data & Model \\
\hline \multicolumn{4}{|c|}{ A: Variances } \\
\hline$\Delta \varepsilon_{t}$ & real depreciation rate ${ }^{\dagger}$ & 19.787 & 19.787 \\
\hline$\Delta c_{t}-\Delta \hat{c}_{t}$ & consumption growth differential ${ }^{\dagger}$ & 2.448 & 2.448 \\
\hline$r_{t}-\hat{r}_{t}$ & real interest rate differential ${ }^{\dagger}$ & 1.739 & 1.739 \\
\hline \multicolumn{4}{|c|}{ B: First Order Autocorrelation } \\
\hline$r_{t}-\hat{r}_{t}$ & real interest rate differential ${ }^{\dagger}$ & 0.833 & 0.833 \\
\hline$\Delta \varepsilon_{t}$ & real depreciation & -0.116 & -0.043 \\
\hline$\Delta c_{t}-\Delta \hat{c}_{t}$ & consumption growth differential & -0.233 & -0.090 \\
\hline
\end{tabular}

shocks. Panel B reports the autocorrelation properties of the real interest differential, depreciation rate and consumption growth differential. The GMM estimation procedure did not use the latter two autocorrelations, so a comparison of these moments is informative about the model's ability to represent this aspect of the data. As the table shows, this calibration of the model has no trouble replicating the lack of serial correlation in the real USD/EUR depreciation rate. The model also produces little serial correlation in the consumption growth differential, but in this case the correlation is somewhat smaller in absolute value than the correlation estimated from the data.

The GMM procedure also insures that the model can match a key co-movement in real depreciations rates and interest differentials. In U.S. and E.U. data a regression of the future real depreciation rate, $\Delta \varepsilon_{t+1}$, on the current real interest differential, $r_{t}-\hat{r}_{t}$, produces a slope coefficient of -2.95 . This estimate is significantly different from the value of one implied by UIP. The GMM estimation procedure insures that the calibration of the model exactly reproduces this feature of the data. As in Verdelhan (2010), the negative coefficient reflects the fact that equilibrium interest differentials and foreign exchange risk premium move in different directions, but here these movement arise in a world of incomplete risk sharing and financial frictions.

The model is less successful in replicating one other feature of the U.S. and E.U. data; the correlation between the real depreciation rate, $\Delta \varepsilon_{t}$, and the consumption growth differential, $\Delta c_{t}-\Delta \hat{c}_{t}$. The sample correlation is -0.103 , while in the model the unconditional correlation is -0.754 . Producing a negative correlation has long been a challenge for standard models using isoelastic time-separable utility with complete markets (see, e.g., Backus and Smith, 1993), but here the combination of external habits and incomplete risksharing produces too large a negative correlation. Unfortunately there does not appear to be an alternative (reasonable) calibration of the model that produces a correlation between the real depreciation rate and consumption growth differential closer to -0.1. while replicating the forward premium anomaly and moments in Table $2 .{ }^{15}$

\footnotetext{
${ }^{15}$ The problem of simultaneously replicating the forward premium anomaly, the volatility of real depreciation rates, and their
} 


\section{Habits}

Habits are tightly linked to consumption in the calibrated equilibrium of the model. Recall that the level of U.S. habit, $H_{t}$, is related to the surplus ratio, $S_{t}$, and aggregate consumption, $C_{t}$, by the identity, $H_{t}=\left(1-S_{t}\right) C_{t}$. In equilibrium intertemporal smoothing by households insures that aggregate consumption responds immediately and one-for-one with shocks to the endowment trend. The log of equilibrium U.S. consumption can therefore be represented as $c_{t}=\bar{c}_{t}+c_{t}^{\mathrm{CYL}}$, where $\bar{c}_{t}\left(=\bar{z}_{t}\right)$ is the trend in consumption and $c_{t}^{\text {CYL }}$ is the remaining cyclical component driven by the temporary endowment shocks and the risk shocks. Combing this decomposition with the definition of $H_{t}$ and using the fact that $S_{t}$ is stationary, we can represent the dynamics of log U.S. habit by

$$
h_{t}=\bar{h}_{t}+h_{t}^{\mathrm{CYC}}, \quad \text { where }
$$

$$
\bar{h}_{t}=\bar{c}_{t} \quad \text { and } \quad h_{t}^{\mathrm{CYC}}=\ln \left(1-\exp \left(s_{t}\right)\right)+c_{t}^{\mathrm{CYL}}
$$

Permanent shocks to consumption (i.e., shocks to $\bar{c}_{t}$ ) are fully reflected in the level of habit via the trend component $\bar{h}_{t}$. Other shocks affect the level of habit via the cyclical component $h_{t}^{\text {CYC }}$. In the C\&C specification, $c_{t}^{\mathrm{CYL}}=0$ and the $\log$ surplus ratio $s_{t}$ is driven by shocks to $\bar{c}_{t}$. As I discuss below, in this model $c_{t}^{\mathrm{CYL}}$ varies in response to temporary endowment shocks and risk shocks because both shocks produce changes in the terms of trade that affect households' consumption decisions. As a result, even though risk shocks directly affect the level of habit via their impact on the log surplus ratio, $s_{t}$, they do not produce significant variations in habit that are unrelated to consumption.

This feature can be seen from the time series representation of $h_{t}^{\mathrm{CYC}}$. To derive the representation, I first generate time series over 100,000 quarters for $h_{t}^{\mathrm{CYC}}$ and the innovations in cyclical consumption, $c_{t}^{\mathrm{CYL}}-\mathbb{E}_{t-1} c_{t}^{\mathrm{CYL}}$, from the model's equilibrium. I then use these series to estimate the following ARMA model:

$$
h_{t}^{\mathrm{CYC}}=0.982 h_{t-1}^{\mathrm{CYC}}+1.061\left(c_{t}^{\mathrm{CYL}}-\mathbb{E}_{t-1} c_{t}^{\mathrm{CYL}}\right)-0.136\left(c_{t-1}^{\mathrm{CYL}}-\mathbb{E}_{t-2} c_{t-1}^{\mathrm{CYL}}\right)+\epsilon_{t}, \quad R^{2}=0.954
$$

As the $R^{2}$ statistic indicates, cyclical variation in habits are tightly tied to the history of consumption innovations in the model's equilibrium. Of course actual consumption innovations come from four different shocks in the model which have different implications for the dynamics of habits and other variables. This means that the estimated ARMA coefficients have no structural interpretation. ${ }^{16}$ They simply summarize the fact that positive shocks to cyclical consumption are, on average, associated with higher levels of cyclical habit that persist far into the future.

correlation with consumption growth differentials is long-standing in the literature. For example, Verdelhan (2010) replicates the anomaly but not the volatility of depreciation rates or their correlation with consumption. On the other hand, Colacito and Croce (2011) have more success accounting for the volatility of depreciation rates and correlation with consumption, but their model cannot replicate the forward premium anomaly because it generates a constant market price of risk.

${ }^{16}$ The estimated coefficients have extremely small standard errors, on the order of 0.003 , so sampling error is not a concern here. The estimates are also robust to adding further lags of $h_{t}^{\mathrm{CYL}}$ and $c_{t}^{\mathrm{CYL}}-\mathbb{E}_{t-1} c_{t}^{\mathrm{CYL}}$. 


\section{Returns on Foreign Assets and Liabilities}

Table 3 compares the characteristics of U.S. foreign asset and liability returns with the foreign asset returns generated by the model. The statistics on U.S. returns are based on the dataset from Evans (2012b) that contains U.S. foreign asset and liability positions at market value and their associated returns at the quarterly frequency. The data is constructed following procedures described in Gourinchas and Rey (2005) that combine information on the market value for four categories of U.S. foreign asset and liabilities: Equity, Foreign Direct Investment (FDI), Debt and Other; with information on the U.S. International Investment Position reported by the Bureau of Economic Analysis. ${ }^{17}$ To facilitate comparisons with the model, the table reports returns on two categories: "equity" that combines Equity and FDI, and "debt" that combines Debt and Other. I also compute statistics for two sample periods: 1973:I-2007:IV and 1990:I-2007:IV. The former period covers the entire post Bretton-Woods era prior to 2008 financial crisis, while the latter covers the period after the adoption of the Euro used to compute the statistics in Table 2.

Columns (i) and (ii) of panels A and B report the sample means and standard deviations for log excess returns on U.S. foreign assets, liabilities and their equity and debt components computed as $r_{j, t+1}^{z}-r_{t}$, where $r_{j, t+1}^{z}$ for $\mathrm{Z}=\{\mathrm{A}, \mathrm{L}\}$ denotes the $\log$ real return on asset/liability $j$. Column (iii) reports Sharpe ratios, computed as the sample average of gross excess returns, $R_{j, t+1}^{z}-R_{t}$, divided by their sample standard deviation, while columns (iv) and (v) show the sample means and standard deviations of the portfolio shares, $\alpha_{j, t}^{z}$. Panel C reports analogous statistics computed from simulating the model over 100,000 quarters. Since the model is symmetric, simulations of the U.S. foreign liability returns produce identical moments.

An inspection of the table reveals that the sample statistics computed from the U.S. data are generally comparable with those implied by the model. Log excess foreign asset returns in the model have a somewhat higher mean and standard deviation than in the two data samples, but the Sharpe ratio implied by the model closely matches the ratio computed in the second data sample. It is worth emphasizing that the model's equilibrium is calibrated to match the moments of exchange rates, interest rates and consumption in Table2 rather than the behavior of these returns, so some differences between the sample statistics in Panels A and B and the model statistics are to be expected. Moreover, the U.S. data on returns comes from portfolios with different time-varying shares that are not present in the model. In particular, columns (iv) and (v) show that on average equity comprises a larger share of U.S. foreign asset holdings than liability holdings, and that equity shares have been rising through time and becoming more stable. These portfolio composition effects account for some of the differences between the U.S. data and the model's implications.

\footnotetext{
${ }^{17}$ The Web Appendix provides details concerning the construction of the U.S. foreign asset and liability position data and the associated returns.
} 
Table 3: Foreign Asset and Liability Returns

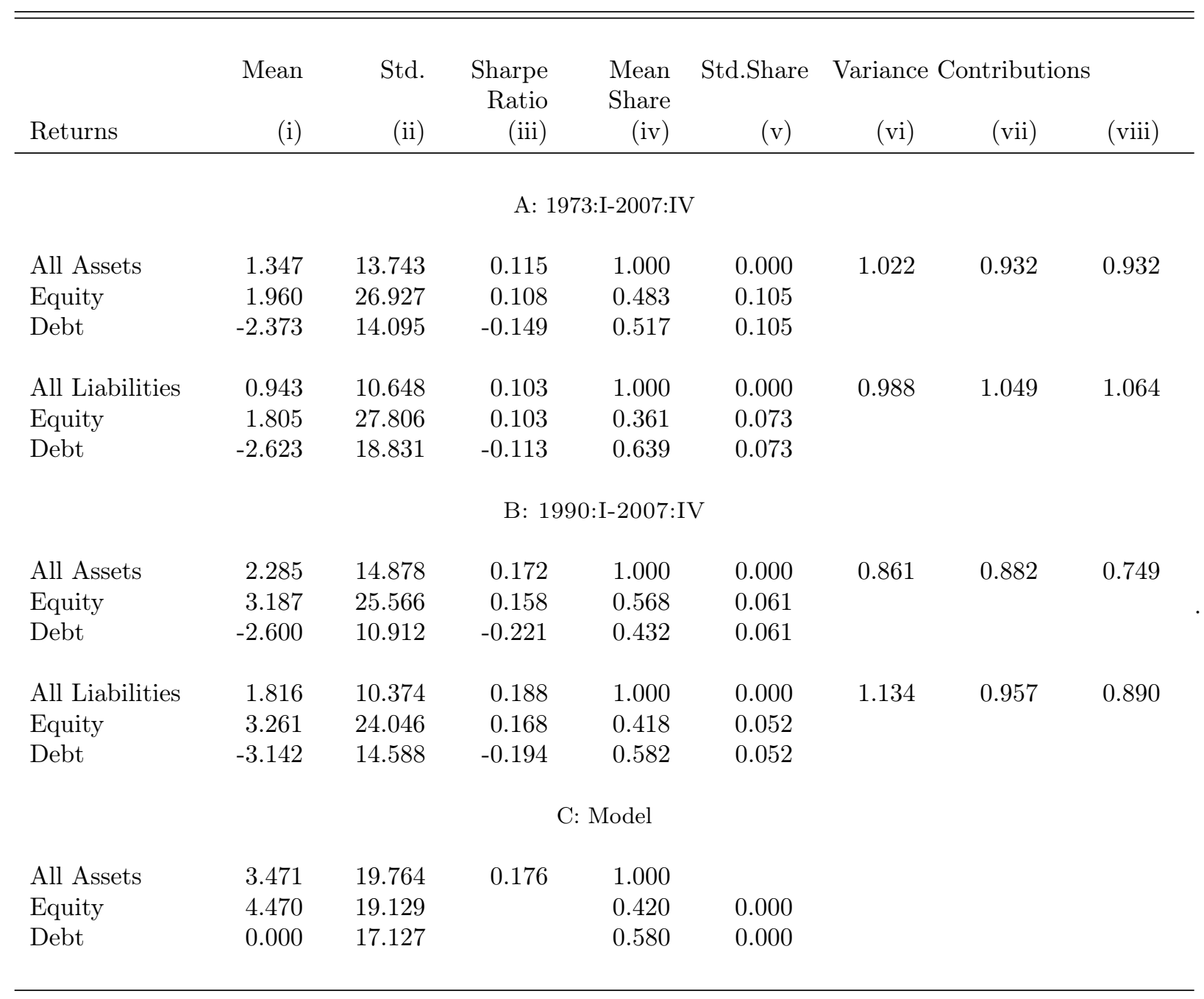

Notes: The upper panels report statistics computed from U.S. data over the sample periods indicated. The lower panel reports statistics computed from the stochastic steady state of the model. Columns (i) and (ii) show the means and standard deviations for log excess returns for all assets listed in the left hand column. All log returns are multiplied by 400. Column (iii) reports the Sharpe ratios. Columns (iv) and (v) show the average and standard deviation of the share of each asset and liability category in total assets and liabilities, respectively. Variance decompositions for the returns on U.S. foreign assets and liabilities are in the three right-hand columns. The variance contribution of returns using constant asset or liability shares, the average of asset and liability shares, and the constant average of asset and liability shares are shown in column (vi)- (viii), respectively.

To assess how composition effects affect portfolio returns in the U.S. data, I compute the log returns on three sets of synthetic portfolios for assets and liabilities. The log portfolio returns are constructed as

$$
r_{t}^{\mathrm{A}}\left(\alpha_{t}^{\mathrm{Z}}\right)=\ln \left(\sum_{j} \alpha_{j, t-1}^{\mathrm{Z}} R_{j, t}^{\mathrm{A}}\right) \quad \text { and } \quad r_{t}^{\mathrm{L}}\left(\alpha_{t}^{\mathrm{Z}}\right)=\ln \left(\sum_{j} \alpha_{j, t-1}^{\mathrm{Z}} R_{j, t}^{\mathrm{L}}\right)
$$

for difference portfolio shares, $\alpha_{j, t}^{\mathrm{Z}}$. The first set of portfolios use the average share for each asset and liability class (i.e., $\alpha_{j, t-1}^{\mathrm{Z}}=\alpha_{j}^{\mathrm{Z}}$ for $\mathrm{Z}=\{\mathrm{A}, \mathrm{L}\}$ and all $j$ ), giving $\log$ portfolio returns of $r_{t}^{\mathrm{A}}\left(\alpha^{\mathrm{A}}\right)$ and $r_{t}^{\mathrm{L}}\left(\alpha^{\mathrm{L}}\right)$. Comparing 
$r_{t}^{\mathrm{A}}\left(\alpha^{\mathrm{A}}\right)$ and $r_{t}^{\mathrm{L}}\left(\alpha^{\mathrm{L}}\right)$ with the actual U.S. portfolio returns provides information on how time-varying changes in the composition of asset and liability portfolios contributes to returns. The second set of portfolios use the average of the asset and liability share (i.e., $\left.\overline{\alpha_{j, t}}=\frac{1}{2} \alpha_{j, t}^{\mathrm{A}}+\frac{1}{2} \alpha_{j, t}^{\mathrm{L}}\right)$ for each class of assets. This gives $\log$ portfolio returns of $r_{t}^{\mathrm{A}}\left(\overline{\alpha_{t}}\right)$ and $r_{t}^{\mathrm{L}}\left(\overline{\alpha_{t}}\right)$. Here any difference between $r_{t}^{\mathrm{A}}\left(\overline{\alpha_{t}}\right)$ and $r_{t}^{\mathrm{L}}\left(\overline{\alpha_{t}}\right)$ and actual returns reflects the effects of asymmetries between asset and liability holdings. The third set of portfolios use the mean of the average asset and liability share (i.e., the mean value of $\overline{\alpha_{j, t}}$ for each $j$ ) to give $\log$ portfolio returns of $r_{t}^{\mathrm{A}}(\bar{\alpha})$ and $r_{t}^{\mathrm{L}}(\bar{\alpha})$. These portfolio returns correspond to the returns in the model because the asset and liability portfolios have the same constant shares.

Columns (vi) - (vii) report the contributions of the synthetic portfolio returns to the variance of actual returns. ${ }^{18}$ In panel A, all the estimated contributions are close to one. Time-variation in the portfolio shares, and differences between composition of U.S. foreign asset and liability portfolios did not materially affect the behavior of U.S. asset and liability returns over this longer sample period. Portfolio composition effects appear to have played a larger role since 1990. In particular, the estimated contributions shown in column (viii) of panel B indicate that time-varying and asymmetric shares contributed between 10 and 25 percent of the sample variability in actual portfolio returns.

Overall, Table 3 shows that the equilibrium of the model produces behavior for foreign asset returns that is broadly consistent with actual U.S. asset and liability returns. Although the actual composition of U.S. foreign portfolios varies between assets and liabilities and through time, these composition effects make a relatively minor contribution to the variability of actual portfolio returns (particularly over the 1973:I2007:IV sample period). ${ }^{19}$ Consequently, the absence of composition effects in the model doesn't greatly impair its ability to replicate the behavior of returns in U.S. data.

\section{Portfolios Shares}

Table 4 reports the shares of domestic and foreign assets in households' portfolios in the stochastic steady state of the model. Column (i) reports the portfolio shares for the benchmark specification where $\wp=0.420$, the value calibrated from U.S. data. Column (ii) shows the steady state portfolio shares in an equilibrium where $\wp=0.491$. The shares of foreign equity and bonds in this equilibrium match the steady state shares in an equilibrium where households freely choose the composition of their foreign asset portfolios (i.e., $\wp=\wp^{*}$ as discussed in Section 2.1). ${ }^{20}$

\footnotetext{
${ }^{18}$ For example, in the case of the first set of synthetic portfolios, we can decompose the variance of actual returns, $r_{t}^{\mathrm{Z}}$, as $\mathbb{V}\left(r_{t}^{\mathrm{Z}}\right)=$ $\mathbb{C V}\left(r_{t}^{\mathrm{Z}}\left(\alpha^{\mathrm{Z}}\right), r_{t}^{\mathrm{Z}}\right)+\mathbb{C V}\left(r_{t}^{\mathrm{A}}-r_{t}^{\mathrm{Z}}\left(\alpha^{\mathrm{Z}}\right), r_{t}^{\mathrm{Z}}\right)$ for $\mathrm{z}=\{\mathrm{A}, \mathrm{L}\}$. The variance contribution of the synthetic portfolio is $\mathbb{C V}\left(r_{t}^{\mathrm{Z}}\left(\alpha^{\mathrm{Z}}\right), r_{t}^{\mathrm{Z}}\right) / \mathbb{V}\left(r_{t}^{\mathrm{Z}}\right)$, which can be estimated by the slope coefficient from a regression of $r_{t}^{z}\left(\alpha^{z}\right)$ on $r_{t}^{z}$.

${ }^{19}$ Notice that the standard deviations for U.S. liability returns are only slightly smaller than those for U.S. foreign assets. Even though U.S. liabilities are more heavily weighted towards debt than U.S. assets, because much of this debt is long-term, capital gains and loss on existing dollar liabilities contribute significantly to the volatility of U.S. liability returns. The idea that the U.S. borrows primarily at the risk free short-term dollar rate is thus a poor approximation to reality.

${ }^{20}$ The portfolio shares in column (ii) are computed from the steady state in which the parameters in Panel B of Table 1 are re-estimated by GMM to insure that the moments implied by the equilibrium also match the data as in Table 2 .
} 
Table 4: Steady State Portfolio Shares

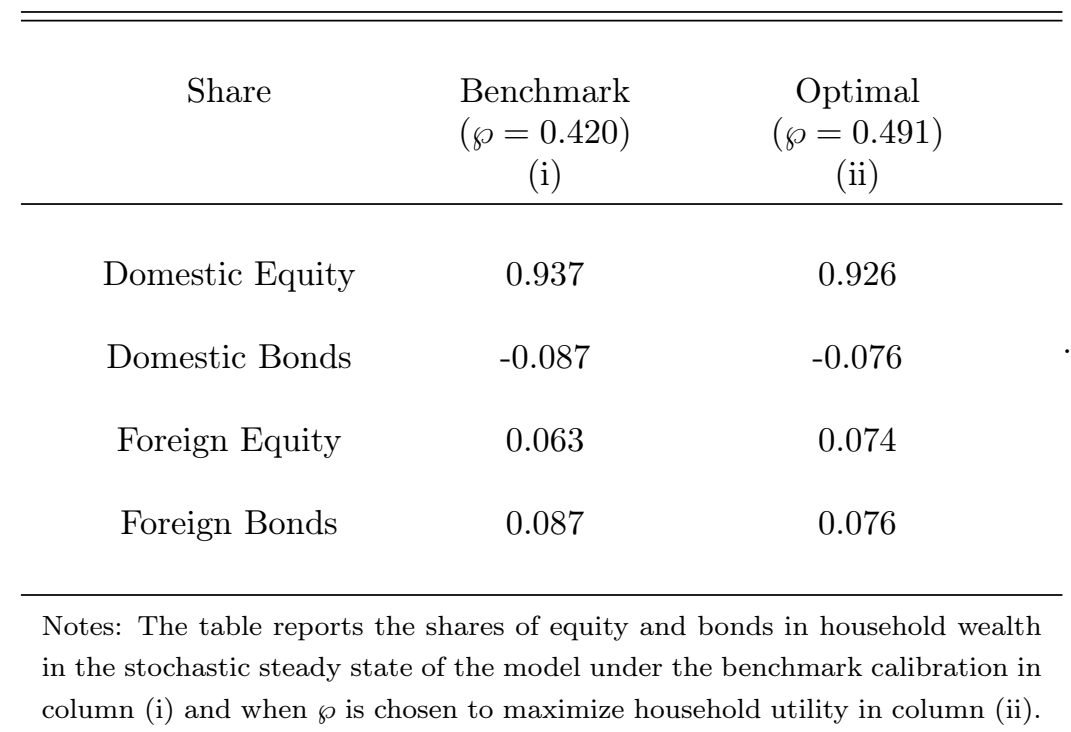

As Table 4 shows, the steady state of the model is characterized by a very high degree of equity home bias. This feature of the model arises for two reasons. First, households receive all their income in the form of dividends from domestic equity and their foreign asset holdings. As such, they are not concerned with hedging non-tradable income risk. Following the logic in Baxter, Jermann, and King (1998), extending the model to include non-tradable (wage) income in households' budgets could lower the degree of equity home bias. Second, the high level of home equity bias arises here because foreign asset portfolios provide a poor hedge against real exchange rate risk. As I show below, in the steady state the expected return on foreign asset portfolios contains a risk premium that reflects the fact that future shocks are likely to produce large capital losses on foreign asset holdings when domestic marginal utility is high. In an equilibrium where households could freely choose the composition of their foreign asset portfolios, this risk premium would be sufficient to fully compensate for the poor hedging properties provided by foreign equity so that households would diversify their portfolio holdings between domestic and foreign equity. In this model households can only hold foreign equity as part of a foreign asset portfolio with fixed shares. The steady state return on this portfolio still contains a risk premium, but it under-compensates households for the risk associated with unexpected movements in foreign equity prices and exchange rates so they choose less exposure to foreign equity. In sum, therefore, home equity bias arises here because foreign equity has poor hedging properties in the presence of risk shocks that are under-compensated by the equilibrium risk premium on foreign asset portfolios when financial frictions are present. 


\section{The Elements of External Adjustment}

I now use the model to study the international transmission of endowment and risk shocks, i.e., the process of external adjustment. This process involves a numerous elements that interact in a complex manner so it is useful to identify them individually before studying the quantitive implications of the model's equilibrium in Section 5.

\subsection{Consumption, Trade Flows and Dividends}

The model's implications for the behavior of consumption and trade flows are quiet standard. The C.E.S specification for the U.S. and E.U consumption baskets implies that the domestic and foreign demand for U.S. goods are given by $C_{t}^{\mathrm{us}}=\eta\left(P_{t}^{\mathrm{us}} / P_{t}\right)^{-\theta} C_{t}$ and $\hat{C}_{t}^{\mathrm{US}}=(1-\eta)\left(\hat{P}_{t}^{\mathrm{Eu}} / \hat{P}_{t}\right)^{-\theta} \hat{C}_{t}$, while the domestic and foreign demand for E.U. goods are give by $\hat{C}_{t}^{\mathrm{EU}}=\eta\left(\hat{P}_{t}^{\mathrm{EU}} / \hat{P}_{t}\right)^{-\theta} \hat{C}_{t}$ and $C_{t}^{\mathrm{EU}}=(1-\eta)\left(P_{t}^{\mathrm{EU}} / P_{t}\right)^{-\theta} C_{t}$, respectively. Combining these demands with definition of the U.S. terms of trade, $\mathcal{T}_{t}=P_{t}^{\mathrm{EU}} / P_{t}^{\mathrm{US}}$, and goods market clearing in (12) gives

$$
\begin{aligned}
& Y_{t}=\eta\left(\eta+(1-\eta) \mathcal{T}_{t}^{1-\theta}\right)^{\frac{\theta}{1-\theta}} C_{t}+(1-\eta)\left(\eta \mathcal{T}_{t}^{1-\theta}+(1-\eta)\right)^{\frac{\theta}{1-\theta}} \hat{C}_{t}, \quad \text { and } \\
& \hat{Y}_{t}=(1-\eta)\left(\eta \mathcal{T}_{t}^{\theta-1}+(1-\eta)\right)^{\frac{\theta}{1-\theta}} C_{t}+\eta\left(\eta+(1-\eta) \mathcal{T}_{t}^{\theta-1}\right)^{\frac{\theta}{1-\theta}} \hat{C}_{t} .
\end{aligned}
$$

These equilibrium conditions have two important implications for the international transmission of endowment and risk shocks. First, shocks to the endowment of either good must be accompanied by variations in the terms of trade and changes in aggregate consumption across countries when households' preferences exhibit consumption home bias. An inspection of (23) reveals that the terms of trade cannot adjust to clear both goods markets at the new endowment levels with the pre-existing levels of aggregate consumption when $\eta>1 / 2$. Similarly, risk shocks also induce changes in the terms of trade and aggregate consumption across countries in the presence of home bias. In this case, the terms of trade cannot adjust to clear both goods markets at pre-existing endowment levels when the risk shock directly affects households' consumption decision in one country. In sum, therefore, home bias in consumption insures that the international transmission of both endowment and risk shocks is facilitated by consumption-switching in the goods markets through changes in the terms of trade.

Consumption-switching also affects international trade flows. By definition U.S. exports and imports are determined by E.U. households' demand for U.S. goods, and U.S. demand for E.U. goods, respectively. So, when measured in terms of the U.S. consumption basket, U.S. exports and imports are given by

$$
X_{t}=(1-\eta)\left(\eta \mathcal{T}_{t}^{1-\theta}+(1-\eta)\right)^{-1} \mathcal{E}_{t} \hat{C}_{t} \quad \text { and } \quad M_{t}=(1-\eta)\left(\eta \mathcal{T}_{t}^{\theta-1}+(1-\eta)\right)^{-1} C_{t}
$$

In the stochastic steady state, $\mathcal{T}=\mathcal{E}=1$ and $C_{t}=\hat{C}_{t}$ so these expressions simplify to $X_{t}=(1-\eta) \hat{C}_{t}$ and 
$M_{t}=(1-\eta) C_{t}$ and trade is balanced between the countries.

Recall that equities are claims to the endowments of U.S. and E.U. goods. In particular, one share of U.S. equity entitles the holder to receive a dividend of $D_{t}=\left(P_{t}^{\text {us }} / P_{t}\right) Y_{t}$, while one share of E.U. equity receives a dividend of $\hat{D}_{t}=\left(\hat{P}_{t}^{\mathrm{EU}} / \hat{P}_{t}\right) \hat{Y}_{t}$. Substituting for relative prices with the terms of trade produces

$$
D_{t}=\left(\eta+(1-\eta) \mathcal{T}_{t}^{1-\theta}\right)^{\frac{-1}{1-\theta}} Y_{t} \quad \text { and } \quad \hat{D}_{t}=\left(\eta+(1-\eta) \mathcal{T}_{t}^{\theta-1}\right)^{\frac{-1}{1-\theta}} \hat{Y}_{t}
$$

Clearly, endowment shocks have a direct impact on domestic dividends. They also have an indirect impact via the terms of trade which also affects foreign dividends. In contrast, risk shocks only affect dividends via the terms of trade.

Dividends are also linked to domestic consumption and the trade balance. In particular, equations (23) - (25) imply that

$$
D_{t}=C_{t}+X_{t}-M_{t}, \quad \text { and } \quad \hat{D}_{t}=\hat{C}_{t}+\left(M_{t}-X_{t}\right) / \mathcal{E}_{t}
$$

Thus U.S. trade surpluses $\left(X_{t}>M_{t}\right)$ push the dividends on U.S. equity above consumption and the dividends on E.U. equity below consumption. As we shall see, these links between trade flows and dividends affect the hedging properties of equities in households' portfolios.

\subsection{Asset Prices}

Asset prices play three important roles in the external adjustment process. First, they determine household wealth at pre-existing asset holdings. Shocks that produce unexpected changes in asset prices induce revaluations of household wealth that affect their consumption and saving decisions. Second, asset price variations produce international capital flows as households re-balance their portfolio holdings of foreign assets and liabilities. Changes in asset prices can also affect the risk premia and risk free rates by pushing households towards their collateral constraints.

The prices of domestic equity are readily determined from the first-order conditions of households' optimizing problems. Let $D_{t} / Q_{t}=1 / \Lambda_{t}^{\mathrm{EQ}}$ denote the dividend-price ratio for U.S. equity. The first-order condition governing optimal share of domestic equity in U.S. households' portfolios implies that

$$
\Lambda_{t}^{\mathrm{EQ}}=\mathbb{E}_{t}\left[\mathcal{M}_{t+1}\left(1+\Lambda_{t+1}^{\mathrm{EQ}}\right) \frac{D_{t+1}}{D_{t}}\right] \quad \text { with } \quad \mathcal{M}_{t+1}=\beta\left(\frac{C_{t+1}}{C_{t}}\right)^{-\gamma}\left(\frac{S_{t+1}}{S_{t}}\right)^{-\gamma} .
$$

Analogously, the first-order condition for E.U. households implies that

$$
\hat{\Lambda}_{t}^{\mathrm{EQ}}=\mathbb{E}_{t}\left[\widehat{\mathcal{M}}_{t+1}\left(1+\hat{\Lambda}_{t+1}^{\mathrm{EQ}}\right) \frac{\hat{D}_{t+1}}{\hat{D}_{t}}\right] \quad \text { with } \quad \widehat{\mathcal{M}}_{t+1}=\beta\left(\frac{\hat{C}_{t+1}}{\hat{C}_{t}}\right)^{-\gamma}\left(\frac{\hat{S}_{t+1}}{\hat{S}_{t}}\right)^{-\gamma},
$$

where $\hat{D}_{t} / \hat{Q}_{t}=1 / \hat{\Lambda}_{t}^{\mathrm{EQ}}$ is the dividend-price ratio for E.U. equity. The prices of U.S. and E.U. equity, measured in terms of domestic consumption, are therefore

$$
Q_{t}=\Lambda_{t}^{\mathrm{EQ}} D_{t} \quad \text { and } \quad \hat{Q}_{t}=\hat{\Lambda}_{t}^{\mathrm{EQ}} \hat{D}_{t} .
$$


Endowment shocks and risk shocks affect equity prices in several different ways. First, risk shocks directly affect the intertemporal marginal rates of substitution, $\mathcal{M}_{t+1}$ and $\widehat{\mathcal{M}}_{t+1}$, that govern dividend-price ratios via their impact on the surplus ratios, $S_{t}$ and $\hat{S}_{t}$. Intuitively, equity prices must change in response to risk shocks to compensate for the uncertainty associated with future dividend flows. Risk shocks also affect equity prices indirectly via their impact on the terms of trade, aggregate consumption and dividends in both countries as discussed above. Similarly, endowment shocks to either good have a direct effect on equity prices via dividends, and indirect effects via the terms of trade.

Shocks to the common trend in the endowments have a different effect on equity prices. They have a one-to-one impact on the level of U.S. and E.U. consumption because households prefer smooth consumption paths, so goods markets clear without any change in the terms of trade. This has two consequences. First, current U.S. and E.U. dividends rise one-for-one with the endowment shock. Second, the shock has no effect on dividend-price ratios because the conditional distributions of future consumption, dividend and surplus growth remain unchanged. As a result, shocks to the common trend in the endowments have the same proportional effect on U.S. and E.U. equity prices.

The real exchange rate also acts as an asset price in the model because it determines the domestic value of the foreign assets portfolios: i.e., $F A_{t}=\mathcal{E}_{t}\left(B_{t}^{\mathrm{EU}}+\hat{Q}_{t} A_{t}^{\mathrm{EU}}\right)$ and $\widehat{F A}_{t}=\left(Q_{t} \hat{A}_{t}^{\mathrm{US}}+\hat{B}_{t}^{\mathrm{US}}\right) / \mathcal{E}_{t}$. The equilibrium real exchange rate is determined by the real interest differentials and the foreign exchange risk premium. Let $\delta_{t}=\mathbb{E}_{t} \varepsilon_{t+1}-\varepsilon_{t}+\hat{r}_{t}-r_{t}$ define the foreign exchange risk premium. ${ }^{21}$ Rewriting this definition as a difference equation in $\varepsilon_{t}$, solving forward, and applying the Law of Iterated expectations produces

$$
\mathcal{E}_{t}=\exp \left(-\mathbb{E}_{t} \sum_{i=0}^{\infty}\left\{r_{t+i}-\hat{r}_{t+i}+\delta_{t+i}\right\}+\mathbb{E}_{t} \bar{\varepsilon}\right),
$$

where $\bar{\varepsilon} \equiv \lim _{t \rightarrow \infty} \varepsilon_{t}$. Since the steady state real exchange rate equals unity, $\mathbb{E}_{t} \bar{\varepsilon}=0$. All variations in the real exchange rate therefore reflect changes in current and expected future real interest differentials, $\hat{r}_{t+i}-r_{t+i}$; and/or changes in current and expected future risk premia, $\delta_{t+i}$.

The equilibrium interest differential is determined by the first-order conditions governing the optimal holdings of domestic bonds

$$
1=\mathbb{E}_{t}\left[\mathcal{M}_{t+1}\right] R_{t}+\mathcal{B}_{t} \quad \text { and } \quad 1=\mathbb{E}_{t}\left[\widehat{\mathcal{M}}_{t+1}\right] \hat{R}_{t}+\hat{\mathcal{B}}_{t}
$$

with $\mathcal{B}_{t}=C_{t}^{\gamma} S_{t}^{\gamma} \mathcal{L}_{t}$ and $\hat{\mathcal{B}}_{t}=\hat{C}_{t}^{\gamma} \hat{S}_{t}^{\gamma} \hat{\mathcal{L}}_{t}$ where $\mathcal{L}_{t}$ and $\hat{\mathcal{L}}_{t}$ are the Lagrange multipliers on the collateral constraints in (18c) and (20c), respectively. Like equity prices, endowment and risk shocks affect real interest rates via their impact on the intertemporal marginal rates of substitution. They can also affect interest rates via the collateral constraints. Shocks that change the value of foreign assets so that the constraints bind produce positive values for $\mathcal{B}_{t}$ and $\hat{\mathcal{B}}_{t}$ and push real rates down relative to $\mathbb{E}_{t}\left[\mathcal{M}_{t+1}\right]$ and $\mathbb{E}_{t}\left[\widehat{\mathcal{M}}_{t+1}\right]$. Intuitively, households' expected utility from additional borrowing exceeds the real interest rate when the collateral constraint is binding.

\footnotetext{
${ }^{21}$ Some definitions of the risk premium also include one half the variance of the real depreciation rate to account for the fact that we are dealing with log rather than gross returns. I use this simpler definition for clarity but fully account for the presence of $\log$ returns when solving the model.
} 
The equilibrium foreign exchange risk premium is similarly determined by the first-order conditions governing households' choice of foreign asset portfolios:

$$
\begin{aligned}
& 0=(1-\wp) \mathbb{E}_{t}\left[\mathcal{M}_{t+1}\left(\frac{\mathcal{E}_{t+1} \hat{R}_{t}}{\mathcal{E}_{t}}-R_{t}\right)\right]+\wp \mathbb{E}_{t}\left[\mathcal{M}_{t+1}\left(\frac{\mathcal{E}_{t+1} \hat{R}_{t}^{\mathrm{EQ}}}{\mathcal{E}_{t}}-R_{t}\right)\right]+\varkappa \mathcal{B}_{t}, \quad \text { and } \\
& 0=(1-\wp) \mathbb{E}_{t}\left[\widehat{\mathcal{M}}_{t+1}\left(\frac{\mathcal{E}_{t} R_{t}}{\mathcal{E}_{t+1}}-\hat{R}_{t}\right)\right]+\wp \mathbb{E}_{t}\left[\widehat{\mathcal{M}}_{t+1}\left(\frac{\mathcal{E}_{t} R_{t}^{\mathrm{EQ}}}{\mathcal{E}_{t+1}}-\hat{R}_{t}\right)\right]+\varkappa \hat{\mathcal{B}}_{t}
\end{aligned}
$$

These equations show that both financial frictions play a role in the determination of the equilibrium foreign exchange risk premium. If households were free to choose their holdings of foreign bonds and equity and there were no collateral constraints, their optimal portfolio choices would imply that the expectations of each of the four terms in brackets equal zero. Under these circumstances the equilibrium risk premium is determined as the solution to $\mathbb{E}_{t}\left[\mathcal{M}_{t+1}\left(\mathcal{E}_{t+1} \hat{R}_{t} / \mathcal{E}_{t}-R_{t}\right)\right]=0$ and $\mathbb{E}_{t}\left[\widehat{\mathcal{M}}_{t+1}\left(\mathcal{E}_{t} R_{t} / \mathcal{E}_{t+1}-\hat{R}_{t}\right)\right]=0$. If, in addition, markets are complete so that $\widehat{\mathcal{M}}_{t+1}=\left(\mathcal{E}_{t+1} / \mathcal{E}_{t}\right) \mathcal{M}_{t+1}$, the solution to these equations can be approximated as $\delta_{t}=\frac{1}{2} \gamma \mathbb{C V}_{t}\left(c_{t+1}+\hat{c}_{t+1}, \varepsilon_{t+1}\right)+\frac{1}{2} \gamma \mathbb{C} \mathbb{V}_{t}\left(s_{t+1}+\hat{s}_{t+1}, \varepsilon_{t+1}\right)$.

The presence of financial frictions push the equilibrium risk premium away from this benchmark in two ways. First, when households can only hold foreign assets in the form of a portfolio, their portfolio decisions depend on a weighted average of excess foreign bond and equity returns. For example, (32a) shows that U.S. households' decision depend on $(1-\wp)\left(\mathcal{E}_{t+1} \hat{R}_{t} / \mathcal{E}_{t}-R_{t}\right)+\wp\left(\mathcal{E}_{t+1} \hat{R}_{t}^{\mathrm{EQ}} / \mathcal{E}_{t}-R_{t}\right)$. Under these circumstances, the foreign exchange risk premium is determined jointly with the risk premium on holding foreign equity. Second, when collateral constraints are present, households value foreign assets not just for their returns and hedging properties, but also for their use as collateral. Ceteris paribus, the households' demand for foreign assets rise when the collateral constraint binds so the equilibrium expected excess return to foreign asset portfolio must fall to compensate. I examine the quantitative significance of these frictions on the behavior of the equilibrium risk premia in Section 5.

\subsection{Saving, Portfolio Holdings and Capital Flows}

Households' savings and portfolio decisions play a central role in the international transmission mechanism. U.S. and E.U. households enter period $t$ with real wealth $W_{t}$ and $\hat{W}_{t}$ that comprises pre-existing holdings of domestic equity, bond and foreign assets (chosen in period $t-1$ ) valued at current asset prices, and the period $t$ dividend payments from their equity holdings. ${ }^{22}$ Households then choose how much of this wealth to save, and how to allocate their savings across domestic bonds, equity and foreign assets. Together these decisions determine households desired changes in asset holdings that drive international capital flows.

Endowment and risk shocks affect households' consumption and savings decisions via the consumptionsaving ratios: $C_{t} /\left(W_{t}-C_{t}\right)=1 / \Lambda_{t}^{\mathrm{C}}$ and $\hat{C}_{t} /\left(\hat{W}_{t}-\hat{C}_{t}\right)=1 / \hat{\Lambda}_{t}^{\mathrm{C}}$. Combining the households' first-order

\footnotetext{
${ }^{22}$ The real value of dividend payments also depends upon the period $t$ real exchange rate/terms of trade; see (25) above.
} 
conditions with these definitions and the budget constraints in (18b) and (20b) produces

$$
\Lambda_{t}^{\mathrm{C}}=\mathbb{E}_{t}\left[\mathcal{M}_{t+1}\left(1+\Lambda_{t+1}^{\mathrm{C}}\right) \frac{C_{t+1}}{C_{t}}\right] \quad \text { and } \quad \hat{\Lambda}_{t}^{\mathrm{c}}=\mathbb{E}_{t}\left[\widehat{\mathcal{M}}_{t+1}\left(1+\hat{\Lambda}_{t+1}^{\mathrm{C}}\right) \frac{\hat{C}_{t+1}}{\hat{C}_{t}}\right] \text {. }
$$

The level of saving and consumption in each country relative to beginning-of-period wealth are therefore

$$
\begin{aligned}
& \text { U.S.: } \quad W_{t}-C_{t}=\frac{\Lambda_{t}^{\mathrm{C}}}{1+\Lambda_{t}^{\mathrm{C}}} W_{t}, \quad C_{t}=\frac{1}{1+\Lambda_{t}^{\mathrm{C}}} W_{t}, \quad \text { and } \\
& \text { U.S.: } \quad \hat{W}_{t}-\hat{C}_{t}=\frac{\hat{\Lambda}_{t}^{\mathrm{C}}}{1+\hat{\Lambda}_{t}^{\mathrm{C}}} \hat{W}_{t}, \quad \hat{C}_{t}=\frac{1}{1+\hat{\Lambda}_{t}^{\mathrm{C}}} \hat{W}_{t} .
\end{aligned}
$$

Equations (33) and (34) display two noteworthy features. First, ceteris paribus, $\Lambda_{t}^{\mathrm{c}}$ and $\hat{\Lambda}_{t}^{\mathrm{c}}$ rise when households anticipate higher growth in their future consumption. As a result, household save a larger fraction of their wealth, consistent with standard intertemporal consumption smoothing. Second, the Lagrange multipliers on the collateral constraints are absent from (33). Financial frictions only affect households consumption/saving decisions indirectly via their impact on the equilibrium intertemporal marginal rate of substitution and prospective future consumption growth.

Savings decisions, portfolio choices and asset price variations all contribute to capital flows. Consider the flows associated with foreign equity. By definition the value of E.U. equity and bonds in U.S. households' portfolio are given by $\mathcal{E}_{t} \hat{Q}_{t} A_{t}^{\mathrm{EU}}=\wp \alpha_{t}^{\mathrm{FA}}\left(W_{t}-C_{t}\right)$ and $\mathcal{E}_{t} B_{i, t}^{\mathrm{EU}}=(1-\wp) F A_{t}$, so the flows of equity and bonds during period $t$ are

$$
\begin{aligned}
\mathcal{E}_{t} \hat{Q}_{t} \Delta A_{t}^{\mathrm{EU}} & =\alpha_{t}^{\mathrm{FA}} \wp\left(W_{t}-C_{t}\right)-\alpha_{t-1}^{\mathrm{FA}} \wp\left(W_{t-1}-C_{t-1}\right) \frac{\mathcal{E}_{t} \hat{Q}_{t}}{\mathcal{E}_{t-1} \hat{Q}_{t-1}} \\
& =\Delta \alpha_{t}^{\mathrm{FA}} \wp\left(W_{t}-C_{t}\right)+\wp \alpha_{t-1}^{\mathrm{FA}}\left[\Delta\left(W_{t}-C_{t}\right)-\left(\frac{\mathcal{E}_{t} \hat{Q}_{t}}{\mathcal{E}_{t-1} \hat{Q}_{t-1}}-1\right)\left(W_{t-1}-C_{t-1}\right)\right],
\end{aligned}
$$

and

$$
\begin{aligned}
\mathcal{E}_{t} \Delta B_{t}^{\mathrm{EU}} & =\alpha_{t}^{\mathrm{FA}}(1-\wp)\left(W_{t}-C_{t}\right)-\alpha_{t-1}^{\mathrm{FA}}(1-\wp)\left(W_{t-1}-C_{t-1}\right) \frac{\mathcal{E}_{t}}{\mathcal{E}_{t-1}} \\
& =\Delta \alpha_{t}^{\mathrm{FA}}(1-\wp)\left(W_{t}-C_{t}\right)+(1-\wp) \alpha_{t-1}^{\mathrm{FA}}\left[\Delta\left(W_{t}-C_{t}\right)-\left(\frac{\mathcal{E}_{t}}{\mathcal{E}_{t-1}}-1\right)\left(W_{t-1}-C_{t-1}\right)\right] .
\end{aligned}
$$

The first term in the second line of each equation identifies the flow resulting from U.S. households' desire to alter the share of foreign assets in their savings. Variations in these flow components are perfectly correlated across equity and bond flows because households cannot adjust the composition of their foreign asset holdings. The second term in each equation identifies the effects of changing savings behavior via $\Delta\left(W_{t}-C_{t}\right)$ and the effects of capital gains or losses on pre-existing positions. Notice that these portfolio rebalancing effects can have differing affects on equity and bond flows. Real capital gains and losses on pre-existing equity positions depend on the variations in foreign equity prices and the real exchange rate, while the gains and loses on 
bonds depend only on changes in the real exchange rate.

Equations (35) and (36) identify U.S. gross capital outflows. By convention, negative outflows represent the purchase of foreign assets by U.S. households which correspond to positive values for $\mathcal{E}_{t} \hat{Q}_{t} \Delta A_{t}^{\mathrm{EU}}$ and $\mathcal{E}_{t} \Delta B_{t}^{\mathrm{EU}}$. Purchases of U.S. equity and bonds by E.U. households, $\left(Q_{t} / \mathcal{E}_{t}\right) \Delta \hat{A}_{t}^{\mathrm{US}}$ and $\left(1 / \mathcal{E}_{t}\right) \Delta \hat{B}_{t}^{\mathrm{US}}$ represent positive U.S capital inflows, and are identified from E.U. households' choice for $\hat{\alpha}_{t}^{\mathrm{FA}}$, and savings, $\hat{W}_{t}-\hat{C}_{t}$ in an analogous manner to (35) and (36).

\section{Quantitative Analysis}

I now use the calibrated equilibrium of the model to study the effects of endowment and risk shocks. The goal of this analysis is to quantify the role played by capital flows in the international transmission of these shocks. For this purpose, I first focus on how consumption and the terms of trade adjust to maintain goods market clearing. These internal adjustments are important drivers equity prices and interest rates. I then study how these factors contribute to the process of external adjustment via their effects on trade flows, foreign asset returns, and hot money capital flows.

\subsection{Internal Adjustment}

To identify the effects of financial frictions, I compare the equilibrium dynamics of the model with the dynamics computed from a complete markets equilibrium where intertemporal marginal rates of substitution

satisfy $\widehat{\mathcal{M}}_{t+1}=\left(\mathcal{E}_{t+1} / \mathcal{E}_{t}\right) \mathcal{M}_{t+1} \cdot{ }^{23}$ Figure 1 shows the impulse responses of consumption and the terms of trade following a positive shock to the U.S. endowment process, and a negative shock to the U.S. log surplus ratio. These responses identify the effect of a one standard deviation shock when the economy is initially in the stochastic steady state. The solid plots show the responses of variables in the benchmark equilibrium; responses in the complete markets equilibrium are shown by the dashed plots.

Overall, Figure 1 shows that the presence of financial frictions have little quantitative impact on the reaction of consumption and the terms of trade to either endowment or risk shocks. In the upper panel, the consumption and terms of trade responses are essentially identical. In the lower panel the responses are larger (in absolute value) under complete markets, but the differences are not economically significant. These results have an important risk-sharing implication. Recall from (7) that the real exchange rate only varies with the terms of trade (because all goods are traded), so the similarity of the terms of trade responses carries over to the real exchange rate. Thus the plots in Figure 1 imply that variations in $\widehat{\mathcal{M}}_{t+1}$ are very similar to those in $\left(\mathcal{E}_{t+1} / \mathcal{E}_{t}\right) \mathcal{M}_{t+1}$ following typical endowment and risk shocks. Even though households face restrictions on international borrowing and foreign asset holding, in the benchmark equilibrium the frictions do not appear to greatly impede international risk-sharing in the face of these shocks.

The economic intuition behind the plots in Figure 1 is straightforward with this risk-sharing perspective. For example, a positive shock to the U.S. endowment (see Panel A) requires a deterioration in the U.S. terms of trade (i.e., a rise in $P_{t}^{\mathrm{EU}} / P_{t}^{\mathrm{US}}$, see Panel C) to maintain goods market clearing at pre-existing consumption

\footnotetext{
${ }^{23}$ In the approximate solution of the model the absence of collateral constraints is sufficient to establish full international risk-sharing.
} 


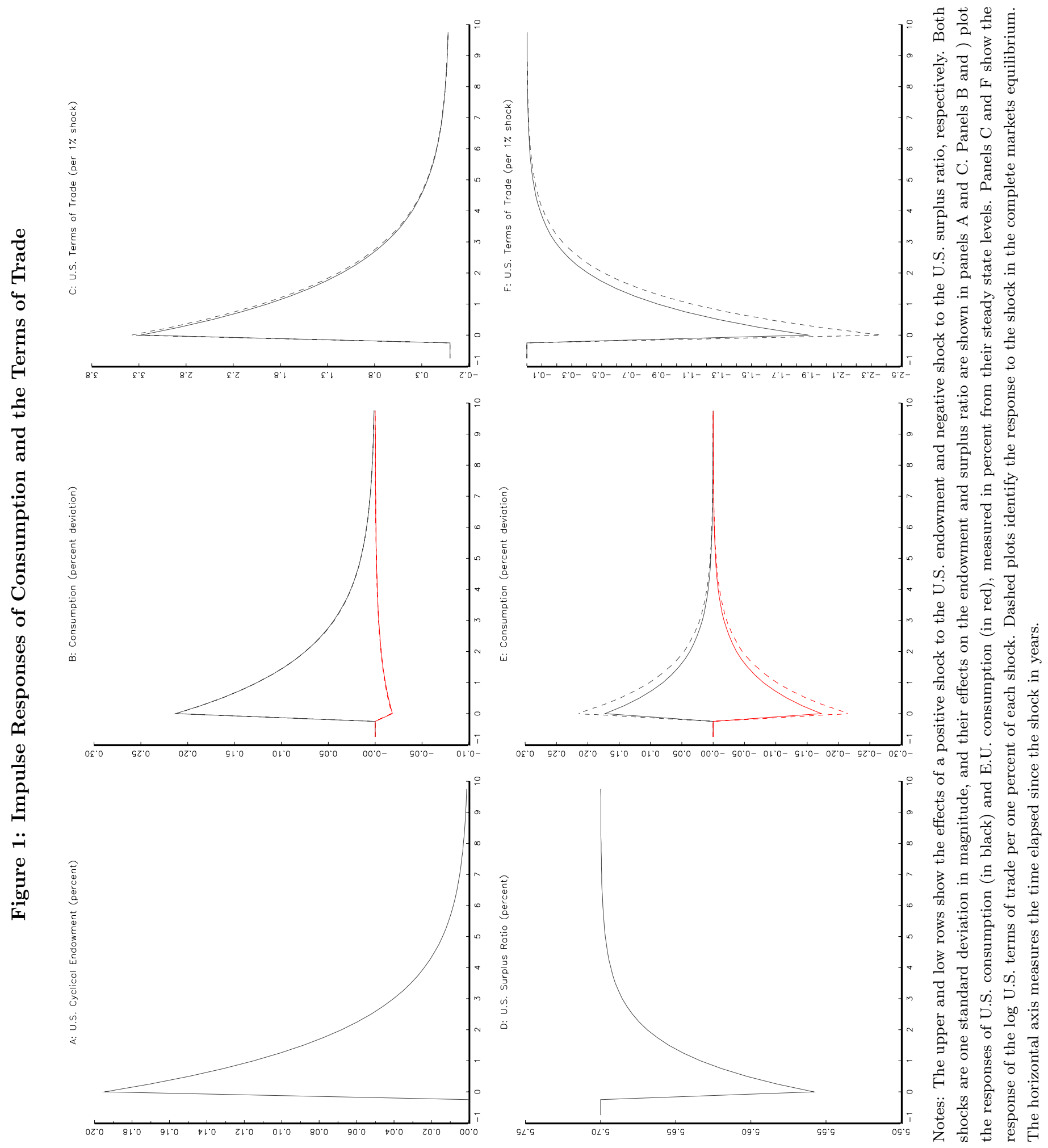


levels. This, in turn, implies a real depreciation of the dollar. So, from risk-sharing perspective, there needs to be a rise in relative consumption, $C_{t} / \hat{C}_{t}$. Panel B of Figure 1 shows that this comes about via a larger rise in U.S. consumption than the fall in E.U. consumption because home bias in consumption $(\eta>1 / 2)$ produces the higher demand for U.S. goods necessary to clear markets. In the case of the risk shock, the fall in the U.S. surplus ratio (see Panel D) makes U.S. households more risk averse; increasing the local curvature of their utility by approximately 6.5 percent. Thus, from risk-sharing perspective, the risk shock must produce immediate appreciation in the real exchange rate to equalize marginal utility across countries. This appreciation also induces an improvement in the U.S. terms of trade in the presence of home bias (see Panel F), so there must be a rise in U.S. consumption and fall in E.U. consumption to clear goods markets (see Panel E).

The upper panels of Figure 2 show the effects of the endowment shock on log equity prices, $q_{t}$ and $\hat{q}_{t}$; $\log$ dividends, $d_{t}$ and $\hat{d}_{t}$; and $\log$ risk free rates, $r_{t}$ and $\hat{r}_{t}$. As above, the responses in the benchmark equilibrium are almost identical to those in the complete markets equilibrium. Specifically, the U.S. endowment shock produces an upward jump in U.S. dividends and equity prices and a fall in the risk free rate. Understanding these effects is straightforward. Since the endowment shock raises U.S. consumption above its steady state level, it induces a fall in expected future consumption growth that lowers the U.S. risk free rate via intertemporal smoothing. The endowment shock also raises the U.S. dividend (which is partially offset by the deterioration in the U.S. terms of trade) and lowers expectations of future dividend growth until the economy returns to the steady state. Together, these expectations concerning future consumption and dividend growth drive down the dividend-price ratio with the result that U.S. equity prices rise more than dividends. The endowment shock also affects the E.U. risk free rate and equity prices via its affect on the terms of trade. In this case the deterioration in the U.S. terms of trade push the risk free rate upward by raising expected future consumption growth. It also increases the real value of E.U. dividends and lowers expected future dividend growth. The net effect is to lower the dividend-price ratio so there is a small fall in E.U. equity prices.

The asset-pricing effects of the U.S. risk shock are shown in the lower panels of Figure 2. In this case all the variations in dividends reflect the effect of the improvement in the U.S. terms of trade that produce a temporary rise (fall) in the real value of U.S. (E.U.) dividends. These valuation effects have very different impacts on equity prices. In the U.S. the risk shock's effect on the surplus ratio lowers the intertemporal marginal rate of substitution producing a larger rise in the dividend-price ratio $1 / \Lambda_{t}^{Q}$ than dividends so U.S. equity prices fall significantly. In contrast the fall in E.U. dividends produces a small drop in equity prices because the risk shock induces a small rise in the dividend-price ratio, $1 / \hat{\Lambda}_{t}^{Q}$. As in Figure 1 , the equity price responses to risk shocks are very similar in benchmark and complete markets equilibria.

Financial frictions play a clearer role in the response of U.S. and E.U. interest rates to the risk shock. When collateral constraints are absent, the households' first-order conditions imply that real interest rates are well-approximated by

$$
\begin{aligned}
& r_{t}=-\ln \beta+\gamma \mathbb{E}_{t} \Delta c_{t+1}+\gamma \mathbb{E}_{t} \Delta s_{t+1}-\frac{1}{2} \gamma^{2} \mathbb{V}_{t}\left(c_{t+1}+s_{t+1}\right), \quad \text { and } \\
& \hat{r}_{t}=-\ln \beta+\gamma \mathbb{E}_{t} \Delta \hat{c}_{t+1}+\gamma \mathbb{E}_{t} \Delta \hat{s}_{t+1}-\frac{1}{2} \gamma^{2} \mathbb{V}_{t}\left(\hat{c}_{t+1}+\hat{s}_{t+1}\right) .
\end{aligned}
$$




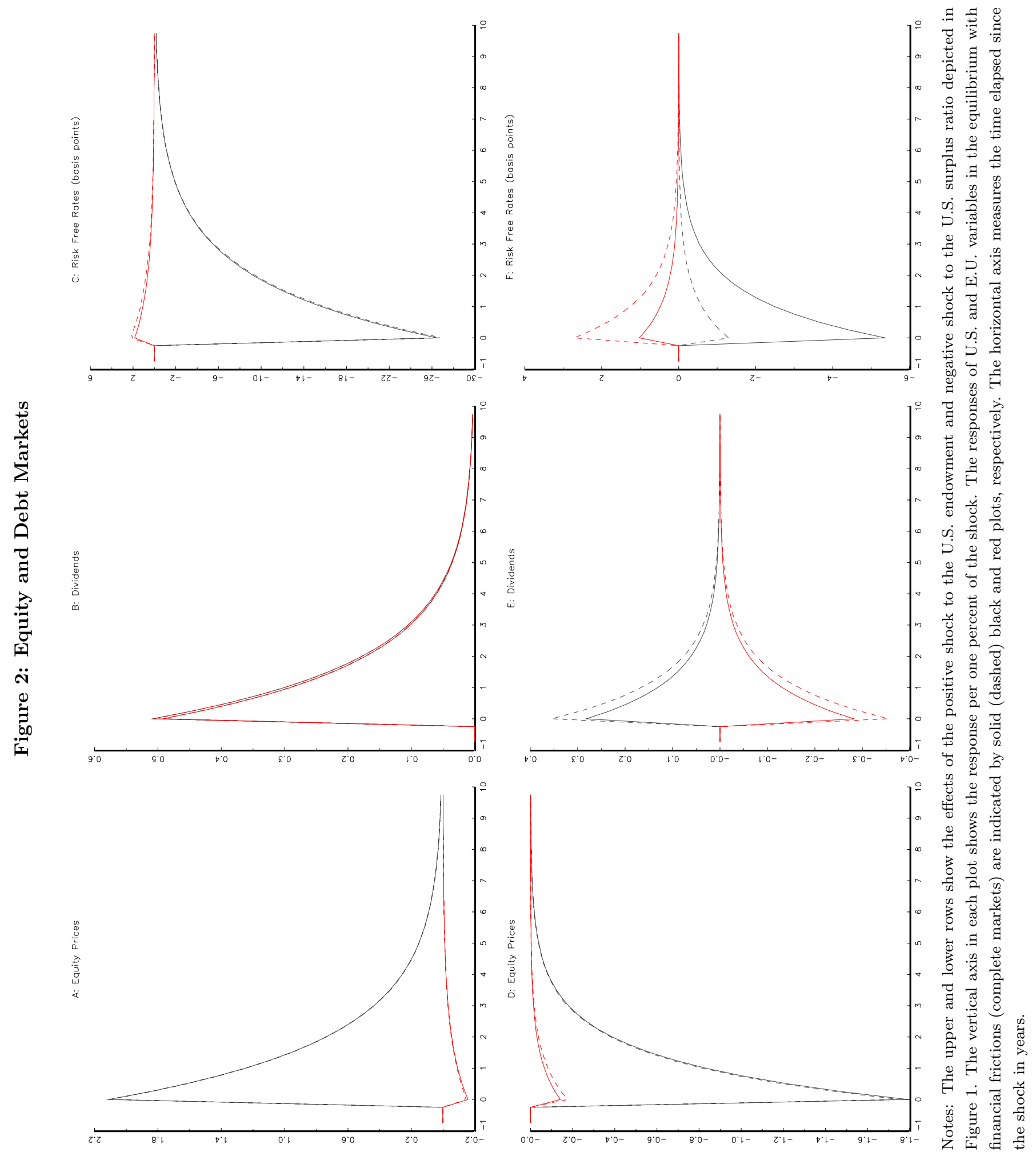


The U.S. risk shock raises both $\gamma \mathbb{E}_{t} \Delta s_{t+1}$ and $\gamma^{2} \mathbb{V}_{t}\left(c_{t+1}+s_{t+1}\right)$ because U.S. households anticipate a future rise in the log surplus ratio and greater volatility in marginal utility. These direct effects act on the equilibrium real interest rate in opposite directions. The rise in $\gamma \mathbb{E}_{t} \Delta s_{t+1}$ puts upward pressure on the real interest rate because households want to borrow more, while in the increase in $\gamma^{2} \mathbb{V}_{t}\left(c_{t+1}+s_{t+1}\right)$ induces greater precautionary saving. In the complete markets equilibrium the precautionary savings channel dominates so the U.S. risk free rate drops further than the fall in $\gamma \mathbb{E}_{t} \Delta c_{t+1}$. The risk shock also produces an rise the E.U. real rate because the improvement in the terms of trade induce a rise in $\gamma \mathbb{E}_{t} \Delta \hat{c}_{t+1}$. The behavior of the risk free rates following the risk shock are shown by the dashed plots in Panel F of Figure 2.

Risk shocks also affect interest rates via their effects on the value of foreign asset holdings when collateral constraints are present. In particular, the real appreciation of the dollar produces a capital loss on U.S. foreign assets reducing their collateral value which in turn pushes down the equilibrium risk free rate in the U.S. ${ }^{24}$ Panel $\mathrm{F}$ in Figure 2 shows that the fall in the U.S. real rate is almost four times larger than the response under complete markets. The collateral constrain also lowers the E.U. rate. In this case the large fall in U.S. equity prices outweighs the effects of the dollar's appreciation producing a capital loss on E.U. households' foreign asset holdings. As Panel F shows, this collateral effect dampens the rise in the E.U. rate relative to the complete markets response.

\subsection{External Adjustment}

I now examine how equilibrium consumption is linked to the behavior of equity prices and interest rates via the trade and capital flows that comprise the external adjustment process. First I derive a simple approximation that links the U.S. foreign asset position to exports, imports and the returns on foreign assets and liabilities. I then use this approximation to study how endowment and risk shocks affect the U.S. net foreign asset position, and compare these implications of the model with estimates from U.S. data.

\section{Net Foreign Assets, Trade and Returns}

In the steady state of the model households hold long positions in domestic equity, and foreign assets, and a short position in domestic bonds. Thus U.S. foreign assets comprise a portfolio of E.U. equity and bonds with a real value of $F A_{t}=\mathcal{E}_{t}\left(B_{t}^{\mathrm{EU}}+\hat{Q}_{t} A_{t}^{\mathrm{EU}}\right)$, while U.S. foreign liabilities comprise U.S. equity and bonds held by E.U. households with a real value of $F L_{t}=\hat{B}_{t}^{\mathrm{us}}+Q_{t} \hat{A}_{t}^{\mathrm{us}}\left(=\widehat{F A}_{t} \mathcal{E}_{t}\right)$. Combining these definitions with the bond and equity market clearing conditions in (10) and (11); the aggregated budget constraint for U.S. households in (8); and the equation for dividends in (26) gives

$$
F A_{t}-F L_{t}=X_{t}-M_{t}-R_{t}^{\mathrm{FL}} F L_{t-1}+R_{t}^{\mathrm{FA}} F A_{t-1},
$$

where $R_{t}^{\mathrm{FL}}=\hat{R}_{t}^{\mathrm{FA}}\left(\mathcal{E}_{t+1} / \mathcal{E}_{t}\right)$ is the gross real return on U.S. foreign liabilities.

Equation (38) is the consolidated U.S. budget constraint that links changes in foreign assets and liabilities to exports, imports and returns. These links place restrictions on the process of external adjustment. To

\footnotetext{
${ }^{24}$ The fall in E.U. equity prices also contributes a small amount to the capital loss.
} 
see how, let $N F A_{t}=F A_{t}-F L_{t}$ and $R_{t}^{\mathrm{NFA}}=\left(R_{t}^{\mathrm{FA}} F A_{t-1}-R_{t}^{\mathrm{FA}} F L_{t-1}\right) / N F A_{t-1}$ denote the value of and return on the U.S. net foreign asset position. Using these definitions we can rewrite (38) as $N F A_{t}=$ $X_{t}-M_{t}+R_{t}^{\mathrm{NFA}} N F A_{t-1}$. Iterating this expression forward, and taking conditional expectations produces

$$
N F A_{t}=-\mathbb{E}_{t}\left[\sum_{i=1}^{\infty}\left(\prod_{j=1}^{i} R_{t+j}^{\mathrm{NFA}}\right)^{-1}\left(X_{t+i}-M_{t+i}\right)\right]+\lim _{k \rightarrow \infty} \mathbb{E}_{t}\left(\prod_{j=1}^{k} R_{t+j}^{\mathrm{NFA}}\right)^{-1} N F A_{t+k}
$$

In the steady state of the model net foreign asset positions are zero, so the last terms on the right hand side disappears leaving

$$
N F A_{t}=-\mathbb{E}_{t}\left[\sum_{i=1}^{\infty}\left(\prod_{j=1}^{i} R_{t+j}^{\mathrm{NFA}}\right)^{-1}\left(X_{t+i}-M_{t+i}\right)\right] .
$$

Thus, at any point in time, the value of the U.S. net foreign asset position must reflect households expectations concerning the future path of net exports, $X_{t}-M_{t}$, and the returns on net foreign assets, $R_{t}^{\mathrm{NFA}}$.

Equation (39) identifies the international solvency constraint that must hold in any model where international Ponzi-schemes are ruled out. In a world where the only internationally traded asset is a single risk free real bond with a constant return $R,(38)$ simplifies to $N F A_{t}=-\mathbb{E}_{t} \sum_{i=1}^{\infty} R^{-i}\left(X_{t+i}-M_{t+i}\right)$, so changes in the net foreign asset position only reflect revisions in the expected future path of net exports. Under these circumstances all external adjustments to shocks take place through the "trade channel": that is via changes in future net exports. Moreover, since the net foreign asset position simply reflects a country's long or short position in bonds, capital gains and losses on pre-existing net asset positions cannot play any role in the adjustment process.

In this model equation (39) places a more complex set of restrictions on the adjustment process because two bonds and two equities are traded internationally. As a consequence, shocks can induce revisions in expected future returns on both foreign assets and liabilities, as well as net exports, and unexpected changes in exchange rates and equity prices can produce capital gains or losses on pre-existing net foreign asset positions. While (39) continues to hold in this more complex environment, examining how these factors interact is considerably facilitated by considering an approximation.

To derive the approximation, I first rewrite (38) as

$$
\ln \left(\frac{F A_{t}}{R_{t}^{\mathrm{FA}} F A_{t-1}}-\left[1-\frac{M_{t}}{R_{t}^{\mathrm{FA}} F A_{t-1}}\right]\right)=\ln \left(\frac{F L_{t}}{R_{t}^{\mathrm{FL}} F L_{t-1}}-\left[1-\frac{X_{t}}{R_{t}^{\mathrm{FL}} F L_{t-1}}\right]\right)+\ln \left(\frac{R_{t}^{\mathrm{FL}}}{R_{t}^{\mathrm{FA}}} \frac{F L_{t-1}}{F A_{t-1}}\right) .
$$

In the stochastic steady state, exports and imports are constant shares of consumption, $X_{t}=(1-\eta) \hat{C}_{t}$ and $M_{t}=(1-\eta) C_{t}$; the returns on foreign assets and liabilities are equal and constant, $R_{t}^{\mathrm{FA}}=R_{t}^{\mathrm{FL}}=R_{t}^{\mathrm{F}}$; and both foreign assets and liabilities are constant fractions of households savings, $F A_{t-1}=\alpha^{\mathrm{F}}\left(W_{t-1}-C_{t-1}\right)$ and $F L_{t-1}=\alpha^{\mathrm{F}}\left(\hat{W}_{t-1}-\hat{C}_{t-1}\right)$, where $\alpha^{\mathrm{F}}$ is the steady state value for the portfolio shares, $\alpha_{t}^{\mathrm{FA}}$ and $\hat{\alpha}_{t}^{\mathrm{FA}}$. The steady state is also characterized by a constant common consumption growth rate $g$ and savings-toconsumption ratios, $\Lambda_{t}^{\mathrm{C}}=\hat{\Lambda}_{t}^{\mathrm{C}}=\Lambda^{\mathrm{c}}$. Under these circumstances, the terms in square brackets in (40) are constants equal to $\kappa=1-\frac{(1-\eta) \exp (g)}{R^{\mathrm{F}} \alpha^{\mathrm{F}} \Lambda^{\mathrm{C}}} \in(0,1)$. Taking a first-order Taylor series approximation to the left- 
and right-hand sides of (40) around the steady state, and simplifying the resulting expression produces

$$
n f a_{t}=-(1-\kappa) \mathbb{E}_{t} n x_{t+1}-\mathbb{E}_{t}\left(r_{t+1}^{\mathrm{FA}}-r_{t+i}^{\mathrm{FL}}\right)+\kappa \mathbb{E}_{t} n f a_{t+1},
$$

where $n f a_{t}=\ln \left(F A_{t} / F L_{t}\right)$ and $n x_{t}=\ln \left(X_{t} / M_{t}\right)$ are the $\log$ ratios of foreign assets to liabilities and exports to imports. Finally, I iterate forward and take conditional exceptions (noting that $\lim _{k \rightarrow \infty} \mathbb{E}_{t} \kappa^{k} n f a_{t+k}=0$ ) to obtain

$$
\begin{gathered}
n f a_{t}=n f a_{t}^{\mathrm{TR}}+n f a_{t}^{\mathrm{VAL}} \quad \text { where } \\
n f a_{t}^{\mathrm{TR}}=-(1-\kappa) \mathbb{E}_{t} \sum_{i=1}^{\infty} \kappa^{i-1} n x_{t+i} \quad \text { and } \quad n f a_{t}^{\mathrm{VAL}}=-\mathbb{E} \sum_{i=1}^{\infty} \kappa^{i-1}\left(r_{t+i}^{\mathrm{FA}}-r_{t+i}^{\mathrm{FL}}\right) .
\end{gathered}
$$

The approximation in (41) embodies the central features of the international solvency constraint in (39). For example, (41) implies that a shock producing an upward revision in the expected future path for U.S. net exports (i.e., a rise in $\mathbb{E}_{t} n x_{t+i}$ ) must also produce either an fall in expected future returns on foreign assets $\mathbb{E}_{t} r_{t+i}^{\mathrm{FA}}$, a rise in expected future liability returns $\mathbb{E}_{t} r_{t+i}^{\mathrm{FL}}$, and/or a fall in value of net foreign assets (i.e., a fall in $n f a_{t}$ ). In the special case were a single riskless bond is the only internationally traded asset, returns on foreign assets and liabilities are equal so (41) simplifies to $n f a_{t}=n f a_{t}^{\mathrm{TR}}=-(1-\kappa) \mathbb{E}_{t} \sum_{i=1}^{\infty} \kappa^{i-1} n x_{t+i}$. I refer to $n f a_{t}^{\mathrm{TR}}$ as the trade component of the net foreign asset ratio. The effects of revisions in expected future returns are identified by the valuation component, $n f a_{t}^{\mathrm{VAL}} \cdot 25$

There are two main advantages to using (41) rather than (39) to study external adjustment. First, (41) links trade flows and returns to the net foreign asset position via a linear present value relation rather than through the complex nonlinear relation in (39). This facilitates the examination of how net foreign assets behave in the model and in actual U.S. data. Second, expressions for the log returns on U.S. foreign assets and liabilities are readily determined from the model's equilibrium conditions. Variations in these returns are empirically important, so it proves useful to examine their theoretical drivers in the model.

\section{Drivers of the U.S. Net Foreign Asset Position}

We can use the approximate solvency constraint in (41) and a VAR to study the U.S. external adjustment process. The VAR is used to construct the forecasts for net exports, $n x_{t}$, and the return differentials, $r_{t}^{\mathrm{NFA}}=r_{t}^{\mathrm{FA}}-r_{t}^{\mathrm{FL}}$, that appear in the definitions of the trade and valuation components, $n f a_{t}^{\mathrm{TR}}$ and $n f a_{t}^{\mathrm{VAL}}$. I then compare the actual movements in $n f a_{t}$ against these estimates of $n f a_{t}^{\mathrm{TR}}$ and $n f a_{t}^{\mathrm{VAL}}$ derived from the VAR.

I estimate the trade and valuation components with several VAR specifications. In the base specification I estimate a VAR for three variables: the return differential $r_{t}^{\mathrm{NFA}}$, the growth differential between exports and imports $\Delta n x_{t}=\Delta x_{t}-\Delta m_{t}$, and the sum the log net asset position and exports, $n x a_{t}=n f a_{t}+n x_{t}$. I include

\footnotetext{
${ }^{25}$ Gourinchas and Rey (2007) derive a similar approximation to the dynamics in (38) around a deterministic trend path where solvency is satisfied. Their approximation links the cyclical components of exports, imports and the foreign asset and liability positions rather than the trade flows and positions themselves.
} 
the latter two variables because the U.S. time series for $n x_{t}$ and $n f a_{t}$ are quiet persistent in the sample period (1973:I, 2007:IV). The approximation in (41) implies that $n x a_{t}=-\mathbb{E}_{t} \sum_{i=1}^{\infty} \kappa^{i-1}\left(\Delta n x_{t+i}+r_{t+i}^{\mathrm{NFA}}\right)$, so shocks producing persistent variations in $n x_{t}$ should have little impact on $n x a_{t}$ because they have small effects on the near-term forecasts for $\Delta n x_{t}$. In addition, I estimate VARs that include $\Delta x_{t}$ and $\Delta m_{t}$ instead of $\Delta n x_{t}$, as well as $r_{t}^{\mathrm{FA}}$ and $r_{t}^{\mathrm{FL}}$ instead of $r_{t}^{\mathrm{NFA}}$. In all these specifications the returns on foreign assets and liabilities are constructed from the actual U.S. portfolios with time-varying shares. To facilitate comparisons between the U.S. data and the model, I also estimate VARs where the returns on assets and liabilities are constructed from portfolios with constant shares equal to the sample average, $r_{t}^{\mathrm{FA}}(\bar{\alpha})$ and $r_{t}^{\mathrm{FL}}(\bar{\alpha})$.

Let $\mathcal{Y}_{t}=\tilde{A} \mathcal{Y}_{t-1}+\tilde{V}_{t}$ represent the estimates of a VAR written in first-order form, where the vector $\mathcal{Y}_{t}$ appropriately stacks the current and lagged values of all the VAR's variables, and $\tilde{A}$ is the companion matrix of estimated VAR coefficients. I compute estimates of the trade and valuation components as

$$
\widetilde{n f a_{t}^{\mathrm{TR}}}=-\imath^{\mathrm{TR}} \tilde{A}(I-\kappa \tilde{A}) \mathcal{Y}_{t}-n x_{t} \quad \text { and } \quad \widetilde{n f a_{t}^{\mathrm{VAL}}}=-\imath^{\mathrm{VAL}} \tilde{A}(I-\kappa \tilde{A}) \mathcal{Y}_{t}
$$

where $\imath^{\mathrm{TR}}$ and $\imath^{\mathrm{VAL}}$ are vectors such the $\Delta n x_{t}=\imath^{\mathrm{TR}} \mathcal{Y}_{t}$ and $r_{t}^{\mathrm{NFA}}=\imath^{\mathrm{VAL}} \mathcal{Y}_{t}$.

By definition, $n f a_{t}=\widetilde{n f a_{t}^{\mathrm{TR}}}+\widetilde{n f a_{t}^{\mathrm{VAL}}}+\xi_{t}$, where $\xi_{t}$ is a composite error comprising the approximation error in (41) and the estimation error associated with forecasting the future path for $\Delta n x_{t}$ and $r_{t}^{\mathrm{NFA}}$ from the VAR. We may therefore decompose the unconditional variance of the log net foreign asset ratio as

$$
\mathbb{V}\left(n f a_{t}\right)=\mathbb{C V}\left(\widetilde{n f} a_{t}^{\mathrm{TR}}, n f a_{t}\right)+\mathbb{C V}\left(\widetilde{n f} a_{t}^{\mathrm{VAL}}, n f a_{t}\right)+\mathbb{C V}\left(\xi_{t}, n f a_{t}\right)
$$

where $\mathbb{V}($.$) and \mathbb{C V}(.,$.$) denote the variance and covariance operators, respectively. The first term on the$ right-hand-side identifies the variance contribution of the estimated trade component, the second identifies the contribution of the valuation component. I estimate these contributions as the slope coefficient from the OLS regression of the estimated component on $n f a_{t}$ :

$$
\widetilde{n f}_{t}^{\mathrm{TR}}=\beta^{\mathrm{TR}} n f a_{t}+\zeta_{t}^{\mathrm{TR}} \quad \text { and } \quad \widetilde{n f} a_{t}^{\mathrm{VAL}}=\beta^{\mathrm{VAL}} n f a_{t}+\zeta_{t}^{\mathrm{VAL}}
$$

By least squares, $\beta^{\mathrm{TR}}=\mathbb{C} \mathbb{V}\left(\widetilde{n f a_{t}}{ }^{\mathrm{TR}}, n f a_{t}\right) / \mathbb{V}\left(n f a_{t}\right)$ and $\beta^{\mathrm{VAL}}=\mathbb{C V}\left(\widetilde{n f a_{t}}{ }^{\mathrm{VAL}}, n f a_{t}\right) / \mathbb{V}\left(n f a_{t}\right)$ so the regression coefficients provide estimates of the variance contributions. I also compute confidence bands for these estimates using White (1980) heteroskedastic consistent standard errors.

Panel A of Table 5 reports estimates of $n f a_{t}$ variance decomposition for the U.S. between 1973:I, 2007:IV computed from different VAR specifications. In all cases I report results based on second-order VARs, but I obtain similar results using first- and third-order ones as well. The left-hand column lists the variables included in the VAR. The center columns report the estimates of $\beta^{\mathrm{TR}}, \beta^{\mathrm{VAL}}$ and $\beta^{\mathrm{TR}}+\beta^{\mathrm{VAL}}$ together with their 95 percent confidence bands. The right-hand column of the table reports the value for $\kappa$ used to compute the $n f a_{t}$ components. The values for $\kappa$ of 0.988 and 0.980 maximize $\beta^{\mathrm{TR}}+\beta^{\mathrm{VAL}}$ for the VAR specifications in rows $\mathrm{A}$ and $\mathrm{B}$, respectively.

The results in Panel A show a consistent pattern in the estimated variance contributions of the trade and valuation components across the different VAR specifications. In all cases the variations in the estimates of 


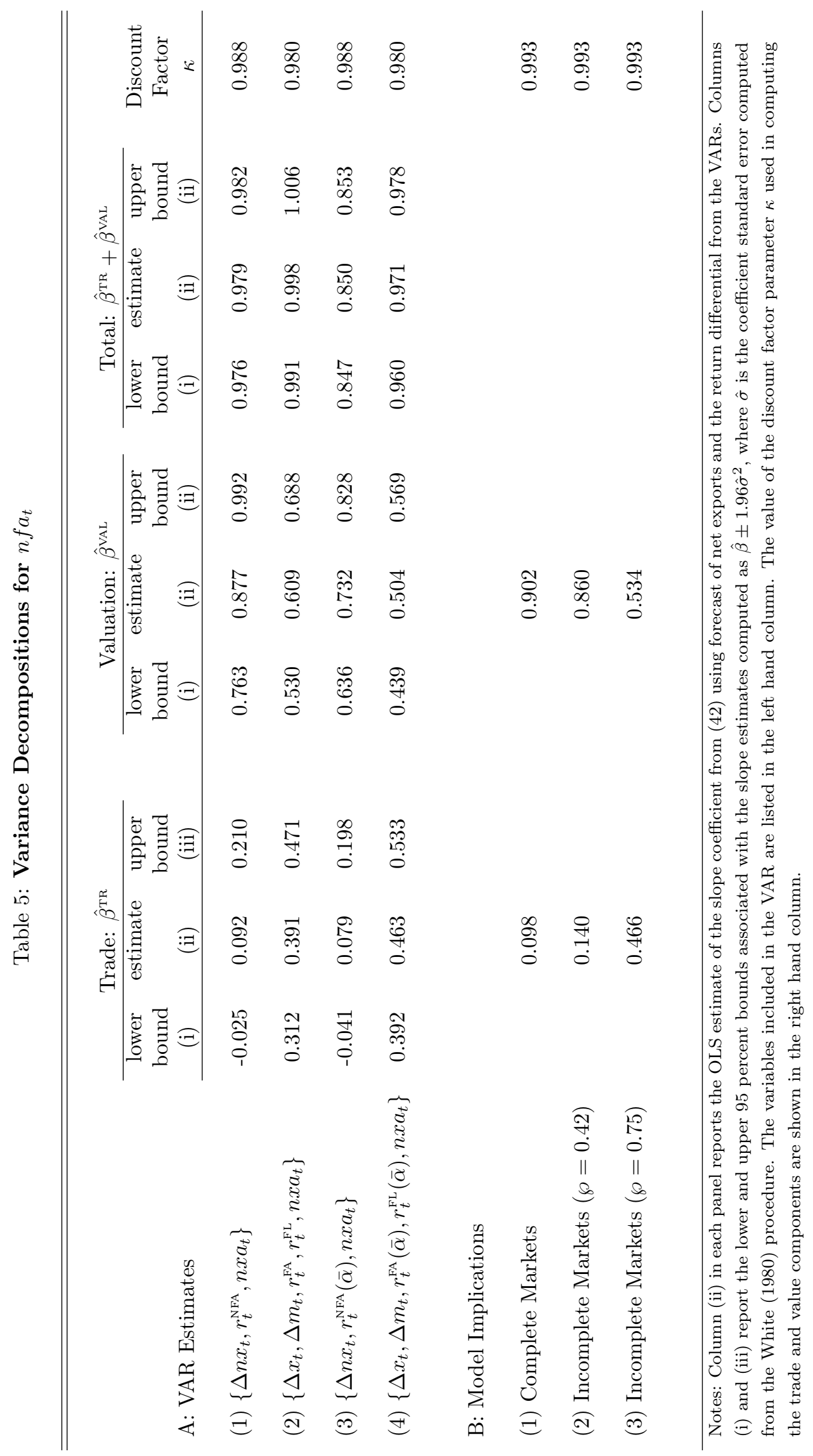


the expected future return differentials contribute more to the sample variance of the log net foreign asset ratio than the estimated revisions future trade flows. ${ }^{26}$ There are, however, some noteworthy differences across the estimates based on different VAR specifications. Comparing rows (1) and (2) we see that the variance contribution of the trade (valuation) component is larger (smaller) when based on separate VAR forecasts for export and import growth and returns than when based on VAR forecast for net export growth and return differentials. Although both VAR specifications generate estimates of the trade and valuation components that account for almost all the sample variation in the $n f a_{t}$ (the estimates of $\beta^{\mathrm{TR}}+\beta^{\mathrm{VAL}}$ are close to one), it is hard to precisely pin down how real-time forecasts of future trade flows and returns differentials were changing over the sample period. The estimates in rows (3) and (4) provide information on the importance of changes in the composition of U.S. asset and liabilities portfolios. Here I report results derived from VARs that replace the returns on actual portfolios with the returns on asset and liability portfolios where the share of equity are fixed at the sample average of 0.42 . This restriction reduces the estimated variance contributions of the valuation components. It also reduces the explanatory power of the VAR for $n f a_{t}$, as measured by the estimates of $\beta^{\mathrm{TR}}+\beta^{\mathrm{VAL}}$, compared to their counterparts in rows A and B. This finding is consistent with the idea that real-time forecasts for future return differentials factor in the effects of changing portfolio compositions.

Panel $\mathrm{B}$ of Table 5 reports values for $\beta^{\mathrm{TR}}$ and $\beta^{\mathrm{VAL}}$ implied by different equilibria of the model. These values are computed from unconditional variances and covariances for $n f a_{t}, n f a_{t}^{\mathrm{TR}}$ and $n f a_{t}^{\mathrm{VAL}}$ using $\kappa=0.993$, which is the value for $\kappa$ implied by the model's steady state. Rows (1) and (2) show that variations in the valuation components account for high fractions of the variance in $n f a_{t}$ in the benchmark and complete markets equilibria. Indeed, the contribution of the valuation component in the benchmark equilibrium in row (2) appears at the upper end of the range of estimates based on the U.S. data. Of course these calculations are based on an equilibrium of a model that was calibrated to match the sample moments of real exchange rates, interest rates and consumption growth differentials. It is not too surprising that the values for $\beta^{\text {TR }}$ and $\beta^{\text {VAL }}$ implied by the external adjustment mechanism in the model do not exactly match the estimates from U.S. data. Moreover, the values for $\beta^{\mathrm{TR}}$ and $\beta^{\mathrm{VAL}}$ implied by model appear to be quite sensitive to the value for $\wp$, the share of equity in households' foreign asset portfolios. In equilibria (with frictions) where $\wp>0.42$, the values for $\beta^{\mathrm{TR}}$ and $\beta^{\mathrm{VAL}}$ fall well within the range of estimates in Panel I. For example, row (3) shows that when $\wp$ is set to 0.75 , and all the other parameters are at their benchmark values, the model's equilibrium implies that $\beta^{\mathrm{TR}}=0.466$ and $\beta^{\mathrm{VAL}}=0.534$.

Overall, the results in Table 5 show that variations in expected future return differentials between foreign assets and liabilities made a major historic contribution to the variability of the U.S. net foreign asset ratio. They also show that variations in expected future return differentials make a similarly important contribution to the dynamics of the net foreign asset ratio in the model. As I noted in Section 2, this feature of the model is new to the literature. To understand its theoretical foundation, I next consider how endowment and risk shocks affect the value of net foreign assets via their impact on forecasts for future foreign asset returns and trade flows.

\footnotetext{
${ }^{26}$ Gourinchas and Rey (2007) estimate a smaller variance contribution from the valuation component in their decomposition of the cyclical component of $n f a_{t}$. If I replace $n x a_{t}$ with a cyclical component estimated with the HP filter in my analysis, I also find a much small variance contribution from revisions in forecasts of future return differentials.
} 


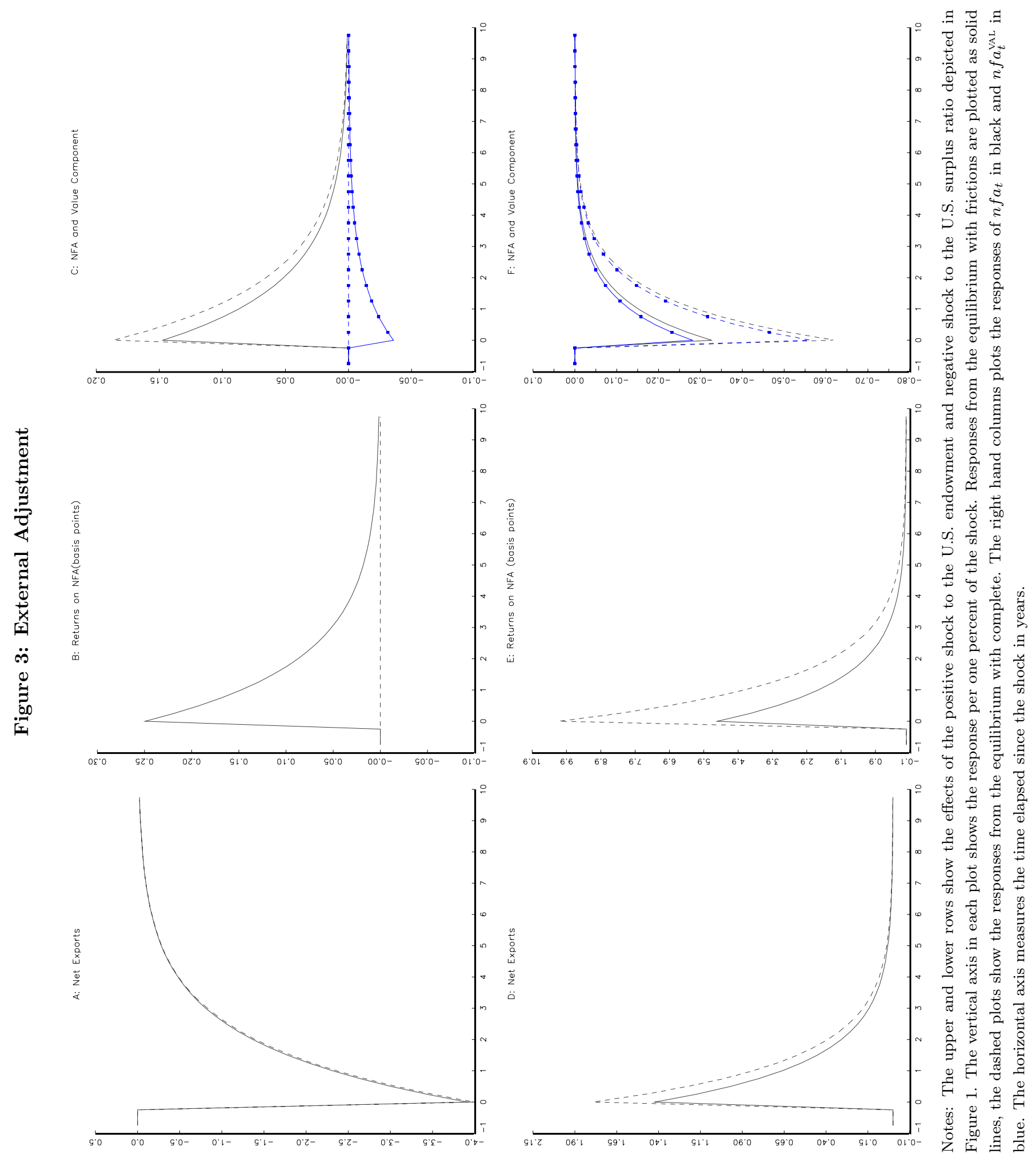


Figure 3 shows the impulse responses of the log net export ratio, $n x_{t}$, the expected return differential on net foreign assets, $\mathbb{E}_{t} r_{t+1}^{\mathrm{NFA}}$, the $\log$ net foreign asset ratio, $n f a_{t}$, and its valuation component, $n f a_{t}^{\mathrm{VAL}}$. As above, the solid and dashed plots show the responses in the benchmark and complete markets equilibria, respectively. Panels A-C plot the responses to the U.S. endowment shock. Recall that this shock produces a rise in U.S. consumption and a deterioration in the U.S. term of trade (to clear goods markets). These effects produce a rise in U.S. demand for E.U. goods and a fall in the E.U. demand for U.S. goods so $n x_{t}$ initially falls before gradually rising back to its steady state level. As Panel A shows, the paths for $n x_{t}$ in the benchmark and complete markets equilibria are very similar. Panel B plots the responses of the expected return differential on U.S. foreign assets $\mathbb{E}_{t} r_{t+1}^{\mathrm{NFA}}=\mathbb{E}_{t}\left(r_{t+1}^{\mathrm{FA}}-\Delta \varepsilon_{t+1}-\hat{r}_{t+1}^{\mathrm{FA}}\right)$. Under complete markets the shock has no effect on $\mathbb{E}_{t} r_{t+1}^{\mathrm{NFA}}$, but when frictions are present it temporarily raises $\mathbb{E}_{t} r_{t+1}^{\mathrm{NFA}}$ by a very small amount. This difference arises because the depreciation of the dollar produces an unanticipated capital gain and loss for U.S. and E.U. households, respectively. In principle, such gains a losses interact with the collateral constraints to move equilibrium expected excess returns on domestic equity and foreign assets (see below), but in this case the effects are economically insignificant. This means that most of the variation in the value of U.S. net foreign asset position occurs via the trade channel. Panel C shows that the presence of financial frictions dampens the rise in $n f a_{t}$ (relative to the response under complete markets) because revisions in the expected path for $r_{t+1}^{\mathrm{NFA}}$ generate a fall in the value component.

Two aspects of these results are worth noting. First the response patterns in panels A-C are entirely consistent with the standard process of international adjustment that underlies the intertemporal approach to the current account. In this case the transitory endowment shock produces capital gains on U.S. households' holdings of domestic equity and foreign assets that they use to raise consumption, producing temporary current account deficits that are financed by higher dividends on their equity holdings. As in a standard model where only a single bond is traded, the adjustment of the net foreign asset position following the shock comes primarily via the trade channel, but at the time the shock hits there are capital gains an losses on existing asset holdings. Unexpected valuation effects play a role in the external adjustment process following (temporary) endowment shocks even though revisions in expect future trade flows account for most of the variations in the net foreign asset position.

The second feature concerns the implications of the plots for the $n f a_{t}$ variance contributions in Table 5 . Since little (or none) of the variation in $n f a_{t}$ following a temporary endowment shock comes from changes in $n f a_{t}^{\mathrm{VAL}}$, the impulse responses indicate that such shocks cannot be an important drivers of $n f a_{t}$ variations in U.S. data. If they were, the estimates of $\beta^{\mathrm{TR}}$ would be close to one. At the same time, Table 5 shows that the models' equilibrium implies a small value for $\beta^{\mathrm{TR}}$ and large value $\beta^{\mathrm{VAL}}$, so the external adjustment process following risk shocks must be quite different.

Panels D-F in Figure 3 show the impulse responses produced by the U.S. risk shock (that lowers the U.S. surplus ratio). This shock induces a real appreciation of the dollar, a rise in U.S. consumption and a fall in E.U. consumption to clear goods markets. These responses produce a fall in the ratio of E.U. to U.S. consumption expenditure $\mathcal{E}_{t} \hat{C}_{t} / C_{t}$, and a rise in the share of spending on U.S. goods in each country's consumption basket. These factors affect net exports in opposite directions, but in the benchmark equilibrium the latter factor dominates producing the rise in net exports shown in Panel D. Notice, also, that the effects 
of the risk shock on trade are much smaller than those of the endowment shock shown in Panel A.

The risk shock has a much bigger effect on the expected return differential on U.S. foreign assets, $\mathbb{E}_{t} r_{t+1}^{\mathrm{NFA}}$. As Panel E shows, in the benchmark equilibrium the rise in $\mathbb{E}_{t} r_{t+1}^{\mathrm{NFA}}$ induced by the risk shock is almost 20 times the rise produced by the endowment shock, while in the complete markets equilibrium the rise in $\mathbb{E}_{t} r_{t+1}^{\mathrm{NFA}}$ is almost 40 times larger. The effects of the U.S. net foreign asset ratio are shown in Panel F. Here we see that changes in the valuation component, $n f a_{t}^{\mathrm{VAL}}$ account for the lion's share of the $n f a_{t}$ responses in both equilibria. In contrast to the adjustment following endowment shocks, risk shocks produce variations in the net foreign asset ratio primarily via the valuation channel; i.e. via changes in the expected future return differentials on U.S. foreign assets, $\mathbb{E}_{t} r_{t+i}^{\mathrm{NFA}}$.

The plots in Panels D-F reconcile the results in Table 5 and the analysis of the adjustment process following temporary endowment shocks. The small value for $\beta^{\mathrm{TR}}$ and large value $\beta^{\mathrm{VAL}}$ implied by the model's equilibrium arise because: (i) risk shocks affect the net foreign asset ratio via the valuation channel, and (ii) they are the dominant source of cyclical dynamics in the model. To understand exactly why risk shocks play such an important role in the external adjustment process, we next need to examine their effects on equilibrium risk premia and capital flows.

\subsection{Risk Premia, Asset Holdings and Capital Flows}

In this last section I address two outstanding questions: First, why are forecasts of the net asset return differential, $\mathbb{E}_{t} r_{t+i}^{\mathrm{NFA}}$, much more susceptible to risk shocks than endowment shocks? Second, what role do international capital flows play in the external adjustment process?

\section{Risk Premia}

To address these questions, I focus on the equity risk premia and the risk the premia on holding foreign assets. Combining the first-order conditions for domestic equity, bonds and foreign assets in (27), (28), (31) and (32), we can derive the following approximations:

$$
\begin{aligned}
& r p_{t}^{\mathrm{EQ}} \equiv \mathbb{E}_{t}\left[r_{t+1}^{\mathrm{EQ}}-r_{t}\right]+\frac{1}{2} \mathbb{V}_{t}\left(r_{t+1}^{\mathrm{EQ}}\right)=\gamma \mathbb{C V}_{t}\left(r_{t+1}^{\mathrm{EQ}}, c_{t+1}+s_{t+1}\right)-\ln \left(1-\mathcal{B}_{t}\right), \\
& \widehat{r p}_{t}^{\mathrm{EQ}} \equiv \mathbb{E}_{t}\left[\hat{r}_{t+1}^{\mathrm{EQ}}-\hat{r}_{t}\right]+\frac{1}{2} \mathbb{V}_{t}\left(\hat{r}_{t+1}^{\mathrm{EQ}}\right)=\gamma \mathbb{C} \mathbb{V}_{t}\left(\hat{r}_{t+1}^{\mathrm{EQ}}, \hat{c}_{t+1}+\hat{s}_{t+1}\right)-\ln \left(1-\widehat{\mathcal{B}}_{t}\right), \\
& r p_{t}^{\mathrm{FA}} \equiv \mathbb{E}_{t}\left[r_{t+1}^{\mathrm{FA}}-r_{t}\right]+\frac{1}{2} \mathbb{V}_{t}\left(r_{t+1}^{\mathrm{FA}}\right)=\gamma \mathbb{C} \mathbb{V}_{t}\left(r_{t+1}^{\mathrm{FA}}, c_{t+1}+s_{t+1}\right)+\ln \left(1-\varkappa \mathcal{B}_{t} /\left(1-\mathcal{B}_{t}\right)\right) \quad \text { and } \\
& \widehat{r p}_{t}^{\mathrm{FA}} \equiv \mathbb{E}_{t}\left[\hat{r}_{t+1}^{\mathrm{FA}}-\hat{r}_{t}\right]+\frac{1}{2} \mathbb{V}_{t}\left(\hat{r}_{t+1}^{\mathrm{FA}}\right)=\gamma \mathbb{C} \mathbb{V}_{t}\left(\hat{r}_{t+1}^{\mathrm{FA}}, \hat{c}_{t+1}+\hat{s}_{t+1}\right)+\ln \left(1-\varkappa \widehat{\mathcal{B}}_{t} /\left(1-\widehat{\mathcal{B}}_{t}\right)\right) .
\end{aligned}
$$

The left-hand-side of these equations includes the variance term, a Jensen inequality term, to account for the fact that we are working with log returns. The right-hand-side shows two determinants of the risk premia. The first equals minus one times the conditional covariance between the risky return and the $\log$ 
intertemporal marginal rate of substitution (e.g., $-\mathbb{C} \mathbb{V}_{t}\left(r_{t+1}^{\mathrm{EQ}}, \ln \mathcal{M}_{t-1}\right)$ in equation 43a). These covariances embody the conventional hedging properties of the risky assets reflected in the equilibrium risk premia. The second term on the right-hand-side identifies the direct effects of the collateral constraints. When the constraint binds the domestic risk free rate falls relative to the expected marginal rate of substitution which pushes up the domestic equity premium. A binding collateral constraint also makes holding foreign assets more attractive. In the benchmark equilibrium this lowers the equilibrium expected return on foreign assets by more than the risk free rate so the risk premia on foreign assets falls.

The effects of endowment and risk shocks on risk premia in the complete markets equilibrium are straightforward. In this equilibrium the risk premia only depend on the covariance terms because $\mathcal{B}_{t}=\widehat{\mathcal{B}}_{t}=0$ for all $t$. As a consequence, only risk shocks have measurable effects on the risk premia. For example, recall from Figure 2 that the U.S. risk shock produces a large unexpected fall in domestic equity prices. Since the associated capital loss occurred when U.S. households had unexpectedly high marginal utility, they perceive domestic equity as a poor hedge against future risk shocks. Households also recognize that these shocks are more likely to occur in the future because the conditional variance $\mathbb{V}_{t}\left(s_{t+1}\right)$ is decreasing in $s_{t}$, so the equilibrium equity premium must rise to compensate. Similarly, the risk shock raises the risk premium on foreign assets because the real appreciation of the dollar produces a capital loss on U.S. households' foreign asset portfolios.

When financial frictions are present both the endowment and risk shocks can affect the equilibrium risk premia via the collateral constraints. In principle, an endowment or risk shock could produce a large enough capital loss on foreign asset holdings that households are immediately pushed to the point where the constrain binds. Under these circumstances, the equilibrium risk premia are directly affected by the non-zero values for $\mathcal{B}_{t}$ or $\widehat{\mathcal{B}}_{t}$ shown on the right-hand side of (43). However, in the benchmark equilibrium households typically react to the capital losses produced by endowment and risk shocks by adjusting their portfolios so that the constraints do not bind (i.e., $\mathcal{B}_{t}$ or $\widehat{\mathcal{B}}_{t}$ remain at zero). ${ }^{27}$ These adjustments affect the risk premia because they change the joint conditional distribution of future consumption and returns. Intuitively, when markets are incomplete the effects of future shocks on asset prices and consumption depend on how households reallocate portfolios now, so reallocations to avoid binding collateral constraints affect the equilibrium risk premia via their effects on the covariance terms in (43).

Let us now consider the link between the risk premia in (43) and the expected return differential on the U.S. net foreign asset position, $\mathbb{E}_{t} r_{t+1}^{\mathrm{NFA}}$. By definition, $r_{t+1}^{\mathrm{NFA}}=r_{t+1}^{\mathrm{FA}}-\Delta \varepsilon_{t+1}-\hat{r}_{t+1}^{\mathrm{FA}}$, where $r_{t+1}^{\mathrm{FA}}$ and $\hat{r}_{t+1}^{\mathrm{FA}}$ are the log returns on the U.S. and E.U. foreign asset portfolios, respectively. Following Campbell and Viceira (2002), these portfolio returns are well-approximated by

$$
\begin{aligned}
& r_{t+1}^{\mathrm{FA}}=\hat{r}_{t}+\Delta \varepsilon_{t+1}+\frac{1}{2} \wp(1-\wp) \mathbb{V}_{t}\left(\hat{r}_{t+1}^{\mathrm{EQ}}\right)+\wp\left(\hat{r}_{t+1}^{\mathrm{EQ}}-\hat{r}_{t}\right) \quad \text { and } \\
& \hat{r}_{t+1}^{\mathrm{FA}}=r_{t}-\Delta \varepsilon_{t+1}+\frac{1}{2} \wp(1-\wp) \mathbb{V}_{t}\left(r_{t+1}^{\mathrm{EQ}}\right)+\wp\left(r_{t+1}^{\mathrm{EQ}}-r_{t}\right) .
\end{aligned}
$$

\footnotetext{
${ }^{27}$ In principle a large enough shock could push households to the point where the constraints actually bind. As I noted in Section 3, this is not possible in the approximate solution I study where household's sub-utility functions take the form of (22): shocks can push households arbitrary close to the point where the constraint binds, but never to the point with it actually does.
} 
Combining these expressions with the definition of $r_{t+1}^{\text {NFA }}$ and taking expectations produces

$$
\begin{aligned}
\mathbb{E}_{t} r_{t+1}^{\mathrm{NFA}}=\frac{1}{2}\left\{r p_{t}^{\mathrm{FA}}-\widehat{r}_{t}^{\mathrm{FA}}\right\} & +\frac{1}{2}\left\{\widehat{r p}_{t}^{\mathrm{EQ}}-r p_{t}^{\mathrm{EQ}}\right\} \\
+ & \frac{1}{2}\left\{\mathbb{V}_{t}\left(\hat{r}_{t+1}^{\mathrm{FA}}\right)-\mathbb{V}_{t}\left(r_{t+1}^{\mathrm{FA}}\right)\right\}-\frac{1}{4} \wp^{2}\left\{\mathbb{V}_{t}\left(\hat{r}_{t+1}^{\mathrm{EQ}}\right)-\mathbb{V}_{t}\left(r_{t+1}^{\mathrm{EQ}}\right)\right\} .
\end{aligned}
$$

Here we see that the expected return differential depends on the difference between two sets of risk premia: the difference between the risk premia on U.S. and E.U. foreign asset portfolios, $r p_{t}^{\mathrm{FA}}-\widehat{r p}_{t}^{\mathrm{FA}}$; and the difference between the domestic equity premia in the E.U. and U.S., $\widehat{r p}_{t}^{\mathrm{EQ}}-r p_{t}^{\mathrm{EQ}}$. The third term on the right-hand-side identifies the Jensen inequality effects.

The effects of endowment and risk shocks on forecasts of the future return differential, $r_{t+i}^{\mathrm{NFA}}$, are easily understood with the aid of (43) and (44). Consider, first, the effects of the U.S. endowment shock. When markets are complete these shocks have no effect on the expected return differential because the hedging properties of domestic equities and foreign assets (identified by the covariance terms in 43) remain unchanged. Under these circumstances, there is no compensating equilibrium change in either the equity or foreign asset risk premia so the expected future return differential remains constant. When financial frictions are present, the endowment shock produces a very small rise in $\mathbb{E}_{t} r_{t+i}^{\mathrm{NFA}}$ via its effects on the E.U. collateral constraint. Recall from Figures 1 and 2 that the shock produces a real depreciation of the dollar and a rise in U.S. equity prices. These asset-pricing effects work in opposite directions on the value of E.U. foreign assets: $\widehat{F A}_{t}=\left(\hat{B}_{t}^{\mathrm{US}}+Q_{t} \hat{A}_{t}^{\mathrm{US}}\right) / \mathcal{E}_{t}$. On balance $\widehat{F A}_{t}$ falls driving E.U. households closer to their collateral constraint, which in turn raises the E.U. equity premia, $\widehat{r p}_{t}^{\mathrm{EQ}}$, and lowers the E.U. foreign asset premium, $\widehat{r p}_{t}^{\mathrm{FA}}$. As (44) shows, these risk-premia affects raise $\mathbb{E}_{t} r_{t+i}^{\mathrm{NFA}}$, but in the benchmark equilibrium the effect is very small (see Panel $\mathrm{C}$ of Figure 3). Consequently, the process of external adjustment following an endowment shock overwhelming takes place via the trade channel.

In contrast, external adjustment following a risk shock primarily takes place through the valuation channel because the shock raises expected future return differentials $\mathbb{E}_{t} r_{t+i}^{\mathrm{NFA}}$. Under complete markets, risk shocks affect $\mathbb{E}_{t} r_{t+i}^{\mathrm{NFA}}$ by changing the hedging properties of domestic and foreign assets in both countries. Recall that the U.S. risk shock makes U.S. equity and foreign assets a worse hedge against future risk shocks so the equilibrium risk premia on U.S. equity and foreign assets must rise to compensate. The U.S. risk shock also lowers the E.U. foreign asset risk premium because it produces a fall in E.U. consumption and a real appreciation of the dollar. The former effect increases E.U. marginal utility, while the latter produces a capital gain on the portion of E.U. foreign assets held in bonds. (The fall in U.S. equity prices offsets the gain on E.U. foreign equity holdings.) The increased likelihood of future U.S. risk shocks therefore produces a fall in the E.U. foreign asset risk premium. Thus, the U.S. risk shock changes the hedging properties of domestic equity and foreigns assets to produce a rise in $r p_{t}^{\mathrm{FA}}-\widehat{r p}_{t}^{\mathrm{FA}}$ and $r p_{t}^{\mathrm{EQ}} \cdot{ }^{28}$ As (44) shows, these changes in the risk premia have offsetting affects on $\mathbb{E}_{t} r_{t+i}^{\mathrm{NFA}}$, but in the complete markets equilibrium the former effects dominate so $\mathbb{E}_{t} r_{t+i}^{\mathrm{NFA}}$ rises.

The effects of the U.S. risk shock on $\mathbb{E}_{t} r_{t+i}^{\mathrm{NFA}}$ are smaller in the benchmark equilibrium. Since the equi-

\footnotetext{
${ }^{28}$ The risk shock also raises E.U. equity premium, $\widehat{r p}_{t}^{\mathrm{EQ}}$, but the effect is insignificant because the capital loss on E.U. equity is very small; see Panel D in Figure 2.
} 
librium responses of equity prices, consumption and the real exchange rate are very similar to the responses under complete markets (see the lower panels of Figures 1 and 2), the risk shock changes the hedging properties of domestic equity and foreign assets in the manner described above. Additionally, in this equilibrium, the shock affects the U.S. equity and foreign asset risk premia via the collateral constraints. In particular, the real appreciation of the dollar produces a capital loss on pre-existing U.S. foreign asset holdings that drives U.S. households towards the constraint. In response, U.S. households reallocate their portfolios pushing $r p_{t}^{\mathrm{EQ}}$ higher and $r p_{t}^{\mathrm{FA}}$ lower than in the complete markets equilibrium. The net result is to dampen the rise in $\mathbb{E}_{t} r_{t+i}^{\mathrm{NFA}}$ relative to the complete markets response as shown in Panel $\mathrm{E}$ of Figure 3.

\section{Capital Flows}

To this point we have studied the process of external adjustment following endowment and risk shocks and how the presence of financial frictions moderates the strength of the valuation channel by dampening the effects of risk shocks on the risk premia. I now turn to the remaining aspect of the external adjustment process, the behavior of capital flows.

Table 6: Capital Flows

\begin{tabular}{cccc}
\hline \hline $\begin{array}{c}\text { Variables } \\
\text { (i) }\end{array}$ & $\begin{array}{c}\text { Benchmark } \\
(\mathrm{ii})\end{array}$ & $\begin{array}{c}\text { Complete Markets } \\
(\mathrm{iii})\end{array}$ & $\begin{array}{c}\text { Ratio } \\
(\mathrm{iv})\end{array}$ \\
& A: Standard Deviations & \\
$w_{t}-c_{t}$ & 0.302 & 0.297 & 1.016 \\
$f a_{t}$ & 0.782 & 0.654 & 1.195 \\
$\alpha_{t}^{\mathrm{EQ}}$ & 0.089 & 0.077 & 1.155 \\
$\alpha_{t}^{\mathrm{EA}}$ & 0.212 & 0.183 & 1.158 \\
$\mathcal{E}_{t} \Delta B_{t}^{\mathrm{EU}}$ & 0.167 & 0.152 & 1.098 \\
$\mathcal{E}_{t} \hat{Q}_{t} \Delta A_{t}^{\mathrm{EU}}$ & 0.120 & 0.109 & 1.101
\end{tabular}

B: Return Chasing Contributions

Bond Flows: $\mathcal{E}_{t} \Delta B_{t}^{\mathrm{EU}} \quad 0.717 \quad 0.714$

Equity Flows: $\mathcal{E}_{t} \hat{Q}_{t} \Delta A_{t}^{\mathrm{EU}} \quad 1.381 \quad 1.381$

Notes: Panel A reports the unconditional standard deviation from simulations of the benchmark equilibrium in column (ii) and the complete markets equilibrium column (iii) for the variables listed in column (i). Column (iv) reports the ratio of the statistics in columns (ii) to (iii). Panel B reports the variance contribution of the return chasing components in U.S. foreign bond flows and equity flows in the benchmark and complete markets equilibria. All statistics are computed from simulations spanning 100,000 quarters. 
Panel A in Table 6 reports the unconditional standard deviations from simulations of the benchmark and complete markets equilibria for U.S. log savings, $w_{t}-c_{t}$; the log value of U.S. foreign assets, $f a_{t}$; the U.S. portfolio shares for domestic equity and foreign assets, $\alpha_{t}^{\mathrm{EQ}}$ and $\alpha_{t}^{\mathrm{FA}}$; and the U.S. capital outflows for bonds and equity, $\mathcal{E}_{t} \Delta B_{t}^{\mathrm{EU}}$ and $\mathcal{E}_{t} \hat{Q}_{t} \Delta A_{t}^{\mathrm{EU}}$. These statistics show that the presence of collateral constraints has little impact on the volatility of savings. This is consistent with the similarity of the impulse responses for consumption, dividends and trade flows across in the different equilibria depicted in Figures 1-3. Households find it optimal in the presence of collateral constraints to approximate the real consumption and savings decisions they would make under complete markets. The constraints play a larger role on households' financial decisions. As the ratios in column (iv) show, the volatility of the U.S. foreign asset position is approximately 20 percent higher when the constraints are present. By definition $f a_{t}=\ln \alpha_{t}^{\mathrm{FA}}+w_{t}-c_{t}$, so the higher volatility in $f a_{t}$ induced by frictions reflects more variability in households' choice for $\alpha_{t}^{\mathrm{FA}}$. In fact the standard deviations of both the foreign asset and domestic equity portfolio shares are approximately 15 percent higher in the benchmark equilibrium. The presence of collateral constraints also raises the standard deviations of U.S. capital outflows by approximately 10 percent. Bond flows are more volatile than equity flows in both equilibria because the share of E.U. equities in U.S. foreign assets is fixed at $\wp=0.42$. The volatility of equity outflows is higher than bond outflows in equilibria with $\wp>0.5$.

The statistics in Panel B identify the contribution of U.S. households' portfolio reallocation decisions to U.S. capital outflows. Recall from equations (35) and (36) that a portion of the equity and bond outflow, $\mathcal{E}_{t} \hat{Q}_{t} \Delta A_{t}^{\mathrm{EU}}$ and $\mathcal{E}_{t} \Delta B_{t}^{\mathrm{EU}}$, can be attributed to the change in the portfolio share $\alpha_{t}^{\mathrm{FA}}:$ i.e., $\Delta \alpha_{t}^{\mathrm{FA}} \wp\left(W_{t}-C_{t}\right)$ and $\Delta \alpha_{t}^{\mathrm{FA}}(1-\wp)\left(W_{t}-C_{t}\right)$. Panel B reports the variance contributions of these so-called "return chasing contributions" to the bond and equity outflows. Even though these components are perfectly correlated across the flows, their variance contributions are quite different because the effects of capital gains and losses on pre-existing foreign bond and equity positions differs. Notice, also that the variance decompositions are almost identical across the two equilibria. The presence of collateral constraints raise the volatility of capital outflows but has little affect on the role played by portfolio reallocations. ${ }^{29}$

We can study the role of capital flows in the external adjustment process in greater detail with the aid of Figure 4. Here I plot the impulse responses of U.S. and E.U. bond and equity holdings following the endowment and risk shocks. Each panel shows the percent deviation from the steady state holdings. For example, Panel A plots the deviations in U.S. holdings of U.S. bonds, $100 \times\left(B_{t}^{\text {us }}-\bar{B}_{t}^{\text {us }}\right) / \bar{B}_{t}^{\text {us }}$, and the deviations in E.U. holdings of E.U. bonds, $100 \times\left(\hat{B}_{t}^{\mathrm{EU}}-\overline{\hat{B}}_{t}^{\mathrm{EU}}\right) / \overline{\hat{B}}_{t}^{\mathrm{EU}}$, where bars indicate steady state values. As above, the upper and lower panels show the responses following the endowment and risk shocks, with solid and dashed lines indicating the responses in the benchmark and complete markets equilibria, respectively.

Two features of the plots in Figure 4 immediately stand out: First, the changes in bond and equity positions following endowment shocks are extremely small and are far smaller than the changes induced by the risk shocks. Since $\mathcal{E}_{t} \hat{Q}_{t} \Delta A_{t}^{\mathrm{EU}}, \mathcal{E}_{t} \Delta B_{t}^{\mathrm{EU}},\left(Q_{t} / \mathcal{E}_{t}\right) \Delta \hat{A}_{t}^{\mathrm{US}}$ and $\left(1 / \mathcal{E}_{t}\right) \Delta \hat{B}_{t}^{\mathrm{US}}$ represent U.S. capital outflows

\footnotetext{
${ }^{29}$ These variance decomposition results are similar to the findings reported elsewhere in the literature. For example, Tille and van Wincoop (2010) find that changes in portfolio shares are an important driver of flows following endowment shocks in a model where only equity is traded internationally. Similarly, Evans and Hnatkovska (2005) show that the return chasing component contributes most to the variance of bond and equity flows driven by productively shocks in a model with incomplete markets.
} 
and inflows for equities and bonds, the capital flows produced by endowment shocks must be very small. Indeed, it turns out that endowment shocks account for less than one percent of the variance in bond and equity flows produced by simulations of the benchmark and complete markets equilibria. Thus, capital flows appear to play an insignificant role in the adjustment process following endowment shocks.

The economic intuition behind this result is straightforward. Endowments shocks are typically too small to affect equilibrium risk premia so households keep their portfolio shares constant. ${ }^{30}$ As a consequence, when the shock hits U.S. households issue more domestic bonds to balance the capital gains on their preexisting domestic equity and foreign asset positions. The corresponding change in the U.S. and E.U. bond positions are shown in panels $\mathrm{A}$ and $\mathrm{B}$ of Figure 4. This small bond flow is sufficient to finance the initial U.S. current account deficit that follows the endowment shock. It is then reversed as U.S. households buy back the their bonds with the proceeds of higher domestic dividends.

The second striking feature in Figure 4 appears in the lower panels. Here we see that the initial changes in the foreign bond and equity positions produced by risk shocks are economically large, and are approximately twice the size when collateral constraints are present. These position changes are an important driver of bond and equity capital flows. In particular, the plots in panels $\mathrm{F}$ and $\mathrm{H}$ show that risk shocks induce sharp initial falls in foreign bond and equity positions of both U.S. and E.U. households. They therefore represent large positive bond and equity foreign capital outflows across the world economy.

To understand the source of these capital flows, recall that the U.S. risk shock produces a real appreciation of the dollar and a fall in the domestic value of E.U. equity. Thus, E.U. equity holdings contribute more to the capital loss U.S. households sustain on their foreign asset portfolio than do E.U. bonds. If households were free to choose the composition of their foreign asset portfolio, the risk shock would produce a larger risk premium on foreign equity than bonds to compensate U.S. households for their inferior hedging properties in the face of future risk shocks. However, since the composition of the portfolio is fixed (i.e., $\wp=0.42$ ), the risk shock raises the risk premium on the foreign portfolio instead, $r p_{t}^{\mathrm{FA}}$. In the absence of collateral constraints, this rise in $r p_{t}^{\mathrm{FA}}$ under-compensates U.S. households for the risk associated with holding E.U. equity, so they reduce their exposure to foreign assets by lowering $\alpha_{t}^{\mathrm{FA}} \cdot{ }^{31}$ When coupled with the fall in U.S. saving, this portfolio reallocation produces an eight percent fall in U.S. holdings of foreign bonds and equity, as shown by the dashed black plots in panels $\mathrm{F}$ and $\mathrm{H}$ of Figure 4. E.U. households reduce their foreign asset holdings for the similar reason. Recall that the U.S. risk shock lowers the E.U. foreign asset risk premium $\widehat{r p}_{t}^{\mathrm{FA}}$. This lower premium under-compensates E.U. households the risk associated with holding U.S. equity, so they lower their exposed to foreign assets by reducing $\hat{\alpha}_{t}^{\mathrm{FA}}$. Although E.U. households savings remain relatively stable (because the capital loss on U.S. equity is offset by the exchange rate), the fall in $\hat{\alpha}_{t}^{\mathrm{FA}}$ and appreciation of the dollar produce a fall in E.U. holdings of U.S. bonds of approximately 12 percent.

Collateral constraints amplify the effects of the risk shocks on capital flows. The U.S. risk shock produces capital losses on pre-existing U.S. equity and foreign asset positions as well as a desired portfolio reallocation

\footnotetext{
${ }^{30}$ Of course it is possible that an endowment shock hits when households are already close to their collateral constraints so that the equilibrium risk premia and portfolio shares change. Under these circumstances, the shock would produce a more complex pattern of capital flows, but the simulations indicate that such patterns are very rare.

${ }^{31}$ Because the risk shock increases the local curvature of U.S. utility, households are more concerned about the undercompensation for equity risk than over-compensation for bond risk in the foreign portfolio.
} 


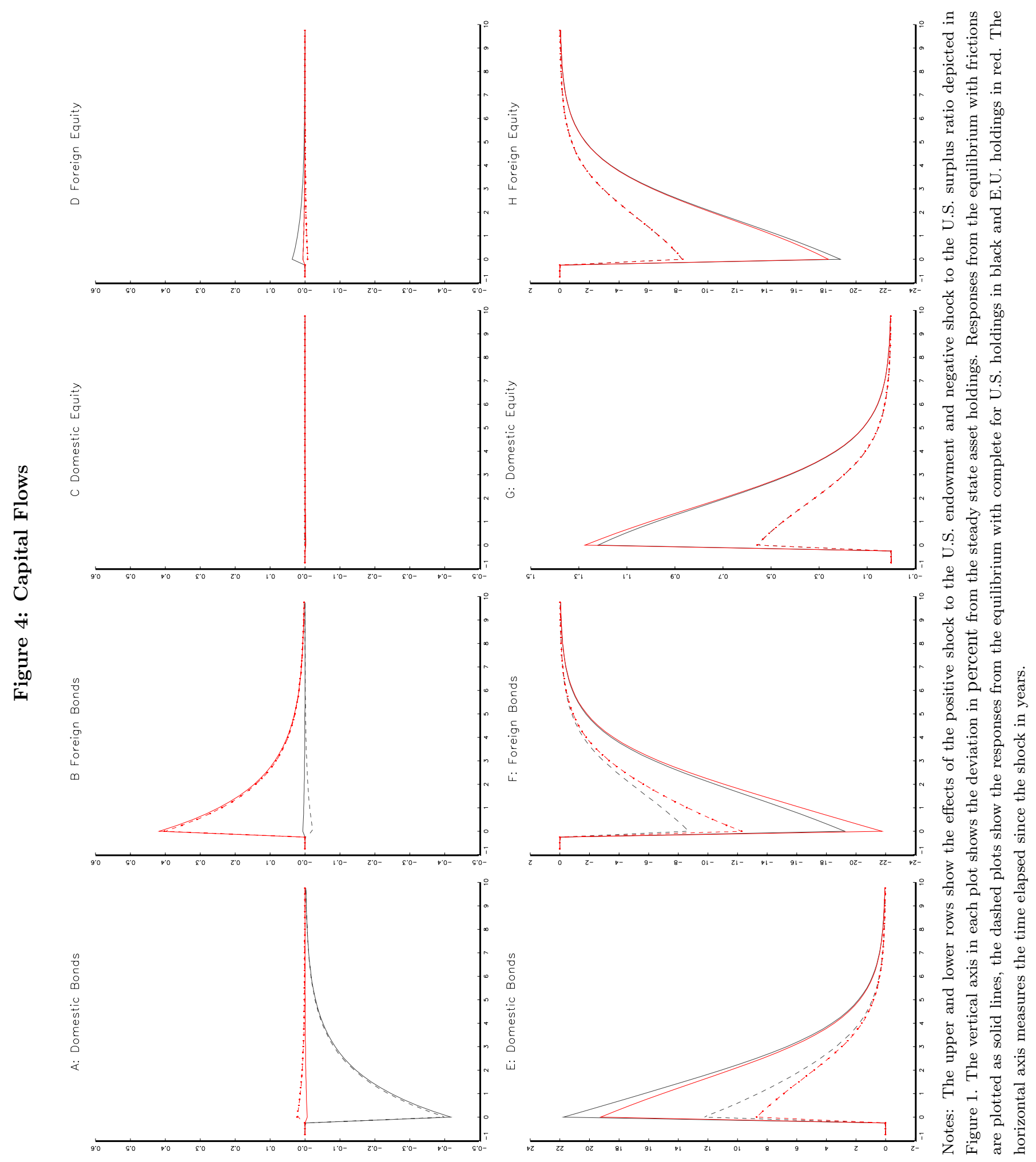


that lowers $\alpha_{t}^{\mathrm{FA}}$. Together, these effects lower the value of foreign asset holdings that can be used as collateral when issuing U.S. bonds. In response, U.S. households sell a larger fraction of their foreign asset portfolio in order to buy back more outstanding U.S. bonds. These actions produce the larger U.S. capital outflows depicted in panels $\mathrm{F}$ and $\mathrm{H}$ of Figure 4. The reallocation of E.U. portfolios has a similar collateral effect on E.U. outflows. In this case the fall in $\hat{\alpha}_{t}^{\mathrm{FA}}$ reduces the value of foreign assets available for E.U. households to use when issuing E.U. bonds. And, as a result, E.U. households sell foreign assets to buy back previously issued domestic bonds. As Figure 4 shows, the size of the E.U. bond and equity outflows produced by these transactions are very similar to their U.S. counterparts.

Table 7: U.S. Asset and Liability Position Changes

\begin{tabular}{ccccc}
\hline \hline & Equity Assets & Debt Assets & $\begin{array}{c}\text { Equity } \\
\text { Liabilities }\end{array}$ & Debt Liabilities \\
\hline Equity Assets & & 0.682 & 0.903 & 0.440 \\
Debt Assets & 0.399 & 0.298 & 0.611 & 0.847 \\
Equity Liabilities & 0.877 & 0.617 & -0.062 & 0.383 \\
Debt Liabilities & -0.015 & & & \\
\end{tabular}

Notes: The table reports correlations between changes in U.S. foreign asset and liability positions at the annual frequency above and quarterly frequency below the leading diagonal. All positions are valued at market prices converted to constant dollars. Correlations are computed from the 1973:I-2007:IV sample period.

Finally, it is instructive to compare the dynamics of foreign asset and liability holdings in the model with actual changes in U.S. foreign asset and liability positions. Table 7 reports the correlations between quarterly and annual changes in gross U.S. asset and liability positions in equity and debt in the post Bretton-Woods era. Here we see that annual changes in gross positions are positively correlated across assets and liabilities and across debt and equity. At the quarterly frequency the correlations are smaller, and slightly negative for equities with debt liabilities. ${ }^{32}$ In contrast, changes in foreign equity and bond holdings are perfectly correlated in the model because households cannot change the composition of their foreign asset portfolios. The correlations in Table 7 indicate the presence of some "stickiness" in the composition of U.S. foreign asset and liability portfolios, but the reallocation friction in the model is too restrictive to accurately account for this aspect of the data.

\footnotetext{
${ }^{32}$ Coeurdacier, Kollmann, and Martin (2010) examine correlations of annual changes between net foreign equity positions and bond positions. They report an average correlation across the G-7 countries of -0.27 and in the U.S. -0.09. In these data the net correlations are 0.186 and -0.135 at the quarterly and annual frequency, respectively. Interpreting these net correlations is tricky because, as Table 7 shows, the correlations between equity and debt asset positions differ from the correlation between equity and debt liability positions at the quarterly and annual frequencies.
} 


\section{Conclusion}

In this paper I developed a new open economy macro model to study the role of hot money capital flows in the international adjustment process. The model contains a novel combination of features (i.e., external habits, financial frictions, portfolio choice and incomplete risk-sharing) that can replicate key features of international data when risk shocks are the dominant drivers international adjustment. My analysis of the

model reveals that hot money capital flows are an integral part of the external adjustment process following risk shocks. This process produces variations in the value of a country's net foreign asset position that mainly reflect revisions in expected future return differentials between foreign assets and liabilities, i.e. via the valuation channel. Consistent with this implication of the model, I also find that forecasts of future return differentials contribute most to the volatility of the U.S. net foreign asset position in the post Bretton-Woods era.

Overall, these findings provide a different perspective to the view that hot money flows are a source of international instability. Admittedly, the model rules out the possibility that domestic production can be adversely affected by capital outflows, which is a real concern for some countries. On the other hand, my analysis does show that hot money flows can be part of an empirically relevant international adjustment process that allows households to fund consumption paths that approximate the paths under complete markets. In this sense, the portfolio reallocations that drive hot money flows facilitate a level of international risk-sharing that would otherwise be impossible in the presence of financial frictions. Of course, the question of how these risk-sharing benefits of hot money flows stack up against the costs of potential instability remains open.

\section{References}

Abel, A. B. (1990): "Asset Prices under Habit Formation and Catching Up with the Joneses," American Economic Review, 80(2), 38-42.

Backus, D. K., and G. W. Smith (1993): "Consumption and Real Exchange Rates in Dynamic Exchange Economies with Nontraded Goods," Journal of International Economics, 35(3-4), 297-316.

Bansal, R., and I. Shaliastovich (2010): "A Long-Run Risks Explanation of Predictability Puzzles in Bond and Currency Markets," Discussion paper, Fuqua School of Business, Duke University.

Bansal, R., And A. Yaron (2004): "Risks for the long run: A potential resolution of asset pricing puzzles," The Journal of Finance, 59(4), 1481-1509.

Baxter, M., U. J. Jermann, and R. G. King (1998): "Nontraded Goods, Nontraded Factors, and International Non-diversification," Journal of International Economics, 44(2), 211-229.

Bekaert, G., E. Engstrom, and Y. Xing (2009): "Risk, uncertainty, and asset prices," Journal of Financial Economics, 91(1), 59-82. 
Bohn, H., and L. L. Tesar (1996): "U.S. Investment in Foreign Markets: Portfolio Rebalancing or Return Chasing?," American Economic Review, Papers and Proceedings, 86(2), 77-81.

Boldrin, M., L. J. Christiano, and J. D. M. Fisher (2001): "Habit Persistence, Asset Returns, and the Business Cycle," The American Economic Review, 91(1), pp. 149-166.

Brunnermeier, M. K., T. M. Eisenbach, and Y. Sannikov (2012): "Macroeconomics with Financial Frictions: A Survey," Working Paper 18102, National Bureau of Economic Research.

Buraschi, A., And A. Jiltsov (2007): "Habit Formation and Macroeconomic Models of the Term Structure of Interest Rates," The Journal of Finance, 62(6), 3009-3063.

Campa, J. M., and L. S. Goldberg (2008): "Pass-Through of Exchange Rates to Consumption Prices: What Has Changed and Why?," in International Financial Issues in the Pacific Rim: Global Imbalances, Financial Liberalization, and Exchange Rate Policy (NBER-EASE Volume 17), NBER Chapters, pp. 139-176. National Bureau of Economic Research, Inc.

Campbell, John Y., A. W. L., and A. C. MacKinlay (1997): The econometrics of financial markets. Princeton Univ Press.

Campbell, J. Y., and J. H. Cochrane (1999): "By force of habit: A consumption-based explanation of aggregate stock market behavior," Journal of Political Economy, 107(2), 205-251.

Campbell, J. Y., and L. M. Viceira (2002): Strategic Asset Allocation. Oxford University Press.

Chan, Y. L., and L. Kogan (2002): "Catching Up with the Joneses: Heterogeneous Preferences and the Dynamics of Asset Prices," Journal of Political Economy, 110(6), pp. 1255-1285.

Clatessens, S., M. P. Dooley, and A. Warner (1995): "Portfolio Capital Flows: Hot or Cold?," The World Bank Economic Review, 9(1), 153-174.

Coeurdacier, N., and P.-O. Gourinchas (2008): "When Bonds Matter: Home Bias in Goods and Assets," Working Paper Series 2008-25, Federal Reserve Bank of San Francisco.

Coeurdacier, N., R. Kollmann, and P. Martin (2010): "International portfolios, capital accumulation and foreign assets dynamics," Journal of International Economics, 80(1), 100-112.

Coeurdacier, N., and H. Rey (2012): "Home Bias in Open Economy Financial Macroeconomics," Journal of Economic Literature, 51(1), 63-115.

Coeurdacier, N., H. Rey, and P. Winant (2011): "The risky steady state," American Economic Review, 101(3), 398-401.

Colacito, R., and M. M. Croce (2011): "Risks for the Long Run and the Real Exchange Rate," Journal of Political Economy, 119(1), 153-181. 
Constantinides, G. M. (1990): "Habit Formation: A Resolution of the Equity Premium Puzzle," Journal of Political Economy, 98(3), pp. 519-543.

Corsetti, G., L. Dedola, and S. Leduc (2008): "International Risk Sharing and the Transmission of Productivity Shocks," Review of Economic Studies, 75(2), 443-473.

Corsetti, G., And P. T. Konstantinou (2012): "What Drives US Foreign Borrowing? Evidence on the External Adjustment to Transitory and Permanent Shocks," American Economic Review, 102(2), 1062-92.

Detemple, J. B., and F. Zapatero (1991): "Asset prices in an exchange economy with habit formation," Econometrica, pp. 1633-1657.

Devereux, M. B., And A. Sutherland (2010a): "Country portfolio dynamics," Journal of Economic Dynamics and Control, 34(7), $1325-1342$.

Devereux, M. B., and A. Sutherland (2010b): "Solving for Country Portfolios in Open Economy Macro Models," Journal of the European Economic Association, forthcoming.

ENGEL, C. (1996): "The forward discount anomaly and the risk premium: A survey of recent evidence," Journal of Empirical Finance, 3(2), 123-192.

Engel, C. (1999): "Accounting for US Real Exchange Rate Changes," Journal of Political Economy, 107(3), 507.

Engel, C. (2013): "Exchange Rates and Interest Parity," vol. 4 of Handbook of International Economics. Elsevier.

Engel, C., and A. Matsumoto (2009): "The International Diversification Puzzle When Goods Prices Are Sticky: It's Really about Exchange-Rate Hedging, Not Equity Portfolios," American Economic Journal: Macroeconomics, 1(2), 155-88.

Evans, M. D. D. (2011): Exchange-Rate Dynamics, Princeton Series in International Finance. Princeton University Press.

_ (2012a): "Exchange-Rate Dark Matter," IMF Working Paper 12/66, International Monetary Fund.

_ (2012b): "International Capital Flows and Debt Dynamics," IMF Working Paper 12/175, International Monetary Fund.

Evans, M. D. D., And V. Hnatkovska (2005): "International Capital Flows, Returns and World Financial Integration," Working Paper 11701, National Bureau of Economic Research.

Evans, M. D. D., And V. Hnatkovska (2007): "International financial integration and the real economy," IMF Staff Papers, 54(2), 220-269.

Evans, M. D. D., And V. Hnatkovska (2012): "A method for solving general equilibrium models with incomplete markets and many financial assets," Journal of Economic Dynamics and Control, 36(12), 1909 $-1930$. 
Ferson, W. E., and G. M. Constantinides (1991): "Habit persistence and durability in aggregate consumption: Empirical tests," Journal of Financial Economics, 29(2), 199 - 240.

Forsgren Anders, P. G., And M. Wright (2002): "Interior Methods for Nonlinear Optimization," SIAM Review, 44, 525-597.

Froot, K. A., P. G. J. O'Connell, and M. S. Seasholes (2001): "The portfolio flows of international investors," Journal of Financial Economics, 59(2), 151-193.

Froot, K. A., And M. Teo (2004): "Equity Style Returns and Institutional Investor Flows," NBER Working Papers 10355, National Bureau of Economic Research, Inc.

Gourinchas, P.-O., And H. Rey (2005): "From World Banker to World Venture Capitalist: US External Adjustment and the Exorbitant Privilege," Working Paper 11563, National Bureau of Economic Research.

Gourinchas, P.-O., And H. Rey (2007): "International financial adjustment," Journal of Political Economy, 115(4), 665-703.

Gourinchas, P.-O., And H. Rey (2013): "External Adjustment, Global Imbalances, Valuation Effects," Handbook of International Economics, 4.

Hau, H., and H. Rey (2004): "Can Portfolio Rebalancing Explain the Dynamics of Equity Returns, Equity Flows, and Exchange Rates?," American Economic Review Papers and Proceedings, 94(2), 126-133.

Hau, H., and H. Rey (2006): "Exchange Rates, Equity Prices, and Capital Flows," Review of Financial Studies, 19(1), 273-317.

Heaton, J. (1995): "An Empirical Investigation of Asset Pricing with Temporally Dependent Preference Specifications," Econometrica, 63(3), pp. 681-717.

Heyerdahl-Larsen, C. (2012): "Asset Prices and Real Exchange Rates with Deep Habits," manuscript, London Business School.

Hnatkovska, V. (2010): "Home bias and high turnover: Dynamic portfolio choice with incomplete markets," Journal of International Economics, 80(1), 113 - 128.

Jeanne, O., And A. Korinek (2010): "Managing Credit Booms and Busts: A Pigouvian Taxation Approach," Working Paper 16377, National Bureau of Economic Research.

Jermann, U. J. (1998): "Asset pricing in production economies," Journal of Monetary Economics, 41(2), $257-275$.

JudD, K. L., And S.-M. GuU (2001): "Asymptotic methods for asset market equilibrium analysis," Economic Theory, 18(1), 127-157.

Kazimov, K. (2010): "Comparing Methods for Solving GE Models with Portfolio Choice," manuscript, Georgetown University. 
Kim, Sunghyun H., R. K., And J. Kim (2010): "Solving the incomplete market model with aggregate uncertainty using a perturbation method," Journal of Economic Dynamics and Control, 34(1), 50-58.

LEwis, K. K. (1995): "Puzzles in international financial markets," in Handbook of International Economics, ed. by G. M. Grossman, and K. Rogoff, vol. 3 of Handbook of International Economics, chap. 37, pp. 1913-1971. Elsevier.

(2011): "Global Asset Pricing," Working Paper 17261, National Bureau of Economic Research.

Lucas, Robert E., J. (1990): "Why Doesn't Capital Flow from Rich to Poor Countries?," The American Economic Review, 80(2), pp. 92-96.

MendozA, E. G. (2010): "Sudden Stops, Financial Crises, and Leverage," The American Economic Review, 100(5), 1941-1966.

Menzly, L., T. Santos, and P. Veronesi (2004): "Understanding Predictability," Journal of Political Economy, 112(1), pp. 1-47.

Moore, M. J., And M. J. Roche (2010): "Solving exchange rate puzzles with neither sticky prices nor trade costs," Journal of International Money and Finance, 29(6), 1151-1170.

Obstfeld, M., And K. S. Rogoff (1995): "The intertemporal approach to the current account," vol. 3 of Handbook of International Economics, pp. 1731-1799. Elsevier.

Pavlova, A., and R. Rigobon (2008): "Equilibrium portfolios and external adjustment under incomplete markets," manuscript, London Business School.

Preston, B., And M. Roca (2007): "Incomplete Markets, Heterogeneity and Macroeconomic Dynamics," Working Paper 13260, National Bureau of Economic Research.

Reinhart, C. M., and V. R. Reinhart (2008): "Capital Flow Bonanzas: An Encompassing View of the Past and Present," Working Paper 14321, National Bureau of Economic Research.

Santos, T., and P. Veronesi (2010): "Habit formation, the cross section of stock returns and the cash-flow risk puzzle," Journal of Financial Economics, 98(2), 385 - 413.

Schmitt-Grohe, S., And M. URIBe (2003): "Closing small open economy models," Journal of International Economics, 61(1), 163-185.

Stathopoulos, A. (2012): "Asset prices and risk sharing in open economies," manuscript, University of Southern California, Marshall School of Business.

Stepanchuk, S., and V. Tsyrennikov (2013): "International Portfolios: A Comparison of Solution Methods," Mimeo, Vienna University of Economics and Business.

Sundaresan, S. M. (1989): "Intertemporally dependent preferences and the volatility of consumption and wealth," Review of financial Studies, 2(1), 73-89. 
Tille, C., And E. van Wincoop (2010): "International Capital Flows," Journal of International Economics, 80(2), 157-175.

Verdelhan, A. (2010): "A Habit-Based Explanation of the Exchange Rate Risk Premium," The Journal of Finance, 65(1), 123-146.

White, H. (1980): "A heteroskedasticity-consistent covariance matrix estimator and a direct test for heteroskedasticity," Econometrica, pp. 817-838. 


\section{A Web Appendix (Not For Publication).}

\section{A.1 U.S. Net Foreign Asset Positions and Returns}

The empirical analysis uses data on the market value of U.S. foreign asset and liability positions and their associated returns at the quarterly frequency. These data come from an extension of the dataset first constructed by Gourinchas and Rey (2007), (hereafter G\&R). In the Appendix of their paper, G\&R provide a detailed description of how they compute the market value of U.S. asset and liability positions. I follow their detailed description to extend each data series to 2007:IV (using revised data when available). Below I provide an overview of how the data were constructed (drawing heavily on G\&R).

\section{Data Sources}

Information on the U.S. asset and liability positions comes from four primary sources: the U.S. Department of Commerce's Bureau of Economic Analysis (BEA), the Federal Reserve Flows of Funds accounts (FFA), the Global Financial Database (GFD) and the IMF's International Financial Statistics (IFS).

Since 1976 the BEA provides data in its International Investment Position of the United States (IIP) on the end-of-year positions for gross assets and liabilities for four categories: Equity, Foreign Direct Investment (FDI), Debt (corporate and government bonds), and Other (mostly bank loans and trade credits). The BEA also reports quarterly flow data in the U.S. International Transactions (USIT) tables since 1960 for some flow series and since 1982 for others. The FFA contain information on quarterly flows and positions for the "rest of the world" since 1952. Although these data cover a longer sample period, the data on Debt, FDI, and Other are recorded at historical cost rather than market value. Furthermore, the FFA uses NIPA concepts that differ subtly from their BOP equivalents employed by the BEA. G\&R provide a detailed description of how these accounting concepts are reconciled so that the FFA data can be used to supplement the BEA position data. Market returns for the four classes of U.S. foreign assets and liabilities are computed using equity returns, interest rates, and exchange-rate data from the GFD and IFS.

\section{Positions Calculations}

Let $F A_{j, t}$ and $F L_{i, t}$ denote the dollar value of the end-of-quarter $t$ position for U.S. foreign asset $j$ and foreign liability $i$, respectively. Positions are updated according

$$
F A_{j, t}=F A_{j, t-1}+F l o w_{j, t}+D i s_{j, t}, \quad \text { and } \quad F L_{i, t}=F L_{i, t-1}+F l o w_{i, t}+D i s_{i, t}
$$

where $F l o w_{j, t}$ and $F l o w_{i, t}$ denote the period- $t$ flows that enter the balance of payments for asset $j$ and liability $i$; while $D i s_{j, t}$ and $D i s_{i, t}$ are the discontinuities reflecting a market valuation adjustment between the end of quarters $t-1$ and $t$. In the first three quarters of each year the discontinuities are computed from estimates of the capital gains on existing positions: i.e., $D i s_{j, t}=\mathcal{K}_{j, t} F A_{j, t-1}$ and $D i s_{i, t}=\mathcal{K}_{i, t} F L_{i, t-1}$, where $\mathcal{K}_{j, t}$ and $\mathcal{K}_{i, t}$ are the dollar capital gains for asset $j$ and liability $i$ during quarter $t$. These capital gains are computed directly from market data (see below). In the last quarter of each year, the discrepancies 
reconcile the position and flow data from the IIP with the accrued position from flows and capital gains in the previous three quarters: e.g., Dis $s_{j, t}=F A_{j, t}-F l o w_{j, t}-F A_{j, t-1}$. This procedure insures that the position data for each asset and liability category match the IIP data at an annual frequency.

The following series are used to compute the quarterly flow data:

- Asset Equity: After 1982:I, BEA USIT Table 7b, line A2 before 1998:I, then USIT Table 7a, line A4.

- Asset Debt: After 1982:I, BEA USIT Table 7b, line A13 before 1998:I, then USIT Table 7a, line A18.

- Asset FDI: BEA USIT Table 1, line 51.

- Asset Other: The residual from total BEA asset flows: total assets (USIT Table 1, line 40, U.S. owned assets abroad) minus Equity, Debt, and FDI flows.

- Liability Equity: The sum of BEA equity (SCB before 1982:I, USIT Table 7b line B2 between 1982:I and 1998:I, Table 7a line B4 after) and equity held by foreign officials (SCB before 1982:I, USIT Table 7b line memo 4 before 1998:I and Table 7a line memo 4 after).

- Liability Debt: After 1982:I, the sum of private foreign holdings of U.S. corporate and federally sponsored agency bonds (USIT Table 7b line 10 before 1998, Table 7a line 16 and 30) and foreign official holdings of U.S. government securities (USIT Table 1 line 57) and foreign private holdings of U.S. Treasury securities (USIT Table 1 line 65) and corporate and agency bonds held by foreign official agencies (USIT Table 7b line memo 3 before 1998, table 7a memo 3 after 1998). Before 1982, FFA government securities (Table F107.19, FU263061005.Q, U.S. government securities) plus U.S. corporate bonds (Table F107.26, FU263063005.Q, until 1992 including net issues by Netherland Antillean financial subsidiaries of U.S. corporations) minus net issues of corporate bonds from Netherland Antillean financial subsidiaries of U.S. corporations.

- Liability FDI: After 1976:IV, from BEA direct investment (USIT Table 1 line 64). Before 1976:IV the series are adjusted upwards for discontinuity in coverage (see G\&R for details).

- Liability Other: After 1982:I defined as residual from total BEA liabilities: total liabilities (USIT Table 1 line 55) minus Debt, Equity and FDI. Between 1960Q1 and 1981Q4, defined as 3 BEA liabilities minus FFA debt and FFA equity.

The following series are used to compute the year-end positions:

- Asset Equity: After 1976, positions from BEA IIP Table 2 line 21 (corporate stocks, including results from the U.S. Treasury's 1994 and 1997 Benchmark Surveys of U.S. Ownership of Foreign Long-term Securities). Before 1976, positions available from Survey of Current Business (paper version).

- Asset Debt: After 1976, positions from BEA IIP Table 2 line 20 (Bonds, including results from the U.S. Treasury's 1994 and 1997 Benchmark Surveys of U.S. Ownership of Foreign Long-term Securities). Before 1976, positions available from Survey of Current Business (paper version). 
- Asset FDI: After 1980 from IMF IIP (line B8505@C111) equivalent to BEA IIP Table 2 line 18 (but BEA only available after 1982).

- Asset Other: After 1976. IIP Table 2 line 5 (U.S. official reserve assets) minus line 6 (Gold) plus line 10 ( U.S. Government assets, other than official reserve assets) plus line 22 ( U.S. claims on unaffiliated foreigners reported by U.S. non-banking concerns) and line 23 ( U.S. claims reported by U.S. banks, not included elsewhere). The levels do not include Gold reserves.

- Liabilities Equity: After 1980, positions from IMF IIP (B8660@C111). The IMF data includes equity holdings by foreign official agencies. Before 1980, comparison of the BEA IIP Table 40 (corporate stocks) show that foreign official holdings are 0. Before 1976, positions available from Survey of Current Business (paper version).

- Liabilities Debt: After 1980, positions from IMF IIP (B8669@C111). Includes foreign official agencies holdings of corporate bonds (reported separately in BEA IIP). Between 1976 and 1981, from BEA IIP (Table 2) line 27 (foreign official holdings of U.S. government securities) plus line 37 (foreign private holdings of U.S. Treasuries) plus line 39 (foreign private holdings of corporate and other bonds) plus line 32 (foreign official holdings of other assets). Between 1971 and 1976, same positions available from Survey of Current Business (paper version).

- Liabilities FDI: From IMF IIP (B8555@C111), at market value, identical to BEA IIP (Table 2 line 36 ) after 1982.

- Liabilities Other: After 1976, from BEA IIP. Table 2 line 30 (Other U.S. Government liabilities) and line 31 (U.S. liabilities reported by U.S. banks, not included elsewhere) and line 41 (U.S. currency) and line 42 (U.S. liabilities to unaffiliated foreigners reported by U.S. non-banking concerns) and line 43 (U.S. liabilities reported by U.S. banks, not included elsewhere).

\section{Return Calculations}

The returns and capital gains on the asset and liability categories are computed from the portfolio-weighted averages of the returns and capital gains on the individual securities that comprise each category at the quarterly frequency. The portfolio shares for the underlying securities come from U.S. Treasury reports on U.S. holdings of foreign securities and foreign portfolio holdings of U.S. securities. Linear interpolation is used to compute the portfolio shares between reports. All returns and capital gains are converted into U.S. dollars at the end-of-period spot exchange rate.

Once the returns for each category of assets and liabilities have been computed, returns on the U.S. aggregate foreign asset and liability are calculated as $R_{t}^{\mathrm{FA}}=\sum_{j} \alpha_{j, t-1}^{\mathrm{A}} R_{j, t}^{\mathrm{A}}$ and $R_{t}^{\mathrm{FL}}=\sum_{i} \alpha_{i, t-1}^{\mathrm{L}} R_{i, t}^{\mathrm{L}}$ where; $R_{j, t}^{\mathrm{A}}$ is the (gross) dollar return on asset category $j$ between the end of quarters $t-1$ and $t$, and $R_{i, t}^{\mathrm{L}}$ is the corresponding return on liability category $i$. The portfolio shares for each category of asset and liability are defined by $\alpha_{j, t}^{\mathrm{A}}=F A_{j, t} / F A_{t}$ and $\alpha_{i, t}^{\mathrm{L}}=F L_{i, t} / F L_{t}$ where $F A_{t}=\sum_{j} F A_{j, t}$ and $F L_{t}=\sum_{i} F L_{i, t}$. Table 3 reports statistics for returns on assets and liabilities for "equity" and "debt". In this context, the 
"equity" returns are represented by the returns on the BEA categories of Equity and FDI, while "debt" returns are represented by the return on the BEA categories of Debt and Other. Returns are computed as the weighted averages of the returns on the BEA Equity and FDI categories and the Debt and Other categories, respectively, using the relative shares of Equity and FDI (Debt and Other) to compute the weights. For example, "equity" asset returns are computed by $R_{t}=\lambda_{t-1}^{\mathrm{EQ}} R_{t}^{\mathrm{EQ}}+\left(1-\lambda_{t-1}\right) R_{t}^{\mathrm{FDI}}$ where $\lambda_{t}=$ $F A_{\mathrm{EQ}, t} /\left(F A_{\mathrm{EQ}, t}+F A_{\mathrm{FDI}, t}\right), R_{t}^{\mathrm{EQ}}$ and $R_{t}^{\mathrm{FDI}}$ are the returns on the BEA Equity and FDI categories, with $F A_{\mathrm{EQ}, t}$ and $F A_{\mathrm{FDI}, t}$ their respective positions.

Returns and capital gains are computed as follows for each BEA category:

- Assets Equity: Total returns and capital gains on equities are computed at the quarterly frequency for the following countries: United Kingdom, Japan, France, The Netherlands, Germany, Canada, Sweden, Switzerland, Italy, Mexico Australia and Brazil. Local returns and capital gains are converted into U.S. dollars with end-of-quarter spot exchange rates, i.e. $R_{\mathrm{EQ}, t}^{n}$ and $\mathcal{K}_{\mathrm{EQ}, t}^{n}$ for country $n$. (For countries in the Euro area spot rates are computed as the synthetic bi-lateral rates from the USD/EUR after 1990.) Returns and capital gains on U.S. foreign equity assets are computed as $R_{\mathrm{EQ}, t}^{\mathrm{A}}=\sum_{n} \alpha_{\mathrm{EQ}, t-1}^{n} R_{\mathrm{EQ}, t}^{n}$ and $\mathcal{K}_{\mathrm{EQ}, t}^{\mathrm{A}}=\sum_{n} \alpha_{\mathrm{EQ}, t-1}^{n} \mathcal{K}_{\mathrm{EQ}, t}^{n}$. The country weights, $\alpha_{\mathrm{EQ}, t}^{n}$, are calculated by linear interpolation from the U.S. Treasury's report on U.S. holdings of foreign long-term securities. The series used to compute the returns and capital gains in each country are documented in G\&R.

- Assets Debt: The return is computed as a weighted average of the total return on long-term bonds and total return on short-term bonds. Maturity composition: $75 \%$ long term, $25 \%$ short term, from Table 2 and Table 3 in 2002 treasury report on U.S. foreign portfolio holdings. The long-term return is computed as weighted average dollar holding period return on foreign long-term bonds. The currency weights are taken from the U.S. Treasury surveys of U.S. long-term portfolio holdings of foreign securities (Table 11). The currency weights cover: the U.S. Dollar, Yen, Canadian Dollar, German DMark, U.K. Pound and French Franc. Quarterly returns are calculated from the changes in yields (assuming that yield=coupon and using the formula (10.1.19) in Campbell and MacKinlay 1997, p408) converted into U.S. dollars. The short-term return are computed as a weighted average dollar holding period return on foreign short term bonds. The currency weights are taken from the U.S. Treasury survey of U.S. long term portfolio holdings of foreign securities (Table 14). Capital gains are computed from long-term bond holdings only, using the same country weights as returns. The capital gain is computed as the net rather than total return: i.e. $\ln \left(R_{t}^{\mathrm{NET}}\right)=\ln \left(R_{t}\right)-\ln \left(1+y l d_{t}\right)$, where $R_{t}^{\mathrm{NET}}$ is the net return, $R_{t}$ is the total return and $y l d_{t}$ is the yield. Local net returns are converted into U.S. dollars using the end-of-quarter exchange rate.

- Assets FDI: Returns are constructed using rolling country weights based on BEA's FDI historical cost positions covering, in total, 75 percent of the total position. For each country, total stock return (in dollars) is computed from GFD total return indices and end-of-period exchange rates. Capital gains are computed using the same country weights with composite equity indices and end-of-period exchange rates. 
- Assets Other: Returns equal the returns on short-term debt. No capital gains.

- Liabilities Equity: Returns are computed from S\&P 500 Composite Total Return Index, capital gains are calculated from the S\&P 500 Composite Index.

- Liabilities Debt: This is the weighted average of the total return on long-term bonds and total return on short-term bonds. Maturity composition is 75 percent long term and 25 percent short term, from Table 2 and Table 3 in the U.S. Treasury's (2002) Survey of Foreign Portfolio Holdings of U.S. Securities. Long-term returns are calculated from the change in yields (assuming that yield=coupon and using the formula (10.1.19) in Campbell and MacKinlay 1997, p408). Yields are calculated on U.S. government ten-year constant maturity bonds from IFS (after 1985:III). Short-term returns are computed from the discount on new issues of three-month Treasury Bills from IFS. Capital gains are computed from long-term bond holdings only, using the same country weights as returns. Capital gains are computed from long-term bond holdings only as the net rather than total return.

- Liabilities FDI: As Equity, returns are computed from S\&P 500 Composite Total Return Index and capital gains are calculated from the S\&P 500 Composite Index.

- Liabilities Other: Returns equal the return on short-term debt. No Capital Gains.

I use the price deflator for non-durable consumption expenditure to convert all asset and liability positions into constant dollars, and the dollar returns on asset and liabilities into real returns. The VARs in Section 5.2 also use data on U.S. exports and imports (in constant dollars) from the BEA.

\section{A.2 Solving the Model}

To solve for the equilibrium dynamics of the model I use standard log-linear approximations to the households' first-order conditions from the modified optimization problems and the market clearing conditions to find the equilibrium process for the real exchange rate, real interest rates, and other endogenous variables. These approximations are computed around the model's stochastic steady state. First I summarize the models' equilibrium equations. I then describe the stochastic steady state, the approximations and solution method. Finally, I examine the accuracy of the solution method by studying the distribution of the Euler equation errors.

\section{Equilibrium Conditions}

The model's equilibrium conditions comprise the households' first-order conditions, the market clearing conditions and the exogenous processes for the endowments and consumption surplus ratios. The first-order conditions for the U.S. and E.U. households are : 


$$
\begin{gathered}
1=\beta \mathbb{E}_{t}\left[\left(\frac{C_{t+1}}{C_{t}}\right)^{-\gamma}\left(\frac{S_{t+1}}{S_{t}}\right)^{-\gamma} R_{t+1}^{\mathrm{EQ}}\right], \\
1-(1+\varkappa) \mathcal{B}_{t}=\beta \mathbb{E}_{t}\left[\left(\frac{C_{t+1}}{C_{t}}\right)^{-\gamma}\left(\frac{S_{t+1}}{S_{t}}\right)^{-\gamma} \frac{\mathcal{E}_{t+1}}{\mathcal{E}_{t}}\left\{\hat{R}_{t}+\wp\left(\hat{R}_{t+1}^{\mathrm{EQ}}-\hat{R}_{t}\right)\right\}\right], \\
1-\mathcal{B}_{t}=\beta \mathbb{E}_{t}\left[\left(\frac{C_{t+1}}{C_{t}}\right)^{-\gamma}\left(\frac{S_{t+1}}{S_{t}}\right)^{-\gamma} R_{t}\right], \\
1=\beta \mathbb{E}_{t}\left[\left(\frac{\hat{C}_{t+1}}{\hat{C}_{t}}\right)^{-\gamma}\left(\frac{\hat{S}_{t+1}}{\hat{S}_{t}}\right)^{-\gamma} \hat{R}_{t+1}^{\mathrm{EQ}}\right], \\
1-(1+\varkappa) \hat{\mathcal{B}}_{t}=\beta \mathbb{E}_{t}\left[\left(\frac{\hat{C}_{t+1}}{\hat{C}_{t}}\right)^{-\gamma}\left(\frac{\hat{S}_{t+1}}{\hat{S}_{t}}\right)^{-\gamma} \frac{\mathcal{E}_{t}}{\mathcal{E}_{t+1}}\left\{R_{t}+\wp\left(R_{t+1}^{\mathrm{EQ}}-R_{t}\right)\right\}\right], \\
1-\hat{\mathcal{B}}_{t}=\beta \mathbb{E}_{t}\left[\left(\frac{\hat{C}_{t+1}}{\hat{C}_{t}}\right)^{-\gamma}\left(\frac{\hat{S}_{t+1}}{\hat{S}_{t}}\right)^{-\gamma} \hat{R}_{t}\right] .
\end{gathered}
$$

When the first-order conditions are computed from the original households' problems in (18) and (20) $\mathcal{B}_{t}=C_{t}^{\gamma} S_{t}^{\gamma} \mathcal{L}_{t}$ and $\hat{\mathcal{B}}_{t}=\hat{C}_{t}^{\gamma} \hat{S}_{t}^{\gamma} \hat{\mathcal{L}}_{t}$, where $\mathcal{L}_{t}$ and $\hat{\mathcal{L}}_{t}$ are the Lagrange multipliers on the collateral constraints in (18c) and (20c), respectively.

To approximate the solution of the model, I use the first-order conditions from the modified U.S. problem where households maximize (1) subject to (18b) with $\mathcal{U}\left(C_{i, t}, H_{t}, N_{i, t}\right)$ replacing $\mathcal{U}\left(C_{i, t}, H_{t}\right)$; and the E.U. problem where households maximize (4) subject to (20b) with $\mathcal{U}\left(\hat{C}_{i, t}, \hat{H}_{t}, \hat{N}_{i, t}\right)$ replacing $\mathcal{U}\left(\hat{C}_{i, t}, \hat{H}_{t}\right)$. The first-order conditions from the modified optimization problems take the form of (45) and (46) with

$$
\mathcal{B}_{t}=\mu\left(\frac{C_{t} S_{t}}{\overline{C_{t}}{ }}\right)^{\gamma}\left\{\frac{\bar{N}_{t}}{N_{t}}-1\right\} \quad \text { and } \quad \hat{\mathcal{B}}_{t}=\mu\left(\frac{\hat{C}_{t} \hat{S}_{t}}{\overline{C_{t}}{ } \bar{S}}\right)^{\gamma}\left\{\frac{\bar{N}_{t}}{\hat{N}_{t}}-1\right\}
$$

I use (45a) and (46a) to identify the ratios of equity prices to dividends, $\Lambda_{t}^{\mathrm{EQ}}=Q_{t} / D_{t}$ and $\hat{\Lambda}_{t}^{\mathrm{EQ}}=$ $\hat{Q}_{t} / \hat{D}_{t}$ in (27) and (28). First-order conditions (45a) and (46c) give the expressions for equilibrium risk free rates in (31), while conditions (45b) and (46b) produce (32). The equilibrium consumption ratios $1 / \Lambda_{t}^{\mathrm{C}}=C_{t} /\left(W_{t}-C_{t}\right)$ and $1 / \hat{\Lambda}_{t}^{\mathrm{C}}=\hat{C_{t}} /\left(\hat{W}_{t}-\hat{C}_{t}\right)$, are determined by combining the first-order conditions in 
(45) and (46) with the budget constraints in (18b) and (20b) to give

$$
\begin{aligned}
& \Lambda_{t}^{\mathrm{C}}=\beta \mathbb{E}_{t}\left[\left(\frac{C_{t+1}}{C_{t}}\right)^{1-\gamma}\left(\frac{S_{t+1}}{S_{t}}\right)^{-\gamma}\left(\Lambda_{t+1}^{\mathrm{C}}+1\right)\right]+\mathcal{B}_{t} N_{t} / C_{t} \quad \text { and } \\
& \hat{\Lambda}_{t}^{\mathrm{C}}=\beta \mathbb{E}_{t}\left[\left(\frac{\hat{C}_{t+1}}{\hat{C}_{t}}\right)^{1-\gamma}\left(\frac{\hat{S}_{t+1}}{\hat{S}_{t}}\right)^{-\gamma}\left(\hat{\Lambda}_{t+1}^{\mathrm{C}}+1\right)\right]+\widehat{\mathcal{B}}_{t} \hat{N}_{t} / \hat{C}_{t} .
\end{aligned}
$$

When $\mathcal{B}_{t}=C_{t}^{\gamma} S_{t}^{\gamma} \mathcal{L}_{t}$ and $\hat{\mathcal{B}}_{t}=\hat{C}_{t}^{\gamma} \hat{S}_{t}^{\gamma} \hat{\mathcal{L}}_{t}, \mathcal{B}_{t} N_{t}=0$ and $\widehat{\mathcal{B}}_{t} \hat{N}_{t}=0$ by complimentary slackness, giving (33).

The remaining equilibrium conditions include: the endowment processes in (13), the log surplus ratios in (2) and (6); the equations for U.S. exports and imports in (24), dividends in (25), and the equations linking dividends with consumption and net exports in (26). Market clearing in the goods market implies (23), while in the equity and bond markets clearing requires that

$$
\begin{array}{lll}
\text { Equity } & \text { U.S. : } & Q_{t}=\alpha_{t}^{\mathrm{EQ}} \Lambda_{t}^{\mathrm{C}} C_{t}+\wp \hat{\alpha}_{t}^{\mathrm{FA}} \hat{\Lambda}_{t}^{\mathrm{C}} \mathcal{E}_{t} \hat{C}_{t}, \\
& \text { E.U. : } & \hat{Q}_{t}=\hat{\alpha}_{t}^{\mathrm{EQ}} \hat{\Lambda}_{t}^{\mathrm{C}} \hat{C}_{t}+\wp \alpha_{t}^{\mathrm{FA}} \Lambda_{t}^{\mathrm{C}} C_{t} / \mathcal{E}_{t}, \\
\text { Bonds } & \text { U.S. : } & 0=\left(1-\alpha_{t}^{\mathrm{EQ}}-\alpha_{t}^{\mathrm{FA}}\right) \Lambda_{t}^{\mathrm{C}} C_{t}+(1-\wp) \hat{\alpha}_{t}^{\mathrm{FA}} \hat{\Lambda}_{t}^{\mathrm{C}} \mathcal{E}_{t} \hat{C}_{t}, \quad \text { and } \\
& \text { E.U. : } & 0=\left(1-\hat{\alpha}_{t}^{\mathrm{EQ}}-\hat{\alpha}_{t}^{\mathrm{FA}}\right) \hat{\Lambda}_{t}^{\mathrm{C}} \hat{C}_{t}+(1-\wp) \alpha_{t}^{\mathrm{FA}} \Lambda_{t}^{\mathrm{C}} C_{t} / \mathcal{E}_{t} .
\end{array}
$$

\section{The Stochastic Steady State}

I use four equilibrium conditions to identify the steady state: the first-order conditions determining households' bond holdings, and the goods market clearing conditions. Combining the first-order conditions for E.U. bonds to eliminate the real interest rate, ignoring the Lagrange multipliers and simplifying, we find that

$$
\begin{aligned}
\varepsilon_{t}=\ln \mathbb{E}_{t}\left[\exp \left(\Delta c y_{t+1}+\Delta s_{t+1}+\Delta z_{t+1}\right)^{-\gamma} \exp \left(\varepsilon_{t+1}\right)\right] & \\
& -\ln \mathbb{E}_{t}\left[\exp \left(\Delta \hat{c} \hat{y}_{t+1}+\Delta \hat{s}_{t+1}+\Delta \hat{z}_{t+1}\right)^{-\gamma}\right]
\end{aligned}
$$

where $c y_{t}=c_{t}-y_{t}$ and $\hat{c} \hat{y}_{t}=\hat{c}_{t}-\hat{y}_{t}$. Similarly, the first-order conditions for U.S. bonds imply that

$$
\begin{aligned}
\varepsilon_{t}=\ln \mathbb{E}_{t}\left[\exp \left(\Delta c y_{t+1}+\Delta s_{t+1}+\Delta z_{t+1}\right)^{-\gamma}\right] & \\
& -\ln \mathbb{E}_{t}\left[\exp \left(\Delta \hat{c} \hat{y}_{t+1}+\Delta \hat{s}_{t+1}+\Delta \hat{z}_{t+1}\right)^{-\gamma} \exp \left(-\varepsilon_{t+1}\right)\right] .
\end{aligned}
$$

The goods market clearing conditions in (23) imply that

$$
1=\eta\left(\eta+(1-\eta) \mathcal{T}_{t}^{1-\theta}\right)^{\frac{\theta}{1-\theta}} \exp \left(c y_{t}\right)+(1-\eta)\left(\eta \mathcal{T}_{t}^{1-\theta}+(1-\eta)\right)^{\frac{\theta}{1-\theta}} \exp \left(c \hat{y}_{t}+\hat{z}_{t}-z_{t}\right)
$$


and

$$
1=(1-\eta)\left(\eta \mathcal{T}_{t}^{\theta-1}+(1-\eta)\right)^{\frac{\theta}{1-\theta}} \exp \left(c y_{t}+z_{t}-\hat{z}_{t}\right)+\eta\left(\eta+(1-\eta) \mathcal{T}_{t}^{\theta-1}\right)^{\frac{\theta}{1-\theta}} \exp \left(c \hat{y}_{t}\right)
$$

where

$$
\mathcal{T}_{t}=\left\{\frac{(1-\eta)-\eta \exp \left(\varepsilon_{t}\right)^{1-\theta}}{(1-\eta) \exp \left(\varepsilon_{t}\right)^{1-\theta}-\eta}\right\}^{\frac{1}{1-\theta}}
$$

Equations (49) - (50) comprise a closed system that determines the behavior of $\varepsilon_{t}, c y_{t}$ and $\hat{c} \hat{y}_{t}$ from the exogenous processes for $z_{t}, \hat{z}_{t}, s_{t}$ and $\hat{s}_{t}$. Let $\varepsilon_{t}=\mathcal{F}\left(z_{t}, \hat{z}_{t}, s_{t}-\bar{s}, \hat{s}_{t}-\bar{s}\right)$ denote the solution to (49) - (50), for some some function $\mathcal{F}($.$) . I define the steady state value for the log real exchange rate as$

$$
\bar{\varepsilon}=\mathcal{F}(0,0,0,0)
$$

In words, $\bar{\varepsilon}$ is the value for log real exchange that is consistent with equilibrium in the international asset and goods' markets when collateral constraints are not binding and when the current endowments of U.S. and E.U. goods are equal and both surplus ratios are at their long-run value. Note that the value for $\bar{\varepsilon}$ depends on households' expectations of future shocks to the endowments and surplus ratios conditioned on current steady state information $\left\{y_{t}=\hat{y}_{t}=\mathfrak{T}_{t}, s_{t}=\hat{s}_{t}=\bar{s}\right\}$ via the conditional expectations on the right-hand-side of (49).

The nonlinearities (49) - (50) are too complex to find the form of $\mathcal{F}($.$) analytically, so \mathcal{F}($.$) and hence the$ steady-state real exchange rate must be approximated. In (Evans (2012a) I show that zero is a candidate value for the steady state value for $\varepsilon_{t}$ that satisfies an approximation to $\mathcal{F}($.$) and that this value is locally$ unique. This steady state value for $\varepsilon_{t}$ has a number of sensible economic implications. First, aggregate consumption is equalized across countries (i.e., $c y_{t}=\hat{c} \hat{y}_{t}=0$ solves (50) so $c_{t}=y_{t}=\mathfrak{T}_{t}=\hat{y}_{t}=\hat{c}_{t}$ ), so trade is balanced. The approximation also implies that real interest rates are constant and equal, and that the steady state foreign exchange risk premium is also zero.

\section{Approximations}

I take standard log-normal (second-order) approximations to the terms on the right-hand-side of (45) and (46) and a log-linear approximation to terms on the left-hand-side around the steady state. After some simplification, this produces

$$
\begin{aligned}
r_{t} & =-\ln \beta+\gamma \mathbb{E}_{t}\left(\Delta c_{t+1}+\Delta s_{t+1}\right)-\frac{1}{2} \mathbb{V}_{t}\left(\gamma\left(c_{t+1}+s_{t+1}\right)\right)+\mu\left(n_{t}-\bar{n}_{t}\right) \\
\mathbb{E}_{t} r_{t+1}^{\mathrm{FA}} & =-\ln \beta+\gamma \mathbb{E}_{t}\left(\Delta c_{t+1}+\Delta s_{t+1}\right)-\frac{1}{2} \mathbb{V}_{t}\left(r_{t+1}^{\mathrm{FA}}-\gamma\left(c_{t+1}+s_{t+1}\right)\right)+\mu(\varkappa+1)\left(n_{t}-\bar{n}_{t}\right) \\
\mathbb{E}_{t} r_{t+1}^{\mathrm{EQ}} & =-\ln \beta+\gamma \mathbb{E}_{t}\left(\Delta c_{t+1}+\Delta s_{t+1}\right)-\frac{1}{2} \mathbb{V}_{t}\left(r_{t+1}^{\mathrm{EQ}}-\gamma\left(c_{t+1}+s_{t+1}\right)\right) \\
\hat{r}_{t} & =-\ln \beta+\gamma \mathbb{E}_{t}\left(\Delta \hat{c}_{t+1}+\Delta \hat{s}_{t+1}\right)-\frac{1}{2} \mathbb{V}_{t}\left(\gamma\left(\hat{c}_{t+1}+\hat{s}_{t+1}\right)\right)+\mu\left(\hat{n}_{t}-\bar{n}_{t}\right) \\
\mathbb{E}_{t} \hat{r}_{t+1}^{\mathrm{FA}} & =-\ln \beta+\gamma \mathbb{E}_{t}\left(\Delta \hat{c}_{t+1}+\Delta \hat{s}_{t+1}\right)-\frac{1}{2} \mathbb{V}_{t}\left(\hat{r}_{t+1}^{\mathrm{FA}}-\gamma\left(\hat{c}_{t+1}+\hat{s}_{t+1}\right)\right)+\mu(\varkappa+1)\left(\hat{n}_{t}-\bar{n}_{t}\right) \\
\mathbb{E}_{t} \hat{r}_{t+1}^{\mathrm{EQ}} & =-\ln \beta+\gamma \mathbb{E}_{t}\left(\Delta \hat{c}_{t+1}+\Delta \hat{s}_{t+1}\right)-\frac{1}{2} \mathbb{V}_{t}\left(\hat{r}_{t+1}^{\mathrm{EQ}}-\gamma\left(\hat{c}_{t+1}+\hat{s}_{t+1}\right)\right)
\end{aligned}
$$


These equations determine the equilibrium domestic equity premia and the risk premia, the risk premia on foreign asset holdings, and the foreign exchange risk premium. The former are given by

$$
\begin{aligned}
r p_{t}^{\mathrm{EQ}} & =\mathbb{E}_{t} r_{t+1}^{\mathrm{EQ}}-r_{t}+\frac{1}{2} \mathbb{V}_{t}\left(r_{t+1}^{\mathrm{EQ}}\right)=\gamma \mathbb{V}_{t}\left(r_{t+1}^{\mathrm{EQ}}, \Delta c_{t+1}+\Delta s_{t+1}\right)-\mu\left(n_{t}-\bar{n}_{t}\right), \\
r p_{t}^{\mathrm{FA}} & =\mathbb{E}_{t} r_{t+1}^{\mathrm{FA}}-r_{t}+\frac{1}{2} \mathbb{V}_{t}\left(r_{t+1}^{\mathrm{FA}}\right)=\gamma \mathbb{V}_{t}\left(r_{t+1}^{\mathrm{FA}}, \Delta c_{t+1}+\Delta s_{t+1}\right)+\mu \varkappa\left(n_{t}-\bar{n}_{t}\right), \\
\widehat{r p}_{t}^{\mathrm{EQ}} & =\mathbb{E}_{t} \hat{r}_{t+1}^{\mathrm{EQ}}-\hat{r}_{t}+\frac{1}{2} \mathbb{V}_{t}\left(\hat{r}_{t+1}^{\mathrm{EQ}}\right)=\gamma \mathbb{C V}_{t}\left(\hat{r}_{t+1}^{\mathrm{EQ}}, \Delta \hat{c}_{t+1}+\Delta \hat{s}_{t+1}\right)-\mu\left(\hat{n}_{t}-\bar{n}_{t}\right), \\
\widehat{r p}_{t}^{\mathrm{FA}} & =\mathbb{E}_{t} \hat{r}_{t+1}^{\mathrm{FA}}-\hat{r}_{t}+\frac{1}{2} \mathbb{V}_{t}\left(\hat{r}_{t+1}^{\mathrm{FA}}\right)=\gamma \mathbb{V}_{t}\left(\hat{r}_{t+1}^{\mathrm{FA}}, \Delta \hat{c}_{t+1}+\Delta \hat{s}_{t+1}\right)+\mu \varkappa\left(\hat{n}_{t}-\bar{n}_{t}\right) .
\end{aligned}
$$

To identify the foreign exchange risk premium, I first follow Campbell and Viceira (2002) in approximating the log returns on U.S. and E.U. foreign asset portfolios by:

$$
\begin{aligned}
& r_{t+1}^{\mathrm{FA}}=\Delta \varepsilon_{t+1}+\hat{r}_{t}+\frac{1}{2} \wp(1-\wp) \mathbb{V}_{t}\left(\hat{r}_{t+1}^{\mathrm{EQ}}\right)+\wp\left(\hat{r}_{t+1}^{\mathrm{EQ}}-\hat{r}_{t}\right) \quad \text { and } \\
& \hat{r}_{t+1}^{\mathrm{FA}}=r_{t}-\Delta \varepsilon_{t+1}+\frac{1}{2} \wp(1-\wp) \mathbb{V}_{t}\left(r_{t+1}^{\mathrm{EQ}}\right)+\wp\left(r_{t+1}^{\mathrm{EQ}}-r_{t}\right) .
\end{aligned}
$$

Next, I take conditional expectations and re-arranging to give

$$
\delta_{t}=r p_{t}^{\mathrm{EA}}-\wp \widehat{r}_{t}^{\mathrm{EQ}} \quad \text { and } \quad \delta_{t}=\wp r p_{t}^{\mathrm{EQ}}-\widehat{r p}_{t}^{\mathrm{EA}}
$$

Finally, I average these equations for $\delta_{t}$ and substitute for the equity and foreign asset risk premia from (52) to produce

$$
\begin{aligned}
\delta_{t} & =\frac{1}{2} \gamma \mathbb{C} \mathbb{V}_{t}\left(\varepsilon_{t+1}, c_{t+1}+s_{t+1}\right)+\frac{1}{2} \gamma \mathbb{C V}_{t}\left(\varepsilon_{t+1}, \hat{c}_{t+1}+\hat{s}_{t+1}\right)+\frac{1}{2} \mu(\varkappa-\wp)\left(n_{t}-\hat{n}_{t}\right) \\
& +\frac{1}{2} \gamma \wp \mathbb{C} \mathbb{V}_{t}\left(\hat{r}_{t+1}^{\mathrm{EQ}}+r_{t+1}^{\mathrm{EQ}}, c_{t+1}-\hat{c}_{t+1}+s_{t+1}-\hat{s}_{t+1}\right)-\frac{1}{2} \wp \mathbb{C} \mathbb{V}_{t}\left(\varepsilon_{t+1}, \hat{r}_{t+1}^{\mathrm{EQ}}+r_{t+1}^{\mathrm{EQ}}\right) .
\end{aligned}
$$

In the absence of collateral constraints $(\mu=0)$ and under complete markets, the last three terms on the right-hand-side disappear as noted in the text (Section 4.2).

The equilibrium expected return differential between U.S. foreign assets and liabilities is approximated using (52) as

$$
\begin{array}{r}
\mathbb{E}_{t}\left[r_{t+1}^{\mathrm{FA}}-\Delta \varepsilon_{t+1}-\hat{r}_{t+1}^{\mathrm{FA}}\right]= \\
\mathbb{E}_{t}\left[\Delta \varepsilon_{t+1}+\hat{r}_{t}-\frac{1}{2} \wp^{2} \mathbb{V}_{t}\left(\hat{r}_{t+1}^{\mathrm{EQ}}\right)+\wp\left(\hat{r}_{t+1}^{\mathrm{EQ}}-\hat{r}_{t}\right)+\wp \frac{1}{2} \mathbb{V}_{t}\left(\hat{r}_{t+1}^{\mathrm{EQ}}\right)\right]-\mathbb{E}_{t} \Delta \varepsilon_{t+1} \\
-\mathbb{E}_{t}\left[r_{t}-\Delta \varepsilon_{t+1}-\frac{1}{2} \wp^{2} \mathbb{V}_{t}\left(r_{t+1}^{\mathrm{EQ}}\right)+\wp\left(r_{t+1}^{\mathrm{EQ}}-r_{t}\right)+\wp \frac{1}{2} \mathbb{V}_{t}\left(r_{t+1}^{\mathrm{Q}}\right)\right] \\
=\delta_{t}+\wp \gamma\left\{\mathbb{C V}_{t}\left(\hat{r}_{t+1}^{\mathrm{EQ}}, \Delta \hat{c}_{t+1}+\Delta \hat{s}_{t+1}\right)-C \mathbb{V}_{t}\left(r_{t+1}^{\mathrm{EQ}}, \Delta c_{t+1}+\Delta s_{t+1}\right)\right\} \\
+\wp \mu\left(n_{t}-\hat{n}_{t}\right)+\frac{1}{2} \wp^{2}\left\{\mathbb{V}_{t}\left(r_{t+1}^{\mathrm{Q}}\right)-\mathbb{V}_{t}\left(\hat{r}_{t+1}^{\mathrm{Q}}\right)\right\}
\end{array}
$$

I approximate the equations determining the logs of $\Lambda_{t}^{\mathrm{EQ}}, \hat{\Lambda}_{t}^{\mathrm{EQ}}, \Lambda_{t}^{\mathrm{C}}$ and $\Lambda_{t}^{\mathrm{C}}$ in an analogous fashion from 
(27), (28) and (48) as

$$
\begin{aligned}
& \lambda_{t}^{\mathrm{EQ}}=\ln \beta-\left(1-\kappa^{\mathrm{EQ}}\right) \ln \left(1-\kappa^{\mathrm{EQ}}\right)+(1-\gamma) \mathbb{E}_{t}\left[\Delta c_{t+1}-\gamma \Delta s_{t+1}+\Delta d_{t+1}+\kappa^{\mathrm{EQ}} \lambda_{t+1}^{\mathrm{EQ}}\right] \\
& +\frac{1}{2} \mathbb{V}_{t}\left((1-\gamma) c_{t+1}-\gamma s_{t+1}+d_{t+1}+\kappa^{\mathrm{EQ}} \lambda_{t+1}^{\mathrm{EQ}}\right), \\
& \hat{\lambda}_{t}^{\mathrm{EQ}}=\ln \beta-\left(1-\kappa^{\mathrm{EQ}}\right) \ln \left(1-\kappa^{\mathrm{EQ}}\right)+(1-\gamma) \mathbb{E}_{t}\left[\Delta \hat{c}_{t+1}-\gamma \Delta \hat{s}_{t+1}+\Delta \hat{d}_{t+1}+\kappa^{\mathrm{EQ}} \hat{\lambda}_{t+1}^{\mathrm{EQ}}\right] \\
& +\frac{1}{2} \mathbb{V}_{t}\left((1-\gamma) \hat{c}_{t+1}-\gamma \hat{s}_{t+1}+\hat{d}_{t+1}+\kappa^{\mathrm{Q}} \hat{\lambda}_{t+1}^{\mathrm{Q}}\right), \\
& \lambda_{t}^{\mathrm{C}}=\ln \beta-\left(1-\kappa^{\mathrm{C}}\right) \ln \left(1-\kappa^{\mathrm{C}}\right)+(1-\gamma) \mathbb{E}_{t}\left[\Delta c_{t+1}-\gamma \Delta s_{t+1}+\kappa^{\mathrm{C}} \lambda_{t+1}^{\mathrm{C}}\right] \\
& +\frac{1}{2} \mathbb{V}_{t}\left((1-\gamma) c_{t+1}-\gamma s_{t+1}+\kappa^{\mathrm{w}} \lambda_{t+1}^{\mathrm{w}}\right), \\
& \hat{\lambda}_{t}^{\mathrm{C}}=\ln \beta-\left(1-\kappa^{\mathrm{C}}\right) \ln \left(1-\kappa^{\mathrm{C}}\right)+(1-\gamma) \mathbb{E}_{t}\left[\Delta \hat{c}_{t+1}-\gamma \Delta \hat{s}_{t+1}+\kappa^{\mathrm{C}} \hat{\lambda}_{t+1}^{\mathrm{C}}\right] \\
& +\frac{1}{2} \mathbb{V}_{t}\left((1-\gamma) \hat{c}_{t+1}-\gamma \hat{s}_{t+1}+\kappa \hat{\lambda}_{t+1}^{\mathrm{C}}\right) \text {. }
\end{aligned}
$$

Here $\kappa^{\mathrm{EQ}}=\bar{\Lambda}^{\mathrm{EQ}} /\left(1+\bar{\Lambda}^{\mathrm{EQ}}\right)$ and $\kappa^{\mathrm{C}}=\bar{\Lambda}^{\mathrm{C}} /\left(1+\bar{\Lambda}^{\mathrm{C}}\right)$ where $\bar{\Lambda}^{\mathrm{EQ}}$ and $\bar{\Lambda}^{\mathrm{C}}$ are the steady state values for $\Lambda_{t}^{\mathrm{EQ}} \hat{\Lambda}_{t}^{\mathrm{EQ}}$, $\Lambda_{t}^{\mathrm{C}}$ and $\hat{\Lambda}_{t}^{\mathrm{C}}$.

I approximate the other equilibrium conditions in a straightforward manner around the steady state real exchange rate rate. Using the definition in (7) we can approximate the log real exchange to second order by

$$
\varepsilon_{t}=(2 \eta-1) \tau_{t}
$$

To approximate the goods market clearing conditions, I use (23) to compute $\ln \left(Y_{t} / C_{t}\right)$ and $\ln \left(\hat{Y}_{t} / \hat{C}_{t}\right)$ and then take first-order approximations around the steady state of the resulting expressions. Simplifying the result using (58) produces

$$
\left[\begin{array}{l}
c_{t} \\
\hat{c}_{t}
\end{array}\right]=\left[\begin{array}{cc}
\varphi & 1-\varphi \\
1-\varphi & \varphi
\end{array}\right]\left[\begin{array}{l}
y_{t} \\
\hat{y}_{t}
\end{array}\right]+\left[\begin{array}{c}
-2 \theta \varphi^{2}(1-\eta) / \eta \\
2 \theta \varphi^{2}(1-\eta) / \eta
\end{array}\right] \varepsilon_{t}
$$

where $\varphi=\eta /(2 \eta-1)>0$. Approximations for dividends and trade flows are derived in an analogous manner from (26) and (24) as

$$
\begin{aligned}
d_{t}-c_{t} & =(1-\eta) n x_{t}, \\
\hat{d}_{t}-\hat{c}_{t} & =-(1-\eta) n x_{t}, \\
x_{t} & =\ln (1-\eta)+[1-\varphi(1-\theta)] \varepsilon+\hat{c}_{t} \quad \text { and } \\
m_{t} & =\ln (1-\eta)+\varphi(1-\theta) \varepsilon_{t}+c_{t},
\end{aligned}
$$

where $n x_{t}=x_{t}-m_{t}$. Market clearing in the bond markets implies that $N_{t}=(1+\varkappa) F A_{t}-\hat{B}_{t}^{\mathrm{us}}$ and $\hat{N}_{t}=(1+\varkappa) \widehat{F A}_{t}-B_{t}^{\mathrm{EU}}$. Combining these expressions with the definitions of $F L_{t}$ and $n f a_{t}$ gives

$$
n_{t}-\hat{n}_{t}=\varepsilon_{t}+\ln \left(\frac{(1+\varkappa) \exp \left(n f a_{t}\right)-(1-\wp)}{(1+\varkappa)-(1-\wp) \exp \left(n f a_{t}\right)}\right) \approx \varepsilon_{t}+\frac{2+\varkappa-\wp}{\varkappa+\wp} n f a_{t} .
$$


Finally, I approximate the left- and right-hand sides of the consolidated budget constraint in (40) and take expectations to give

$$
n f a_{t}=-(1-\kappa) \mathbb{E}_{t} n x_{t+1}-\mathbb{E}_{t}\left[r_{t+1}^{\mathrm{FA}}-r_{t+1}^{\mathrm{FL}}\right]+\kappa \mathbb{E}_{t} n f a_{t+1} .
$$

This is equation (41) in the text.

\section{Solution Method}

I use the method of undetermined coefficients to find equations for the endogenous variables that satisfy the approximate equilibrium conditions. For this purpose, I first write the processes for the exogenous variables in vector form:

$$
\left[\begin{array}{c}
\bar{z}_{t} \\
z_{t} \\
\hat{z}_{t} \\
s_{t} \\
s_{t} \\
1
\end{array}\right]=\left[\begin{array}{cccccc}
1 & 0 & 0 & 0 & 0 & g \\
0 & \rho & 0 & 0 & 0 & 0 \\
0 & 0 & \rho & 0 & 0 & 0 \\
0 & 0 & 0 & \phi & 0 & (1-\phi) \bar{s} \\
0 & 0 & 0 & 0 & \phi & (1-\phi) \bar{s} \\
0 & 0 & 0 & 0 & 0 & 1
\end{array}\right]\left[\begin{array}{c}
\bar{z}_{t-1} \\
z_{t-1} \\
\hat{z}_{t-1} \\
s_{t-1} \\
s_{t-1} \\
1
\end{array}\right]+\left[\begin{array}{c}
u_{t} \\
e_{t} \\
\hat{e}_{t} \\
\omega\left(s_{t-1}\right) v_{t} \\
\omega\left(\hat{s}_{t-1}\right) \hat{v}_{t} \\
0
\end{array}\right]
$$

or, more compactly,

$$
\mathcal{X}_{t}=\mathcal{A} \mathcal{X}_{t-1}+\mathcal{U}_{t}
$$

where $\mathcal{X}_{t}$ is the state vector for the economy. Note that the vector of errors, $\mathcal{U}_{t}$ is conditionally heteroskedastic with

$$
\mathbb{V}_{t}\left(\mathcal{U}_{t+1}\right)=\Sigma_{t}=\left[\begin{array}{cccccc}
\sigma_{u}^{2} & 0 & 0 & 0 & 0 & 0 \\
0 & \sigma_{e}^{2} & 0 & 0 & 0 & 0 \\
0 & 0 & \sigma_{e}^{2} & 0 & 0 & 0 \\
0 & 0 & 0 & \omega_{0}-\omega s_{t} & 0 & 0 \\
0 & 0 & 0 & 0 & \omega_{0}-\omega \hat{s}_{t} & 0 \\
0 & 0 & 0 & 0 & 0 & 0
\end{array}\right]
$$

Variations in $\Sigma_{t}$ are linked to the state vector via

$$
\operatorname{Vec}\left(\Sigma_{t}\right)=\left[\begin{array}{c}
\Omega_{1} \\
\Omega_{2} \\
\Omega_{3} \\
\Omega_{4} \\
\Omega_{5} \\
\Omega_{6}
\end{array}\right]\left[\begin{array}{c}
\bar{z}_{t} \\
z_{t} \\
\hat{z}_{t} \\
s_{t} \\
s_{t} \\
1
\end{array}\right]=\Omega \mathcal{X}_{t}
$$


where

$$
\begin{aligned}
& \Omega_{1}=\left[\begin{array}{cccc}
0 & \ldots & 0 & \sigma_{u}^{2} \\
0 & & & 0 \\
0 & 0 \\
0 & & 0 \\
0 & & 0 \\
0 & \ldots & 0
\end{array}\right] \quad \Omega_{2}=\left[\begin{array}{lllc}
0 & \ldots & & 0 \\
0 & & 0 & \sigma_{e}^{2} \\
0 & & 0 \\
0 & & 0 \\
0 & & 0 \\
0 & \ldots & 0
\end{array}\right] \quad \Omega_{3}=\left[\begin{array}{cccc}
0 & \ldots & 0 \\
0 & & 0 \\
0 & & 0 & \sigma_{e}^{2} \\
0 & & 0 \\
0 & & 0 \\
0 & \ldots & 0
\end{array}\right]
\end{aligned}
$$

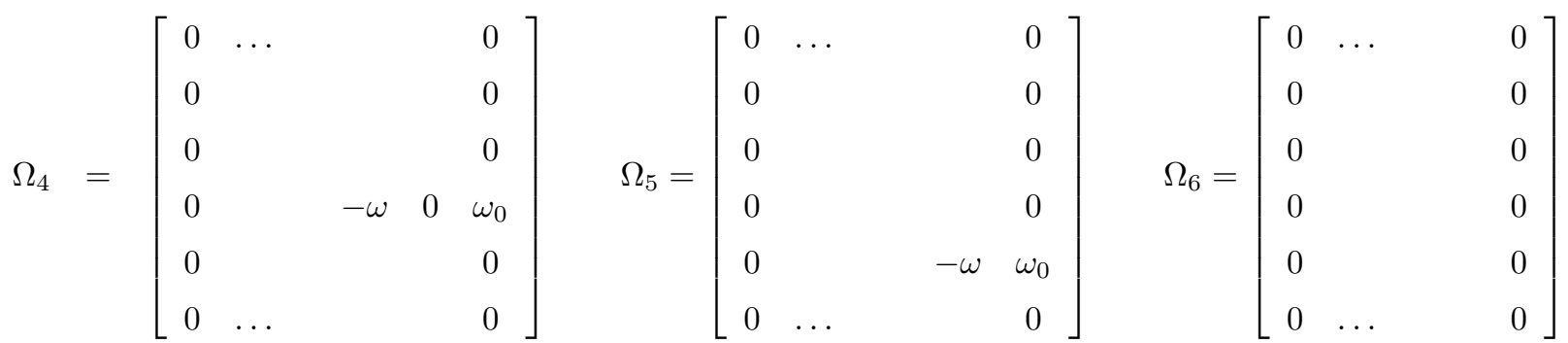

We can use this representation to write $\mathbb{C V}_{t}\left(\zeta_{t+1}, \xi_{t+1}\right)=\left\{l_{\xi} \otimes l_{\zeta}\right\} \Omega \mathcal{X}_{t}$ for any two variables, $\zeta_{t+1}$ and $\xi_{t+1}$, that can be written as $\zeta_{t+1}=l_{\zeta} \mathcal{X}_{t+1}$, and $\xi_{t+1}=l_{\xi} \mathcal{X}_{t+1}$ with coefficient vectors $l_{\zeta}$ and $l_{\xi}$. In the stochastic steady state, $\mathcal{X}_{t}=\overline{\mathcal{X}}_{t}$ so the steady state conditional covariance is $\mathbb{C} \mathbb{V}_{t}\left(\zeta_{t+1}, \xi_{t+1}\right)=\left\{l_{\xi} \otimes l_{\zeta}\right\} \Omega \overline{\mathcal{X}}_{t}$.

I solve the model in two steps: First, I use the method of undetermined coefficients with (62) and (63) to find equations for the equilibrium behavior of $\varepsilon_{t}, \lambda_{t}^{\mathrm{EQ}}$ and $\hat{\lambda}_{t}^{\mathrm{EQ}}$. I then use these equations to determine the behavior of all the other endogenous variables.

To begin, let $\Pi=\left\{\Pi_{y-\hat{y}}^{\varepsilon}, \Pi_{s-\hat{s}}^{\varepsilon}, \Pi_{z}^{\mathrm{EQ}}, \Pi_{\hat{z}}^{\mathrm{EQ}}, \Pi_{s}^{\mathrm{EQ}}, \Pi_{\hat{s}}^{\mathrm{EQ}}, \Pi_{1}^{\mathrm{EQ}}\right\}$ denote the set of unknown coefficients that determine

$$
\begin{aligned}
& \varepsilon_{t}=l_{\varepsilon} \mathcal{X}_{t}, \quad l_{\varepsilon}=\left[\begin{array}{llllll}
0 & \Pi_{y-\hat{y}}^{\varepsilon} & -\Pi_{y-\hat{y}}^{\varepsilon} & \Pi_{s-\hat{s}}^{\varepsilon} & -\Pi_{s-\hat{s}}^{\varepsilon} & 0
\end{array}\right], \\
& \lambda_{t}^{\mathrm{EQ}}=l_{\lambda}^{\mathrm{EQ}} \mathcal{X}_{t}, \quad l_{\lambda}^{\mathrm{EQ}}=\left[\begin{array}{llllll}
0 & \Pi_{z}^{\mathrm{EQ}} & \Pi_{\tilde{z}}^{\mathrm{EQ}} & \Pi_{s}^{\mathrm{EQ}} & \Pi_{\hat{s}}^{\mathrm{EQ}} & \Pi_{1}^{\mathrm{EQ}}
\end{array}\right], \\
& \hat{\lambda}_{t}^{\mathrm{EQ}}=l_{\hat{\lambda}}^{\mathrm{EQ}} \mathcal{X}_{t}, \quad l_{\hat{\lambda}}^{\mathrm{EQ}}=\left[\begin{array}{llllll}
0 & \Pi_{\hat{z}}^{\mathrm{EQ}} & \Pi_{z}^{\mathrm{EQ}} & \Pi_{\hat{s}}^{\mathrm{EQ}} & \Pi_{s}^{\mathrm{EQ}} & \Pi_{1}^{\mathrm{EQ}}
\end{array}\right] .
\end{aligned}
$$

With these expressions, (59) and (60) imply that

$$
\begin{aligned}
c_{t} & =\left\{l_{1}+\varphi l_{2}+(1-\varphi) l_{3}-2 \theta(1-\eta) \varphi(\varphi / \eta) l_{\varepsilon}\right\} \mathcal{X}_{t}=l_{c} \mathcal{X}_{t}, \\
\hat{c}_{t} & =\left\{l_{1}+\varphi l_{3}+(1-\varphi) l_{2}+2 \theta(1-\eta) \varphi(\varphi / \eta) l_{\varepsilon}\right\} \mathcal{X}_{t}=l_{\hat{c}} \mathcal{X}_{t}, \\
n x_{t} & =\left\{l_{\hat{c}}-l_{c}+[1-2 \varphi(1-\theta)] l_{\varepsilon}\right\} \mathcal{X}_{t}=l_{n x} \mathcal{X}_{t} .
\end{aligned}
$$

We can now approximate the log returns on equity by

$$
\begin{aligned}
& r_{t+1}^{\mathrm{EQ}}=(\ln (1+\Lambda)-\kappa \lambda) l_{6}+\kappa l_{\lambda}^{\mathrm{EQ}} \mathcal{X}_{t+1}-l_{\lambda}^{\mathrm{EQ}} \mathcal{X}_{t}+(1-\eta) l_{n x} \Delta \mathcal{X}_{t+1}-l_{c} \Delta \mathcal{X}_{t+1} \quad \text { and } \\
& \hat{r}_{t+1}^{\mathrm{EQ}}=(\ln (1+\Lambda)-\kappa \lambda) l_{6}+\kappa l_{\hat{\lambda}}^{\mathrm{EQ}} \mathcal{X}_{t+1}-l_{\hat{\lambda}}^{\mathrm{EQ}} \mathcal{X}_{t}-(1-\eta) l_{n x} \Delta \mathcal{X}_{t+1}-l_{\hat{c}} \Delta \mathcal{X}_{t+1}
\end{aligned}
$$


so unexpected equity returns are

$$
\begin{aligned}
& r_{t+1}^{\mathrm{EQ}}-\mathbb{E}_{t} r_{t+1}^{\mathrm{EQ}}=\left(\kappa l_{\lambda}^{\mathrm{EQ}}+(1-\eta) l_{n x}-l_{c}\right)\left(\mathcal{X}_{t+1}-\mathbb{E}_{t} \mathcal{X}_{t+1}\right)=l_{r}^{\mathrm{EQ}}\left(\mathcal{X}_{t+1}-\mathbb{E}_{t} \mathcal{X}_{t+1}\right) \quad \text { and } \\
& \hat{r}_{t+1}^{\mathrm{EQ}}-\mathbb{E}_{t} \hat{r}_{t+1}^{\mathrm{EQ}}=\left(\kappa l_{\hat{\lambda}}^{\mathrm{EQ}}-(1-\eta) l_{n x}-l_{\hat{c}}\right)\left(\mathcal{X}_{t+1}-\mathbb{E}_{t} \mathcal{X}_{t+1}\right)=l_{\hat{r}}^{\mathrm{EQ}}\left(\mathcal{X}_{t+1}-\mathbb{E}_{t} \mathcal{X}_{t+1}\right)
\end{aligned}
$$

Next, consider the expected return differential. From (56) and (61) we can write

$$
\begin{aligned}
\mathbb{E}_{t}\left[r_{t+1}^{\mathrm{FA}}-\Delta \varepsilon_{t+1}-\hat{r}_{t+1}^{\mathrm{FA}}\right] & =\delta_{t}+\wp \gamma\left[\mathbb{C V}_{t}\left(\hat{r}_{t+1}^{\mathrm{EQ}}, \hat{c}_{t+1}+\hat{s}_{t+1}\right)-\mathbb{C V}_{t}\left(r_{t+1}^{\mathrm{EQ}}, c_{t+1}+s_{t+1}\right)\right] \\
& +\frac{1}{2} \wp^{2}\left\{\mathbb{V}_{t}\left(r_{t+1}^{\mathrm{EQ}}\right)-\mathbb{V}_{t}\left(\hat{r}_{t+1}^{\mathrm{EQ}}\right)\right\}+\wp \mu\left(\frac{2+\varkappa-\wp}{\varkappa+\wp}\right) n f a_{t}+\wp \mu \varepsilon_{t} \\
& =\delta_{t}+\left(\wp \gamma\left[\left\{\left(l_{\hat{c}}+l_{5}\right) \otimes l_{\hat{r}}^{\mathrm{EQ}}\right\}-\left\{\left(l_{c}+l_{4}\right) \otimes l_{r}^{\mathrm{EQ}}\right\}\right]+\frac{1}{2} \wp^{2}\left[\left\{l_{r}^{\mathrm{EQ}} \otimes l_{r}^{\mathrm{EQ}}\right\}-\left\{l_{\hat{r}}^{\mathrm{EQ}} \otimes l_{\hat{r}}^{\mathrm{EQ}}\right\}\right]\right) \Omega \mathcal{X}_{t} \\
& +\wp \mu\left(\frac{2+\varkappa-\wp}{\varkappa+\wp}\right) n f a_{t}+\wp \mu \varepsilon_{t} .
\end{aligned}
$$

Similarly, (55) and (61) imply that

$$
\begin{aligned}
\delta_{t} & =\frac{1}{2} \gamma \mathbb{C} \mathbb{V}_{t}\left(\varepsilon_{t+1}, c_{t+1}+\hat{c}_{t+1}\right)+\frac{1}{2} \gamma \mathbb{C V}_{t}\left(\varepsilon_{t+1}, s_{t+1}+\hat{s}_{t+1}\right) \\
& +\frac{1}{2} \gamma \wp \mathbb{C} \mathbb{V}_{t}\left(\hat{r}_{t+1}^{\mathrm{Q}}+r_{t+1}^{\mathrm{Q}}, c_{t+1}-\hat{c}_{t+1}+s_{t+1}-\hat{s}_{t+1}\right) \\
& -\frac{1}{2} \wp \mathbb{C} \mathbb{V}_{t}\left(\varepsilon_{t+1}, \hat{r}_{t+1}^{\mathrm{Q}}+r_{t+1}^{\mathrm{Q}}\right)+\frac{1}{2} \mu(\varkappa-\wp)\left(\frac{2+\varkappa-\wp}{\varkappa+\wp}\right) n f a_{t}+\frac{1}{2} \mu(\varkappa-\wp) \varepsilon_{t} \\
& =\frac{1}{2} \gamma\left(\left\{l_{\varepsilon} \otimes\left(l_{c}+l_{\hat{c}}\right)\right\}+\left\{l_{\varepsilon} \otimes\left(l_{4}+l_{5}\right)\right\}\right) \Omega \mathcal{X}_{t} \\
& +\left(\frac{1}{2} \gamma \wp\left\{\left(l_{r}^{\mathrm{EQ}}+l_{\hat{r}}^{\mathrm{EQ}}\right) \otimes\left(l_{c}-l_{\hat{c}}+l_{4}-l_{5}\right)\right\}-\frac{1}{2} \wp\left\{\left(l_{r}^{\mathrm{EQ}}+l_{\hat{r}}^{\mathrm{EQ}}\right) \otimes l_{\varepsilon}\right\}\right) \Omega \mathcal{X}_{t} \\
& +\frac{1}{2} \mu(\varkappa-\wp)\left(\frac{2+\varkappa-\wp}{\varkappa+\wp}\right) n f a_{t}+\frac{1}{2} \mu(\varkappa-\wp) \varepsilon_{t} .
\end{aligned}
$$

Together, these expressions give

$$
\begin{aligned}
\mathbb{E}_{t}\left[r_{t+1}^{\mathrm{FA}}-\Delta \varepsilon_{t+1}-\hat{r}_{t+1}^{\mathrm{FA}}\right] & =\frac{1}{2} \gamma\left\{\left\{l_{\varepsilon} \otimes\left(l_{c}+l_{\hat{c}}\right)\right\}+\left\{l_{\varepsilon} \otimes\left(l_{4}+l_{5}\right)\right\}\right\} \Omega \mathcal{X}_{t} \\
& =+\left(\frac{1}{2} \gamma \wp\left\{\left(l_{r}^{\mathrm{EQ}}+l_{\hat{r}}^{\mathrm{EQ}}\right) \otimes\left(l_{c}-l_{\hat{c}}+l_{4}-l_{5}\right)\right\}-\frac{1}{2} \wp\left\{\left(l_{r}^{\mathrm{EQ}}+l_{\hat{r}}^{\mathrm{EQ}}\right) \otimes l_{\varepsilon}\right\}\right) \Omega \mathcal{X}_{t} \\
& +\left(\wp \gamma\left[\left\{\left(l_{\hat{c}}+l_{5}\right) \otimes l_{\hat{r}}^{\mathrm{EQ}}\right\}-\left\{\left(l_{c}+l_{4}\right) \otimes l_{r}^{\mathrm{EQ}}\right\}\right]+\frac{1}{2} \wp^{2}\left[\left\{l_{r}^{\mathrm{EQ}} \otimes l_{r}^{\mathrm{EQ}}\right\}-\left\{l_{\hat{r}}^{\mathrm{EQ}} \otimes l_{\hat{r}}^{\mathrm{EQ}}\right\}\right]\right) \Omega \mathcal{X}_{t} \\
& +\frac{1}{2} \mu(\varkappa+\wp) l_{\varepsilon} \mathcal{X}_{t}+\mu\left(\frac{2+\varkappa-\wp}{2}\right) n f a_{t} \\
& =l_{r^{n f a}} \mathcal{X}_{t}+\mu\left(\frac{2+\varkappa-\wp}{2}\right) n f a_{t} .
\end{aligned}
$$

Combining this equation with (41) and (62) produces

$$
v n f a_{t}=-(1-\kappa) l_{n x} \mathcal{A} \mathcal{X}_{t}-l_{r^{n f a}} \mathcal{X}_{t}+\kappa \mathbb{E}_{t} n f a_{t+1}
$$

with $v=1+\frac{1}{2} \mu(2+\varkappa-\wp)$. Solving this equation forward gives the equilibrium value for $n f a_{t}$ as

$$
n f a_{t}=l_{n f a} \mathcal{X}_{t} \quad \text { where } \quad l_{n f a}=-\left(\left[v I-\kappa \mathcal{A}^{\prime}\right]^{-1}\left[(1-\kappa) \mathcal{A}^{\prime} l_{n x}^{\prime}-l_{r^{n f a}}^{\prime}\right]\right)^{\prime} .
$$


We can now write the equilibrium foreign exchange risk premium as

$$
\begin{aligned}
\delta_{t} & =\frac{1}{2} \gamma\left(\left\{l_{\varepsilon} \otimes\left(l_{c}+l_{\hat{c}}\right)\right\}+\left\{l_{\varepsilon} \otimes\left(l_{4}+l_{5}\right)\right\}\right) \Omega \mathcal{X}_{t} \\
& +\left(\frac{1}{2} \gamma \wp\left\{\left(l_{r}^{\mathrm{EQ}}+l_{\hat{r}}^{\mathrm{EQ}}\right) \otimes\left(l_{c}-l_{\hat{c}}+l_{4}-l_{5}\right)\right\}-\frac{1}{2} \wp\left\{\left(l_{r}^{\mathrm{EQ}}+l_{\hat{r}}^{\mathrm{EQ}}\right) \otimes l_{\varepsilon}\right\}\right) \Omega \mathcal{X}_{t} \\
& +\frac{1}{2} \mu(\varkappa-\wp)\left(\frac{2+\varkappa-\wp}{\varkappa+\wp}\right) l_{n f a} \mathcal{X}_{t}+\frac{1}{2} \mu(\varkappa-\wp) l_{\varepsilon} \mathcal{X}_{t} . \\
& =l_{\delta} \mathcal{X}_{t} .
\end{aligned}
$$

Using (51), we can also determine the interest differential as

$$
\begin{aligned}
r_{t}-\hat{r}_{t} & =\gamma \mathbb{E}_{t}\left(\Delta c_{t+1}+\Delta s_{t+1}\right)-\gamma \mathbb{E}_{t}\left(\Delta \hat{c}_{t+1}+\Delta \hat{s}_{t+1}\right)+\frac{1}{2} \mathbb{V}_{t}\left(\gamma\left(\hat{c}_{t+1}+\hat{s}_{t+1}\right)\right)-\frac{1}{2} \mathbb{V}_{t}\left(\gamma\left(c_{t+1}+s_{t+1}\right)\right)+\mu\left(n_{t}-\hat{n}_{t}\right) \\
& =\left\{\gamma\left[l_{c}+l_{s}-l_{\hat{c}}-l_{\hat{s}}\right](\mathcal{A}-I)+\frac{\gamma^{2}}{2}\left\{\left(l_{\hat{c}}+l_{\hat{s}}\right) \otimes\left(l_{\hat{c}}+l_{\hat{s}}\right)-\left(l_{c}+l_{s}\right) \otimes\left(l_{c}+l_{s}\right)\right\} \Omega+\mu\left(\frac{2+\varkappa-\wp}{2}\right) \mu l_{n f a}+\mu l_{\varepsilon}\right\} \mathcal{X}_{t} \\
& =l_{r-\hat{r}} \mathcal{X}_{t} .
\end{aligned}
$$

All these calculation use values for $l_{\varepsilon}, l_{\lambda}^{\mathrm{EQ}}$ and $l_{\hat{\lambda}}^{\mathrm{EQ}}$ based on the unknown coefficients in $\Pi$. To complete the solution, we need to find the values for coefficients in $\Pi$ that satisfy the equilibrium conditions of the model. By definition $\mathbb{E}_{t} \Delta \varepsilon_{t+1}=r_{t}-\hat{r}_{t}+\delta_{t}$ so $l_{\varepsilon}$ must satisfy

$$
l_{\varepsilon}(\mathcal{A}-I)=\left(l_{r-\hat{r}}+l_{\delta}\right) .
$$

The values for $l_{\lambda}^{\mathrm{EQ}}$ and $l_{\hat{\lambda}}^{\mathrm{EQ}}$ are similarly pinned down by (57). Combining these approximations with (62) gives

$$
\begin{gathered}
l_{\lambda}^{\mathrm{EQ}}=\left(\ln \beta-\left(1-\kappa^{\mathrm{EQ}}\right) \ln \left(1-\kappa^{\mathrm{EQ}}\right)\right) l_{6}+\left[(1-\gamma) l_{c}-\gamma l_{4}-(1-\eta) l_{n x}\right](\mathcal{A}-I) \\
+\kappa^{\mathrm{EQ}} l_{\lambda}^{\mathrm{EQ}} \mathcal{A}+\frac{1}{2}\left(l_{\lambda \lambda}^{\mathrm{EQ}} \otimes l_{\lambda \lambda}^{\mathrm{EQ}}\right) \Omega \\
l_{\hat{\lambda}}^{\mathrm{EQ}}=\left(\ln \beta-\left(1-\kappa^{\mathrm{EQ}}\right) \ln \left(1-\kappa^{\mathrm{EQ}}\right)\right) l_{6}+\left[(1-\gamma) l_{\hat{c}}-\gamma l_{5}+(1-\eta) l_{n x}\right](\mathcal{A}-I) \\
+\kappa^{\mathrm{EQ}} l_{\lambda}^{\mathrm{EQ}} \mathcal{A}+\frac{1}{2}\left(l_{\hat{\lambda} \hat{\lambda}}^{\mathrm{EQ}} \otimes l_{\hat{\lambda} \hat{\lambda}}^{\mathrm{EQ}}\right) \Omega
\end{gathered}
$$

where $l_{\lambda \lambda}^{\mathrm{EQ}}=(1-\gamma) l_{c}-\gamma l_{4}+(1-\eta) l_{n x}+\kappa l_{\lambda}^{\mathrm{EQ}}$ and $l_{\hat{\lambda} \hat{\lambda}}^{\mathrm{EQ}}=(1-\gamma) l_{\hat{c}}-\gamma l_{5}-(1-\eta) l_{n x}+\kappa l_{\hat{\lambda}}^{\mathrm{EQ}}$. I use a numerical procedure to find values for $\Pi$ such that (64) - (66) are satisfied.

The equilibrium behavior of all the other endogenous variables are easily derived once solutions for the $l_{\varepsilon}, l_{\lambda}^{\mathrm{EQ}}$ and $l_{\hat{\lambda}}^{\mathrm{EQ}}$ vectors are found. We can find the processes for $\left(n_{t}-\bar{n}_{t}\right)$ and $\left(\hat{n}_{t}-\bar{n}_{t}\right)$ by combing the 
expressions for the risk premia in (52) with (53) to give

$$
\begin{aligned}
\mu \varkappa\left(n_{t}-\bar{n}_{t}\right)+\wp \mu\left(\hat{n}_{t}-\bar{n}_{t}\right) & =\delta_{t}+\frac{1}{2} \mathbb{V}_{t}\left(\varepsilon_{t+1}\right)-\gamma \mathbb{C} \mathbb{V}_{t}\left(\varepsilon_{t+1}, c_{t+1}+s_{t+1}\right) \\
& -\wp \mathbb{C} \mathbb{V}_{t}\left(\hat{r}_{t+1}^{Q}, \gamma\left\{c_{t+1}+s_{t+1}-\hat{c}_{t+1}-\hat{s}_{t+1}\right\}-\varepsilon_{t+1}\right), \\
-\mu \varkappa\left(\hat{n}_{t}-\bar{n}_{t}\right)-\wp \mu\left(n_{t}-\bar{n}_{t}\right) & =\delta_{t}-\frac{1}{2} \mathbb{V}_{t}\left(\varepsilon_{t+1}\right)-\gamma \mathbb{C} \mathbb{V}_{t}\left(\varepsilon_{t+1}, \Delta \hat{c}_{t+1}+\Delta \hat{s}_{t+1}\right) \\
& -\wp \mathbb{V}_{t}\left(r_{t+1}^{Q}, \gamma\left[c_{t+1}+s_{t+1}-\hat{c}_{t+1}-\hat{s}_{t+1}\right]-\varepsilon_{t+1}\right) .
\end{aligned}
$$

Rearranging these equations produces

$$
\begin{aligned}
{\left[\begin{array}{c}
n_{t}-\bar{n}_{t} \\
\hat{n}_{t}-\bar{n}_{t}
\end{array}\right]=} & {\left[\begin{array}{cc}
\mu \varkappa & \mu \wp \\
-\wp \mu & -\varkappa \mu
\end{array}\right]^{-1} } \\
& \times\left[\begin{array}{c}
\delta_{t}+\frac{1}{2} \mathbb{V}_{t}\left(\varepsilon_{t+1}\right)-\gamma \mathbb{C} \mathbb{V}_{t}\left(\varepsilon_{t+1}, c_{t+1}+s_{t+1}\right)-\wp \mathbb{C} \mathbb{V}_{t}\left(\hat{r}_{t+1}^{\mathrm{EQ}}, \gamma\left\{c_{t+1}+s_{t+1}-\hat{c}_{t+1}-\hat{s}_{t+1}\right\}-\varepsilon_{t+1}\right) \\
\delta_{t}-\frac{1}{2} \mathbb{V}_{t}\left(\varepsilon_{t+1}\right)-\gamma \mathbb{C} \mathbb{V}_{t}\left(\varepsilon_{t+1}, \hat{c}_{t+1}+\hat{s}_{t+1}\right)-\wp \mathbb{V}_{t}\left(r_{t+1}^{\mathrm{EQ}}, \gamma\left[c_{t+1}+s_{t+1}-\hat{c}_{t+1}-\hat{s}_{t+1}\right]-\varepsilon_{t+1}\right)
\end{array}\right] \\
& =\left[\begin{array}{c}
l_{n} \\
l_{\hat{n}}
\end{array}\right] \mathcal{X}_{t} .
\end{aligned}
$$

The equilibrium behavior of the equity and foreign asset risk premia are easily determined from (52) with these equations for $\left(n_{t}-\bar{n}_{t}\right)$ and $\left(\hat{n}_{t}-\bar{n}_{t}\right)$.

To determine equilibrium portfolio shares, we first need solutions for $l_{\lambda}^{\mathrm{C}}$ and $l_{\hat{\lambda}}^{\mathrm{C}}$. From (57) these vectors must satisfy

$$
\begin{aligned}
& l_{\lambda}^{\mathrm{c}}=\left(\ln \beta-\left(1-\kappa^{\mathrm{C}}\right) \ln \left(1-\kappa^{\mathrm{C}}\right)\right) l_{6}+\left[(1-\gamma) l_{c}-\gamma l_{4}\right](\mathcal{A}-I)+\kappa^{\mathrm{C}} l_{\lambda}^{\mathrm{C}} \mathcal{A}+\frac{1}{2}\left(l_{\lambda \lambda}^{\mathrm{C}} \otimes l_{\lambda \lambda}^{\mathrm{C}}\right) \Omega \\
& l_{\hat{\lambda}}^{\mathrm{C}}=\left(\ln \beta-\left(1-\kappa^{\mathrm{C}}\right) \ln \left(1-\kappa^{\mathrm{C}}\right)\right) l_{6}+\left[(1-\gamma) l_{\hat{c}}-\gamma l_{5}\right](\mathcal{A}-I)+\kappa^{\mathrm{C}} l_{\hat{\lambda}}^{\mathrm{C}} \mathcal{A}+\frac{1}{2}\left(l_{\hat{\lambda} \hat{\lambda}}^{\mathrm{C}} \otimes l_{\hat{\lambda} \hat{\lambda}}^{\mathrm{c}}\right) \Omega
\end{aligned}
$$

where $l_{\lambda \lambda}^{\mathrm{c}}=(1-\gamma) l_{c}-\gamma l_{4}+\kappa l_{\lambda}^{\mathrm{c}}$ and $l_{\hat{\lambda} \hat{\lambda}}^{\mathrm{c}}=(1-\gamma) l_{\hat{c}}-\gamma l_{5}+\kappa l_{\hat{\lambda}}^{\mathrm{c}}$. I solve these equations numerically to find $l_{\lambda}^{\mathrm{C}}$ and $l_{\hat{\lambda}}^{\mathrm{C}}$. Next, I use the identity $c_{t}+\ln \left(1+\Lambda_{t}^{c}\right)=w_{t}$ to write

$$
\begin{aligned}
& \mathbb{C} \mathbb{V}_{t}\left(r_{t+1}^{\mathrm{EQ}}, c_{t+1}+\ln \left(1+\Lambda_{t+1}^{c}\right)\right)=\gamma \alpha_{t}^{\mathrm{EQ}} \mathbb{V}_{t}\left(r_{t+1}^{\mathrm{EQ}}\right)+\gamma \alpha_{t}^{\mathrm{FA}} \mathbb{C} \mathbb{V}_{t}\left(r_{t+1}^{\mathrm{EQ}}, r_{t+1}^{\mathrm{FA}}\right) \\
& \mathbb{C} \mathbb{V}_{t}\left(r_{t+1}^{\mathrm{FA}}, c_{t+1}+\ln \left(1+\Lambda_{t+1}^{c}\right)\right)=\gamma \alpha_{t}^{\mathrm{FA}} \mathbb{V}_{t}\left(r_{t+1}^{\mathrm{FA}}\right)+\gamma \alpha_{t}^{\mathrm{EQ}} \mathbb{C} \mathbb{V}_{t}\left(r_{t+1}^{\mathrm{EQ}}, r_{t+1}^{\mathrm{FA}}\right)
\end{aligned}
$$

Solving these equations for the portfolio shares gives the U.S. portfolio shares as

$$
\left[\begin{array}{c}
\alpha_{t}^{\mathrm{EQ}} \\
\alpha_{t}^{\mathrm{FB}}
\end{array}\right]=\frac{1}{\gamma}\left[\begin{array}{cc}
\mathbb{V}_{t}\left(r_{t+1}^{\mathrm{EQ}}\right) & \mathbb{C V}_{t}\left(r_{t+1}^{\mathrm{EQ}}, r_{t+1}^{\mathrm{FA}}\right) \\
\mathbb{C} \mathbb{V}_{t}\left(r_{t+1}^{\mathrm{EQ}}, r_{t+1}^{\mathrm{FA}}\right) & \mathbb{V}_{t}\left(r_{t+1}^{\mathrm{FA}}\right)
\end{array}\right]^{-1}\left[\begin{array}{c}
\mathbb{C V}_{t}\left(r_{t+1}^{\mathrm{EQ}}, c_{t+1}+\kappa^{\mathrm{C}} \lambda_{t+1}^{\mathrm{C}}\right) \\
\mathbb{C} \mathbb{V}_{t}\left(r_{t+1}^{\mathrm{FA}}, c_{t+1}+\kappa^{\mathrm{C}} \lambda_{t+1}^{\mathrm{C}}\right)
\end{array}\right]
$$

The E.U. portfolio shares are computed using the U.S. shares and the market clearing conditions. In the 
stochastic steady state, $\mathcal{X}_{t}=\overline{\mathcal{X}}_{t}$ so the conditional covariance is $\mathbb{C} \mathbb{V}_{t}\left(\zeta_{t+1}, \xi_{t+1}\right)=\left\{l_{\xi} \otimes l_{\zeta}\right\} \Omega \overline{\mathcal{X}}_{t}$ for any two variables, $\zeta_{t+1}$ and $\xi_{t+1}$. The steady state portfolio shares are computed from (69) using this the steady state conditional moments on the right-hand-side.

\section{Approximation Accuracy}

The solution method uses a novel combination of barrier methods with log-linear approximations around the stochastic steady state so it is important to check its accuracy. Following the literature, I compute the distributions of the Euler equation errors from the households' optimization problems. The errors are defined as $\left|\left(C_{t}-\tilde{C}_{t}^{\mathrm{R}}\right)\right| / C_{t}$, where $C_{t}$ is the value of equilibrium U.S. consumption in quarter $t$ identified by the solution method and $\tilde{C}_{t}^{\mathrm{R}}$ is the quarter $t$ value of U.S. consumption implied by first-order condition for return $\mathrm{R}=\left\{R_{t+1}^{\mathrm{EQ}}, R_{t+1}^{\mathrm{FA}}, R_{t}\right\}$ shown in (46).

I examine five sets of errors. The first three use the first-order conditions from the U.S. households' modified optimization problem (i.e., (46) with $\mathcal{B}_{t}$ defined in (22)). The first-order conditions for the U.S. households' original problem can also be written as (46) where $\mathcal{B}_{t}$ is proportional to the Lagrange multiplier on the U.S. collateral constraint. Since the constraint never binds in the solution of the model, (46) with $\mathcal{B}_{t}=0$ represent the applicable equilibrium conditions when U.S. household face the original optimization problem. Since $\mathcal{B}_{t}$ is absent from the first-order condition involving equity returns (45a), I compute two further sets of Euler equation errors from (45b) and (45b) with $\mathcal{B}_{t}=0$.

Identification of the Euler equation errors requires the computation of conditional expectations concerning the product of future marginal utility and returns. For example, in the case of condition (45a)

$$
\tilde{C}_{t}^{\mathrm{EQ}}=\left(\mathbb{E}_{t}\left[\mathcal{Z}_{t+1}\right]\right)^{-1 / \gamma}, \quad \text { where } \quad \mathcal{Z}_{t+1}=\beta\left(C_{t+1}\right)^{-\gamma}\left(\frac{S_{t+1}}{S_{t}}\right)^{-\gamma} R_{t+1}^{\mathrm{EQ}}
$$

Note that $\mathcal{Z}_{t+1}$ is a known nonlinear function of the state vectors in $t$ and $t+1$, i.e. $\mathcal{Z}_{t+1}=\mathcal{F}\left(\mathcal{X}_{t+1}, \mathcal{X}_{t}\right)$, in the solution of the model. I compute the conditional expectation as the average value for $\mathcal{Z}_{t+1}$ over a set of possible period $t+1$ states, i.e.,

$$
\mathbb{E}_{t}\left[\mathcal{Z}_{t+1}\right]=\frac{1}{\mathcal{N}} \sum_{i=1}^{\mathcal{N}} \mathcal{F}\left(\mathcal{X}_{t+1}^{i}, \mathcal{X}_{t}\right),
$$

where $\mathcal{X}_{t+1}^{i}$ is the $i$ 'th possible value of the state in $t+1$. These values are computed using (62) as $\mathcal{X}_{t+1}^{i}=$ $\mathcal{A} \mathcal{X}_{t}+\operatorname{diag}\left(\Sigma_{t}\right)^{1 / 2} \mathcal{V}_{t+1}^{i}$ where $\mathcal{V}_{t+1}^{i}$ is a i.i.d. vector of mean-zero unit variance normal random variables. The results below use expectations computed from averages across $1000(=\mathcal{N})$ possible future states. Notice that these expectations are conditioned on the state in quarter $t$ (via $\mathcal{X}_{t}$ and the conditional standard deviations in $\left.\operatorname{diag}\left(\Sigma_{t}\right)^{1 / 2}\right)$. To insure that distribution of Euler equation errors comes from a representative portion of the state space, I compute errors from simulations of the model spanning 10,000 quarters, i.e., for a sequence $\left\{\mathcal{X}_{t}\right\}_{t=1}^{10,000}$.

Table 8 reports the mean and upper percentiles of the five Euler equation error distributions. Overall, the errors are economically insignificant. For example, the mean error associated with the first-order condition for equity (45a) is 0.13 percent of consumption. A comparison of columns (ii) and (iii) with (iv) and (v) 
Table 8: Euler Equation Errors

\begin{tabular}{|c|c|c|c|c|c|}
\hline & \multirow[b]{2}{*}{$\begin{array}{l}\text { Equity } \\
\text { (i) }\end{array}$} & \multicolumn{2}{|c|}{ Modified } & \multicolumn{2}{|c|}{ Original } \\
\hline & & $\begin{array}{l}\text { Foreign Assets } \\
\text { (ii) }\end{array}$ & $\begin{array}{l}\text { Risk Free } \\
\text { (iii) }\end{array}$ & $\begin{array}{l}\text { Foreign Assets } \\
\text { (iv) }\end{array}$ & $\begin{array}{c}\text { Risk Free } \\
\text { (v) }\end{array}$ \\
\hline mean & 1.292 & 1.806 & 2.098 & 2.150 & 4.025 \\
\hline \multicolumn{6}{|c|}{ Percentiles } \\
\hline 50 & 0.641 & 1.790 & 1.582 & 2.202 & 4.360 \\
\hline 75 & 1.074 & 2.253 & 2.614 & 2.320 & 4.462 \\
\hline 90 & 2.262 & 2.308 & 3.690 & 2.360 & 4.611 \\
\hline 95 & 3.729 & 2.350 & 4.019 & 2.970 & 4.640 \\
\hline 99 & 9.903 & 8.591 & 9.871 & 9.411 & 10.245 \\
\hline
\end{tabular}

Notes: All entries are of the order $10^{-3}$. Error distributions using the first-order conditions in (46) with $\mathcal{B}_{t}$ defined in (22)) are reported in columns (i) - (iii) and distributions from (45b) and (45b) with $\mathcal{B}_{t}=0$ in columns (iv) and (v). Distributions are based on simulations of the model over 10000 quarters.

reveals that the errors are slightly larger when the first-order conditions come from the households' original optimization problem, but again the differences are not economically significant. These similarities reflect the fact that households rarely make portfolio decisions that leave them close to their collateral constraints.

It is useful to compare these distributions with those reported by Kim and Kim (2010), Evans and Hnatkovska (2012) and Kazimov (2010). Kim and Kim (2010) examine the accuracy of barrier and perturbation methods for solving a multi-agent model with a non-negatively constraint on physical capital but no portfolio choice. They find that the Euler equations errors are large when capital is zero or close to zero. This appears to be much less of a problem here because households can generally keep well away from the point where collateral constraints bind by re-allocating their portfolios. Evans and Hnatkovska (2012) and Kazimov (2010) compare the accuracy of the Evans and Hnatkovska (EH) method that combines perturbations with continuous time approximations with an alternative perturbation method developed by Devereux and Sutherland (2010a) and Tille and van Wincoop (2010) (the DS/TW method) to a sizable open economy model (8 state variables) with portfolio choice and incomplete markets. Overall, the error distributions in Table 8 are comparable to those reported by Evans and Hnatkovska (2012) and Kazimov (2010) for the EH method. The only significant difference appears at the upper end of the distributions in Table 8 where the 99'th. percentiles are two to three times larger. Notice, however, that the errors at the upper end of all five distributions still only represent a one percent consumption error. These errors are comparable to the errors in the upper end of the distributions computed from the DS/TW method. 